Friby Council

\title{
MEDICAL RESEARGH
}

COUNCIL

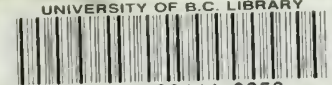

39424004449358

Borna Disease and Enzootic EncephaloMyelitis of Sheep and Cattle BY

S. NICOLAU, M.D., D.Sc., and

I. A. GALLOWAY, B.Sc., M.R.G.V.S.

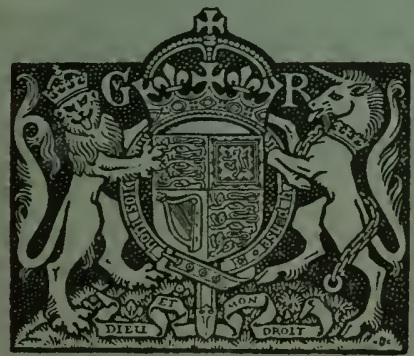

\section{LONDON}

HIS MAJESTY'S STATIONERY OFFICE 1928

SF799

N5

Price 5s. net

ForAG 



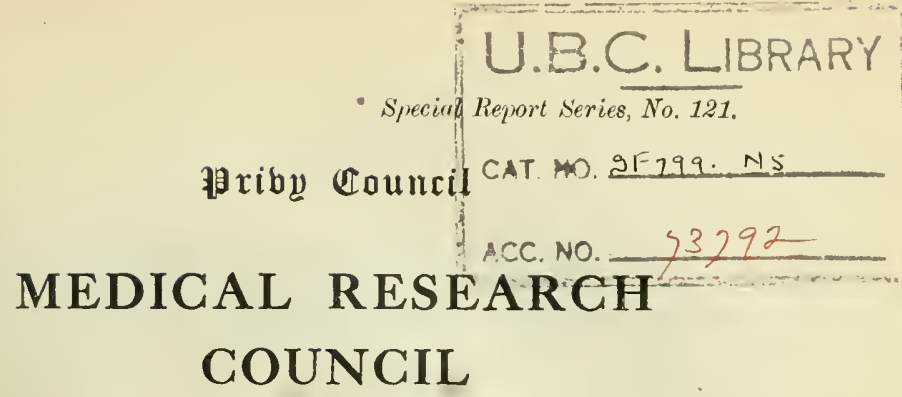

Borna Disease and Enzootic EncephaloMyelitis of Sheep and Cattle BY

S. NICOLAU, M.D., D.Sc., and

I. A. GALLOWAY, B.Sc., M.R.G.V.S.

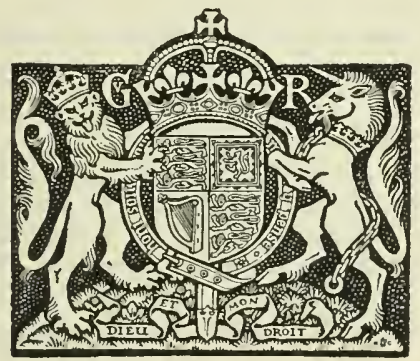

LONDON

PUBLISHED BY HIS MAJESTY'S STATIONERY OFFICE 


\section{MEDICAL RESEARCH COUNCIL.}

The Right Hon. Earl of Baffotr. K.G.. O.M1.. F.R.t. (Chairman).

The Right Hon. Lord Mildiay of Flete. P.('. (Treasurer).

The Right Hon. William Graham, LL.B., M.P.

Sir Hugh K. Axdersox, M.D., F.R.S.

Professor E. P. Cathcart, C.B.E., II.D., D.Sc., F.R.S.

Professor G. Dreyer, C'.B.E., M.D., F.R.S.

Professor T. R. Elliott, C.B.E., D.S.O., M.D., F.R.S.

Sir Archibald E. Garrod, K.C.M.G., D.M., F.R.S.

Sir F'rederick G. Hopkiss, D.Sc., F.R.S.

Sir Charles J. Mlartis, C.M.G., D.Sc., F.R.s.

Sir Charles S. Sherrivgtox, O.M., (i.B.E., F.R.S.

Sir Walter M. Fletcher, K.B.E., M.D., Sc.D., F.R.S. (Necretury . 


\section{PREFACE}

THE present report, which was received for publication in October, 1927 , gives the results of investigations made by Dr. Nicolau and Mr. Galloway, working as guests in the National Institute of Medical Research. These studies of the virus which is responsible for a dangerous communicable disease in horses, cattle and sheep have happily no immediate practical application in this country. Borna disease and its congeners are at present only known in continental Europe and in America. Our present immunity, however, may only be temporary, and in any case it is highly important that we should have the fullest knowledge of these epizootic diseases of other countries.

The scientific advantages gained by close association between studies of disease in animals and studies of human disease have long been obvious. The potential value to medical science of the work now presented hes in two directions. The accurate experimental study of the 'virus' which is the causal agent in this disease is part of the general study of disease riruses, and in this field of work great gain imust come from the free exchange of ideas, methods and results among workers in different parts of it. Besides this, however, Borna disease has special points of interest to students of luman neurology. The infective virus produces changes in the brain and spinal cord, the so-called encephalo-myelitis, which throw hight upon analogous forms of encephalitis and myehtis which occur in sporadic or epidemic form in human beings.

It will be seen that the authors have extended or confirmed the observations of many previous workers, and have gained new knowledge at several points of detail by their experimental work. Fresh studies have been made of the immunity reactions of the virus, and it has been shown that animals may be successfully immunized against it.

Dr. Nicolau was enabled to conduct this work in the National Institute by a grant from the Roumanian Government. Mr. Galloway co-operated with hin in the course of other work upon foot and mouth disease in cattle, which he is doing on behalf of the Ministry of Agriculture and Fisheries. The council are indebted to the Ministry for the facilities they have given for this co-operation.

2Sth .July, 192S.

Medical Research Couscil, 15 York Bulldixgs, LoNDox, W.C. 2. 



\title{
BORNA DISEASE AND ENZOOTIC ENCEPHALO- MYELITIS OF SHEEP AND CATTLE
}

\author{
By S. Nicolat, M.D., D.Sc., Axp I. A. Galloway, B.Sc., \\ M.R.C.T.S.
}

(Tational Institute for Medical Research. Hampstead.)

\section{CONTENTS}

I. Historical axd Geseral

I. Enzootic Encephalo-myelitis of the Horse .

II. Enzootic Encephalo-myelitis of Cattle

III. Enzootic Encephalo-mselitis of Sheep

IV. Malignant Catarrhal Ferer of Cattle

V. Summary

2. Properties of the Virts

I. Inrisibility

II. Filterability: Effect of Dilution

III. Centrifugalization .

IV. Resistance to Glycerine

V. Sensitiveness to Heat and Desiccation

VI. Action of Utra-Fiolet Light

VII. Action of Hexamethylenetetramine (Lrotropine)

V1II. Action of Chloroform and Ether

IX. Action of Formalin

X. Culture

XI. Summary

3. Traxsmissiox of Fqutixe Sitrais to Rabbit axd from Rabbit to Sheep AND VTCE VERSA $\quad$. $\quad$. . . . . . . . . . 23

4. Experimextal Disease is the Rabit . . . . . . . . . 24

I. Experimental Transmission of the Disease to the Rabbit . . . 24

II. Authors' Observations . . . . . . . . . 24

III. Symptomatology of the Disease in the Rabbit . . . . . . 27

IV. Routes by which Rabbits can be Infected. . . . . . . 29

5. A Uthors' Experdexts ox the Traxsmssiox of the DISEase to Moxkeys,

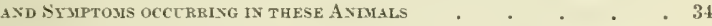

6. Pathogexicity of the Vires of Exzootic Encephalo-jiyelitis for the Ginea-pig, Rat, Jlotse, Axd Fowl . . . . . . . . $3 !$

I. Guinea-pig . . . . . . . . . . . 39

II. Rat . . . . . . . . . . . . 43

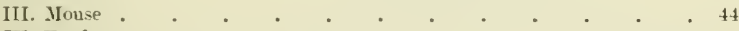

T. Fowl . . . . . . . . . . . . . . 44

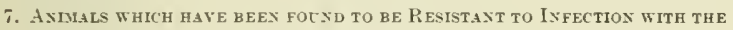
Tires of Exzootic Excephalo-myeltis . . . . . . 44

I. $\operatorname{Dog}$. $\quad$. $\quad$. . . . . . . . 44

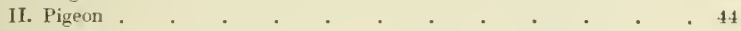

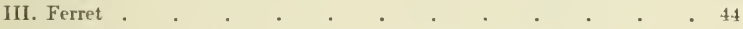

8. Distribetiox of the Vires of Borma Disease is the Aximal Budy . 44

I. Passage of Virus through the Placenta . . . . . . . 41

1I. Distribution of the Virus in Varions Organs and Tissues . . . 4.)

III. Presence of Virus in the Peripheral Nerves of Rabbits inoculated Intracerebrally . . . . . . . . . . 45

IV. Distribution of the Virus in various Organs and Tissues of the Monkey . $4 \$$ 
9. Elminatiox of the Virts from the Aximal Organism .

10. Histopathology of BoRxa Disease . . . . . . . 50

I. Horse

I1. Cattle . . . . . . . . . . . . . . 50

111. Sheep . . . . . . . . . . . . 51

1V. Experimental Borna Disease in Horses and Sheep . . . . . 51

「. Rabbits infected Experimentally . . . . . . . . 51

V. Authors Obserrations . . . . . . . . . . 52

A. Rabbit . . . . . . . 52

(1) Macroscopieal and Microscopical Findings in Diverse Organs 52

(2) Lesions in the Central Jerrous system . . . . . 53

(a) The Brain . . . . . . . 5:

(b) The Midbrain and Medulla Oblongota $\quad$. . $5 s$

(c) The Cerebellum . . . . . . . . . 59

(d) The Spinal Cord . . . . . . . . 5?

(3) Lesions in the Peripheral Jerrous System . . . (it)

(a) The Posterior Nerte Roots . . . . . 1i0

(b) The Spinal Ganglia . . . . . . 60

(c) The Peripheral Teries . . . . . 61

(4) Summary and Discussion . . . . . . (i?

B. The Guinea-pig . . . . . . . lit

C. The Rat and Jouse . . . . . . . lit

D. The Vonkey. . . . . . . . . it

(I) Lesions in the Central Serrons System . . . . 65

(a) Brain . . . . . . . . . . 65

(b) Cerebellum . . . . . . . . (iti

(c) Medulka Oblongala . . . . . . . . . 66

(d) Spinal Cord . . . . . . . . . titi

(c) Sciatic lierve. . . . . . . . (i)

(f) Brachial Nerce $\quad . \quad+\quad . \quad+\quad . \quad 65$

(2) Summary . . . . . . . . . 65

11. Iммкоту

1. Attempts at eonferring Immunity to Rabbits by Inendations of Conattenuated Virus . . . . . . . . . ti!

A. Intracenous Inoculation. . . . . . . . 64

B. Corrieal Inoculation . . . . . . . . . . 71

C. Intratesticular Inoculation . . . . . . . 71

1I. Attempts at conferring I munnity to Rabbits by Inorulat inn of Attenuated

V'irus . . . . . . . . . . . .

A. Nirus inatimated by Ether . . . . . . . 72

B. l'irus killed by chloroform . . . . . . . . . .

(. I'irus trented with Formol . . . . . . . . 73

D. I'irus inactivated by I'ltra-riolet Light . . . . . 7:3

III. Search for Viruciclal Antibodies in the Serum of lmmmizel Animals . 73

15. Experiments on Cross Immunity bet ween the Sitrain of Fquine und that of llvine Origin . . . . . . . . . . . . .

1. Experiments on Cross Immunity letween the Virus of lineplualor. myelitis and other Viruses of the l'jlter-passing firous . . . 7

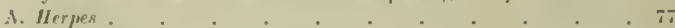

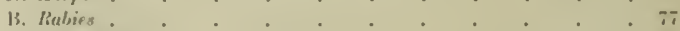

f. Polimnglitis. . . . . . . . . . . . . . . . . .

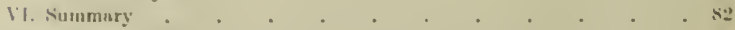

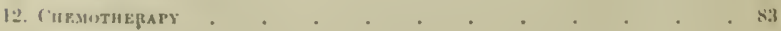

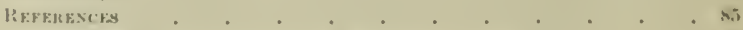

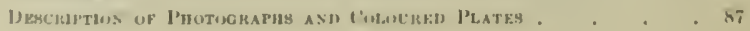




\section{HISTORICAL AND GENERAL}

\section{Exzootic Excephalo-myelitis of the Horse (Borsa DISEASE).}

THE disease has various designations: Enzootic Encephalomyelitis, Meningo-encephalo-myehitis of the Horse, Névraxite enzootique; Mal d'Azeau (after the region where a severe epizootic occurred in Belgium in 1909); Bomasche Kranklueit, Genickstarre, Gehirnruckenmarksentzündung. Gehirnruckenmarkseuche, Nervenfieber; Encephahitis Lymphocytaria Equi.

It is an infectious malady with a mortality rate reaching 90 per cent. in some epizootics. The characteristic symptoms are due to lesions in the nervous system both central and peripheral. which are produced by an ultravisible and fitterable virus.

The name Borua disease, by which the disease is more commonly known. originated from the locality in Saxony where a severe epizootic occurred in the years 1894 to 1896 .

Borna disease has been known for more than a century. It was first described by Wörz in Würtemburg in 1813. Subsequently it was reported from Germany, North America, the Argentine, and Hungary. Since 1900 it has appeared in Russia, in the region of the river Don, in Belgium. France, Italy. Roumania. Germany, and South America. The epizootics have been of varying severity. In 1896 the disease occurred in several districts of Germany, where 1,19s horses were reported to have contracted it: in the epizootic which occurred in the valley of the Colorado and the Brazos in America about 4,000 horses and nules succumbed. In other areas the disease has appeared sporadically.

('limatic conditions appear to have an influence on the spread of the disease. the incidence of which is greater when abnormally warm and moist couditions obtain. The diagram published by Zwick, seifried, and Witte (1926) shows that epizootics generally begin in the month of May and decline later, the eases again becoming sporadic during the winter months.

The period of incubation in the spontaneously contracted disease is difficult to estimate and is therefore not definitely knoww. Toack (1908) considers 9 days to be an average.

Joest (1926) suggests that the portal of entry of the virus is through the nose, but the possibility of ingestion being the mode of infection cannot be excluded.

The onset of the disease may be sudden, but some authors bave reported that fatigne, gastro-intestinal disturbances. and symptoms of affection of the upper respiratory passages precede the onset of characteristic nervous symptoms by as much as 14 days.

The first symptom which usually draws attention to the infected aninual is lassitude: the horse is easily fatigued and appears depressed and indifferent to external impressions. A period of excitation follows, which may last with intermittence till the end of the disease. Tonic 
contractions of diverse groups of muscles occur and there is difficulty in mastication and deglutition. During the stage of excitation external stimuli produce exacerbation of the spasms in certain groups of muscles; champing of the jaws is a common symptom, and salira flows from the commissures of the mouth. The pupils are unequal in size. Soon paresis or paralysis sets in, affecting the hindquarters, the muscles of the tail, nuscles of mastication, muscles of the tongue and of the back to a varying degree. Paraplegia or hemiplegia are not uncommon.

In some cases the symptoms of encephalitis are dominant, in some those of acute myelitis are more evident, while in others symptoms characteristic of affection of both brain and cord coexist. The temperature generally remains normal throughout, and according to Hutyra and Marek (1922) persistent fever indicates secondary complications of a septic nature.

The frequency of the respiration remains little changed, except during periods of excitation, or when the nucleus of origin of the vagus nerre is involved. Towards the end of the disease, however, the respirations become superficial and approach the Cheyne-Stokes type.

The examination of the blood and urine does not indicate any constant change. The cerebrospinal tluid shows lymphocytosis oceasionally. The duration of the disease varies from a few days to 6 weeks. 1

Aetiology. Is has been the case with a number of diseuses subsequently proved to be due to a filterable virus, the disease was at first attributed to the pathogenic action of various cocci. Siedamgrotzky and Schlegel (1596) isolated a Gram-positive diplococcus and Johne (1596) a Gram-negative one. Other observers. Ostertag (1900), C'hristiani (1909), Mareq (1909), Löhr (1910), Lessage and Frisson (1912). have found streptococei or diplococci, each organisun isolated being consictered by the investigator concerned as the aetiological agent. Yore recently Kraus, Kantor, Fischer, and Quiroga (1920) isolated a diplococeus similar to that found by Siedamgrotzky and sichlegel, which they believed to be the aetiological agent of Borma disease until the appearance of the work of Moussu and Marchand in France, and Zwick, Seifried, and Witte in Germany, indicating that ancephalo-myelitis of the horse is produced by an ultravisible and filterable virus. Although the virus isolated by Lloussu and Marchand appears to differ from that isolated by Zwick and his collaborators. it is possible that this may be explained by the fact that two strains of the same virus wher being dealt with (see note on p. 23). Beck and Frohböse (1926) and Ernst and Hahn (1920) nlsu showed that a virus isolated from the brain of borses affected with encephalo-myelitis was capable of infecting rabbits.

Ionst in collaboration with Degen (1909) deterumined the coustant

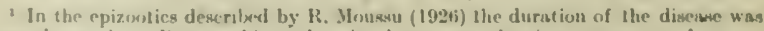
very whort. According to this author, in those cases showing aymptims of an ent. ceptulitis type the evolution is rapiul. In the eases we have studierl denth intervent in 210,32 , nnil 37 hrum." 
presence of certain intrannclear 'inclusions' in the ganglion cells of the Ammon's horn which they considered as reactions of the cell to the parasite and 'similar to Chlamydozoa'. In the opirion of Joest these chlamydozoa, or at least certain forms of their cycle of development. are capable of passing through bacteriological filters.

Siedamgrotzky and Schlegel (1896), Lohr (1910), and Ostertag (1900 et seq.) made frequent attempts to infect laboratory animals by rarious methods of inoculation or by feeding them with cerebrospmal Huid, blood, emulsions of spleen, hiver, kidney, or bone marrow from horses affected with the disease. The results were negative.

In résumé the work of Moussu and Marchand (1924 et seq.), Zwick, Seifried, and Witte (1926). Beck and Frohböse (1926). Ernst and Hahn (1926-7), has shomn definitely that the aetiological factor is a filterable ultravisible virus, and the results obtained by Kraus and his collaborators (1920) and other investigators with their cultures of diplococci or diplo-streptococei must now be considered as due to what Nicolle called microbes de sortie.

\section{Exzootic Excephalo-myelitis of Cattle.}

The epizootiology and symptoms of encephalo-myehtis of cattle are similar to Borna disease of the horse. Hutyra and Marek (1922) refer to outbreaks of disease amongst cattle described by Meyer (1867). Schimidt (1888), C'tz (1896), Röder (1896), and Manfredi d'Ercole (1896) which may be attributed to enzootic encephalo-myelitis. Pröger (1896) recorded the coexistence of this disease with Borna disease, and as Ernst and Hahn (1927) have suggested that the outbreaks of disease in Hungary referred to as 'cerebrospinal memingitis' may also have been encephalo-myelitis. G. Moussu, quoted by P. Moussu (1926), in 1906 studied an enzootic on a farm in the region of Orne which killed 10 cattle in a few weeks. The disease had a similar onset; periods of excitation were observed followed by depres. sion with champing of the jaws, salivation, loss of vision, and muscular twitchings. The possibility of intoxication was excluded, and the symptoms were suggestive of Borna disease. Moussu also considers that the cases of 'cerebrospinal meningitis' of cattle reported by Kragerud and Gunderson (1921) were the same as encephalomyelitis of the horse, and the symptoms described by Causel (1924) in an enzootic of what he termed 'infectious bulbar paralysis' amongst cattle are consistent with the riew that the animals suffered from encephalo-myelitis.

The symptoms of encephalo-myelitis in cattle are similar to those of Borna disease in the horse.

Atiology. Moussu (1926), who described 31 cases of encephalomyelitis of cattle on 18 different farms in France, attempted to transmit the disease to laboratory ammals without success.

Ernst and Hahn (1927) found lesions in the brain of cattle dead of encephalo-myelitis analogous to those in the brain of horses dead of Borna disease; in the lesions the corpuscles of Joest-Degen were seen. With the virus which they recovered they succeeded in producing 
symptoms in rabbits similar to those produced by $Z$ wick with a virus from horses.

The general aspect of the lesions in the brain of rabbits infected with the two viruses and the similar presence of the corpuscles of Joest-Degen suggests that varieties of the same virus are the cause of rucephalo-myelitis of horses and cattle.

\section{Exzootic Excephalo-myelitis of Sheep.}

Eichbaum, Stöhr, and Willie $(1865,1866)$ recorded an enzootic of encephalo-myelitis among sheep, and Roloff (1868). who examined the brain of animals which succumbed to a similar epizootic. found perivascular infiltration in the pia mater. Schmilt (1870), about the same time, described an enzootic of a similar nature in Prussia. Later, Popow (1582) and Wischuikowitsch (1559) (lescribed the llisease in Russia. Prietsch (1696) referred to an enzootic among sheep, and suggested the possibility that the source of infection was the water in troughs contaminated by the virus of Borna disease of horses. Walther (1899) reported aneizootic in two Hocks of sheep in the district of Borna at a time when equine encephalo-myelit is was prevalent; the two diseases, equine and ovine, bore many resemblances to one another. Savigné and Leblane (1897) also have descrihed an enzootic in France.

'The descriptions of these authors differ essentially and may not all refer to the same disease. Hore precise accounts of ovine encephalomyclitis have been published within recent years by spiegl (1922). Priener (1925), Beck and Frohböse (1926), Monssu (1926), Miessne'l (1926), and others, from which it appears that in the spontameous disease of the sheep the same sucession of symptoms ocenr as in horses and cattle. The evolution of the disease mily take as long as from 2 to 12 days. Death generally smperventes. The temperature is variable. In certain cases the temperature may rise to $41^{\circ}$ ('., while in others no pyrexia is observed. According to Moussu (1926) the incubation period averages 27 days.

Aetiology. Beck (1925) stulisil the microscopic lesions in the lorain of sheep dead of the disense. and emphasized their resemblance to those found in the brain of horses deal of Borna diserast. In the ganglion cells of the Ammon's hom of sheep the characteristic oxyplilic intranuclear corpuseles of Joest and Decgen were fomml. in collaboration with frobböse, beck (19:26) transmitted the disease to rablits, and from the similarity in the symptoms and in the lesions produced by the virus isolated by them from sheep with that iselated by \%wick from horses. considered that the two diseases were identical.

About the same time. Voussu and Marchand also passed the diseaso (o) rabbits and transmitted it from sheep to sherep. Later Miessumer

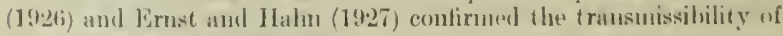
the discasu of sherep to rabbits.

Whe slatl describr later low the experimentul sturly of anzestic "Herphalo-myelitis of shere has shown that the disease is produced hy a virus similar, if not identical, with that which producus Bormat dismane in horse's. 


\section{Malignant Catarrhal Fever of Cattle.}

Glamser (1926) and Dobberstein (1925) found perivascular and parenchymatous infiltration as well as alterations in the ganghion cells of the brain of cattle dead of a disease which they called malignant catarrhal fever. These lesions were similar to those described in Borna disease. Ernst and Hahn (1927) also draw attention to the similarity of the lesions in the brain of cattle deat of this disease with those found in encephalo-myelitis of the horse, and in 3 out of 5 cases they observed the intranuclear corpuscles of Joest-Degen in the ganglion cells of the Ammon's horn. Emulsions from the brain of one of these cases inoculated intracerebrally into rabbits produced a disease similar to experimental Borna disease and transmissible from rabbit to rabbit. They concluded that malignant catarrhal fever of cattle is produced by a virus which approaches very closely, if it be not identical with, that producing encephalo-myelitis in horses.

We might here mention that Erust and Hahn (1927) also made an observation indicating that deer are susceptible to Borna disease. A sick deer was killed by a hunter under curious circumstances. The animal allowed the hunter to approach very closely, drew away in fear, and then rushed on him suddenly. The ears were seen to twitch and the animal turned round in a circle until the hunter, probably more friglitened than the animal, killed it. The head was brought to Iunich. The brain showed the presence of lesions similar to those of Borna disease of the horse, and the intranuclear corpuscles of JoestDegen were observed. Their attempts at transmission of the disease to laboratory animals had given no results at the time of publication of these observations.

\section{Summary.}

From the foregoing résumé of the literature of spontaneous encephalo-myelitis in different species, the following conclusions may be drawn:

(1) The enzootic encephalo-myelitis of horses and cattle and of sheep appears to be the same disease. The symptomatology and the lesions found in the central nervous system are analogous, and the intrannclear corpuseles of Joest-Degen occur in the large ganglion cells of the Ammon's horn in all three species suffering from the disease in question.

(2) From cases of all three diseases a virus has been recovered and shown to be responsible for the disease.

(3) From the observations of Frnst and Hahn it would seem not improbable that, if the animals had not in addition to maligmant catarhal fever a concomitant infection with Borna disease, some of the cases described as malignant catarrhal fever of cattle were encephalo-myelitis.

(4) Deer appear to suffer from a similar disease spontaneously.

(5) The transmission of the disease under natural conditions is probably by the respiratory tract or by ingestion. 


\section{PROPERTIES OF THE VIRUS}

\section{INVISIBILITY.}

The virus in ultravisible. Tarious methods of staining have been used to discover a parasite, but without success. Methods of impregnation with silver have not revealed the presence of parasites in the brain of animals dead of the experimental disease in our hands. The existence of the virus in the brain is, however, associated with the presence of intrannclear corpuscles, first described by Joest and Degen (1909). The interpretation of the nature of these corpuscles which we favour is discussed in the chapter dealing with the histopathology of the disease, and we are persuaded that they are of the same nature as the similar 'inclusions ' found in other diseases produced by filterable viruses, such as fowl plague, fowl pox, distemper, and 'Virus III' disease of rabbits.

\section{Filterability: Effect of Dilutiox.}

Filtration of emulsions containing viruses through filters which hold back bacteria generally greatly dinuinishes the concentration of the virus. There are many reasons for this, apart from the size of the virus. If the virus is contained in or on cellular particles these may be retained, or the virus itself may be adsorbed on the filter. In such adsorption the lydrogen-ion concentration and the electrical charge carried by the virus exert a elecisive intluence. The pressure under which the filtration is carricd ont is also a factor of importance.

Further, the sensitiveness of the tissue into which a tiltrate is inoculated may influence the decision whether a virus is filterable or not. When a sensitive reagent is employed, the passage of an extremely small quantity may be detected. For instance, the dose of neurovaccinia required to infeet a rabbit if inocnlated intracerebrally is $1 / 100$ th to $1 / 1000$ th of that required to produee pustules on applicition to the searified skin. An experimenter nsing the former methor might conclude that the virus passed a bacteria-proof tilter, ome usiug the latter that it diu not. The sensitiveness of the tissue into which a filtrate is inoculated is therefore a factor of capital importance often neglected in interpretations as to the filterability or nen-tilterability of the virus.

'The experiments of Moussu (1926), \%wick, Seifried, and Witte (19:26). and Erust and Hahn (1927) show that the virus of Bornt disuase can pass through ordinary bacteriological tilturs, but that tiltration of the virus is not easily effected. \%wick carried out more than thirty filtration experiments with different filters and inoeulatorl more than 100 rabbits with the various tiltrates before he suceneded in infoeting the animals witls a filtrate.

IVP have carried out two filtration experiments, using the following technique: from the Irain of Rnbbit 275 , which died on tho 32 nel day aftor cerobrul inoculation and exhibited characteristic lusions throughout the nervons systom, anr enulsion 1 : 30 was mado with 
physiological saline. The emulsion was placed in the ice-chest for three hours to allow the coarser particles to deposit. The supernatant fluid was filtered by aspiration under low pressure through a Mandler filter.

\section{Experiment 1.}

The filtrate was inoculated intracerebrally into Rabbits $218 \mathrm{~A}, 168_{\mathrm{A}}$, $228 \mathrm{~A}$, and $201 \mathrm{~A}$, on the 15.3.27.

During a period of 174 days following the inoculation Rabbit $218 \mathrm{~A}$ did not show any svmptoms, and its weight increased in an even curre by 730 gms. After this period had elapsed the resistance of the animal was tested with fresh passage virus by intracerebral inoculation. It died in 37 days after showing typical symptoms of the disease. On microscopic examination of sections of the central nervous system characteristic lesions were found.

Rabbit $168_{\mathrm{A}}$, weighing $700 \mathrm{gms.}$, and Rabbit $22 \delta_{\mathrm{A}}$, weighing 2,080 gms., also remained well for 174 days following the inoculation, and their weights increased to 1,330 gms. and 2,640 gms. respectively. They were both reinoculated intracerebrally with fresh passage virus on September 5, 1927 (174th day since inoculation), and proved not to be refractory to infection; Rabbit $168_{\mathrm{A}}$ dying 14 days and Rabbit 228 A 37 days after inoculation with the test dose. The control rabbit, $25_{\mathrm{A}}$, inoculated intracerebrally on the same date as the others, died 48 days after infection, and typical lesions were found in the central nervous system,

Rabbit 201A was inoculated intracerebrally with filtrate on the 15.3.27.

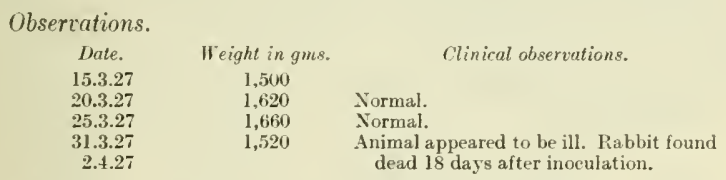

On the autopsy no abnormal condition of the organs was observed and the cultures of the brain remained sterile. On microscopic examination slight infiltration and perivascular lesions were found in the brain, mid-brain, and spinal cord, and, in addition, a marked pathological 'satelhitism' of the nerve-cells. Passage was inade with the brain of this rabbit to a liealthy rabbit, No. $260_{\mathrm{A}}$, with the results given in detail below:

Rabbit $260 \mathrm{~A}$, weighing 1.740 gms., was inoculated intracerebrally with an emulsion of the brain of Rabbit 201A.

It developed a disease of a recurrent nature and succumbed after the second crisis, 161 days after inoculation.

Autopsy. All organs macroscopically normal.

Cultures in broth from the brain remained sterile.

Microscopic examination. Intense and characteristic lesions were found in the brain and in the cord. The intranuclear corpuscles of Joest-Degen were also found. 
Obsertations.

\begin{tabular}{|c|c|}
\hline Date. & Weight in gins. \\
\hline 2.4 .27 & 1.700 \\
\hline 19.4 .27 & $1.81 \times 1$ \\
\hline 28.4 .27 & $1.9(x)$ \\
\hline 5.5 .27 & 1,920 \\
\hline 12.5 .27 & $1,6(x)$ \\
\hline 16.5 .27 & 1.570 \\
\hline 21.5 .27 & 1.620 \\
\hline 30.5 .27 & $1,64 k 1$ \\
\hline 13.6 .27 & 1,640 \\
\hline 22.6 .27 & $1, \pi 40$ \\
\hline 30.6 .27 & 1.770 \\
\hline 15.7 .27 & 1,800 \\
\hline 1.8 .27 & $1.7(x)$ \\
\hline 3.8 .27 & 1.540 \\
\hline 15.8 .27 & $1,30)$ \\
\hline $2+.8 .27$ & 1.1813 \\
\hline 31.5 .27 & $1,(x)(0)$ \\
\hline 9.9 .27 & 980 \\
\hline 12.9 .27 & $x \geq 11$ \\
\hline
\end{tabular}

13.9.27

Nothing abnormal in animal's condition.

Clinical obserentions.

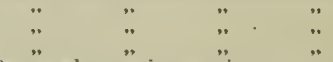

Iepressed, posterior paresis.

Placed on his flank the animal made sereral rain efforls to recover its normal positiou.

Condition ameliorated-slight paresis of hindquarters.

Much improred.

Normal.

,

$*$

Animal ill.

Paresis of hindquarters.

",

Head depressed," paresis of hindquarlers, Ispical symploms of the disease.

Placed on the flank, the rabbit made vain efforts at recovering the normal position.

Found dead 161 days after inocnlation.

\section{Experiment 2 .}

A second filtration experiment was carried out with the same technique. The filtrate through a Mandler filter was inoculated into the brain of four rabbits, $150 \mathrm{~A}, 152 \mathrm{~A}, 210 \mathrm{~A}$, and $231 \mathrm{~A}$.

Rabbit $231 \mathrm{~A}$ died accidentally 5 dilys after inoculation.

Rabbit 210. remamed uniffected and gained progressively in weight.

The protocols of Rabbits $150 \mathrm{~A}$ and $152 \mathrm{~A}$ are given helow.

\section{laabbit 150 A.}

Date.
15.3 .27
20.3 .27
31.3 .27
15.4 .27
28.4 .27
5.5 .27
12.5 .27
21.5 .27
30.5 .27

5.6 .27
13.6 .27
29.6 .27
15.7 .27
1.8 .27
29.8 .27

Heighl gms.

$1.8(x)$

$1, x+111$

$1,8(3)$

2,260

2,320

2,520

$2,+20$

$2,3+11$

2,3411

2.460

$2,6+11$,

2, inx)

$2,(K)$

2,9711

$3,($ KK)
Rabbit 15:A.

Wreight in clinical observa.

gm.s. tions.

$2,2(x)$

2,440

$2,4+1)$

$2,5(x)$

2, (iti)

2,tixil

$2,(620)$

$2,($ isi)

2,15211

2.6511

$2,794)$

ב. IIMI

$2, \sin 41$

$2,(\mathrm{H} M \mathrm{KI}$

$2,(150)$
Sormal.

"

"

.

,

..

.

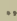

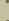

.

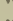

..

Therefore only Rabbit 150.1 showml slight transitory symptoms which ultimately passed away completely. These symptoms may have bern due to tha inoculation of a small dose of virus. 
In order to determine whether the 3 rabbits, $150 \mathrm{~A}, 152 \mathrm{~A}$, and $210 \mathrm{~A}$, had dereloped any degree of immunity as a result of inoculation with the filtrate, 167 days after the first injection they received intracerebrally a virulent emulsion of brain at the same time as a normal rabbit, $25 \mathrm{~A}$. which served as a control. Rabbit $150 \mathrm{~A}$ died on the 49 th day. Rabbit $152 \mathrm{~A}$ on the 40 th day, and Rabbit $210 \mathrm{~A}$ on the 40 th day, and the control rabbit on the 48 th day after inoculation of the test dose. Typical lesions were found in all cases on microscopic examination of sections of brain and spinal cord.

Conclusions. The results in our few experiments support the conclusion of Zwick, Seifried, and Witte (1927) that the virus of Borna disease can pass, though with great difficulty, through bacteriological filters which retain ordinary bacteria, and that the concentration of virus in the filtrate is much reduced.

Zwick succeeded in obtaining an active filtrate after filtering a virulent emulsion of brain through a /sigmondy Bachmann collodion nembrane, of which the size of the pore was estimated to be $0.75 \mu$.

Effect of dilution. Few titration experiments have been made. Zwick records that a virulent emulsion of brain is still capable of producing the disease in a dilution of $1: 10,000$.

\section{Centrifugalization.}

\section{Experiment 1.}

A homogeneous emulsion of virulent brain was made, and after the larger particles had been allowed to deposit, the supernatant fluid was pipetted and centrifugalized for 5 minutes at 5,400 revolutions per minute. The supernatant tluid after centrifugalization was carefully pipetted off and inoculated intracerebrally into three rabbits weighing between 1,300 and $1,500 \mathrm{gms}$. These three rabbits fell ill, showed typical symptoms and died, 39,48 , and 90 days respectively after the inoculation. The characteristic lesions of Borna disease were found in the central nervous system of all three.

(a) Rabbit $322 \mathrm{~B}$. Weight $1,540 \mathrm{gms}$.

(b) Rabbit $321 \mathrm{~B}$. Weight 1,300 gms.

(c) Rabbit $320 \mathrm{~B}$. Weight $1,500 \mathrm{gms}$.

The inoculation was made on 15.3.27. The protocol of the three rabbits is given below:

\begin{tabular}{|c|c|c|c|}
\hline \multirow[b]{2}{*}{$\begin{array}{c}\text { Date. } \\
15.3 .27\end{array}$} & \multicolumn{3}{|c|}{ Rabbit $322 \mathrm{~B}$. } \\
\hline & Weight in gms. & & Clinical obsereations. \\
\hline $\begin{array}{l}10.3 .21 \\
23.3 .27\end{array}$ & $\begin{array}{l}1,5 \pm 0 \\
1,680\end{array}$ & Normal. & \\
\hline 25.3 .27 & 1,700 & , & \\
\hline 31.3 .27 & 1,700 & , & \\
\hline 10.4 .27 & 1,620 & , & \\
\hline 15.4 .27 & 1,580 & ", & \\
\hline 19.4 .27 & 1,420 & Paresis o & ad quarters. \\
\hline 28.4 .27 & 1,220 & Typical s & toms of the discase. \\
\hline 2.5 .27 & — & Found de & 18 days after inoculati \\
\hline
\end{tabular}

Culture of the brain. Negative.

Microscopic examination. Intense and characteristic lesions in the central nervous system. 
Rabbit $321 \mathrm{~s}$.

\begin{tabular}{|c|c|c|c|}
\hline Date. & If eight ingms. & & Clinical obserations. \\
\hline $\begin{array}{l}15.3 .27 \\
23.3 .27\end{array}$ & $\begin{array}{l}1,300 \\
1,280\end{array}$ & Normal. & \\
\hline 25.5 .27 & 1,380 & 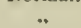 & \\
\hline 31.3 .27 & 1,420 & " & \\
\hline 10.4 .27 & 1,480 & ", & \\
\hline 15.4 .27 & 1,600 & ," & \\
\hline 19.4 .27 & 1,640 & ", & \\
\hline 28.4 .27 & 2,000 & " & \\
\hline 10.5 .27 & 2,100 & $"$ & \\
\hline 21.5 .27 & 2,320 & $"$ & \\
\hline 30.5 .27 & 2,080 & Paresis & indquarters. \\
\hline 5.6 .27 & 1,800 & Typical & ptoms of disease. \\
\hline 11.6 .27 & 1,580 & Coma, $\mathrm{F}$ & d 90 days after infectio \\
\hline
\end{tabular}

Cullures of the brain. Segative.

Ificroscopic examination. Intense and characteristie lesions in the central nervous system.

Rabbit $320 \mathrm{~B}$.

$\begin{array}{ccc}\text { Date. } & \text { Height ingms. } & \text { Clinical obsercalions. } \\ 15.3 .27 & 1,5(n) & \text { Normal. } \\ 23.3 .27 & 1,600 & \text { " } \\ 25.3 .27 & 1,620 & \text {. } \\ 31.3 .27 & 1,440 & \text { Paresis ? } \\ 10.4 .27 & 1,320 & \text { Typical symptoms of the disease. } \\ 15.4 .27 & 1,320 & \text { Died 39 days after infection. }\end{array}$

('ultures from the brain. Negative.

Microscopic examination. Mlild, but eharacteristic lesions in the central nervous system.

\section{Experiment 2.}

A virulent emulsion of brain was allowed to deposit, and the supernatant fluid centrifugalized as in the last experiment $(5,400$ revs. per minute) for 15 minutes. Two rabbits were inoculated intracerebrally with the supernataut fluicl. Both these rabbits developed the diseuse typically with paralysis, and died 28 and 45 days respectively after the inoculation, showing lesions of a characteristic nature in the eentral nervous system.

(a) Rabbit $32+\mathrm{B}$. Wrighlit $1,150 \mathrm{~g} 1 \mathrm{~ms}$.

(b) Rabbit $326 \mathrm{~B}$. Weight 1,150 gus.

The inoculation was made on 15.9.27.

The protocol of these two rabbits is recorded below.

Rabbit $32+\mathrm{B}$.

Date.

15.3 .27

2013.27

25.3 .27

$3+.3 .27$

11.4 .27

15.4 .27

19.4 .27

28.4 .27

240.4 .27
Clinical obserintions.

30

$1,4(x)$

1,330

3.140

$1,1(x)$

1.J(4)

1,080
Sormal.

"

"

.

Conimencement of symplesnn.

Parstysis of hindquarlers.

Found dend th days after inosulation.

r'ultures from thr brain. Negative.

If icroscopir examination. The brsin and spinal corrl whowed llac presence of typeal lergions. 
Rabbit $320 \mathbf{8}$.

Date.

15.3.27

20.3.27

25.3.27

31.3.27

11.4 .27

12.4 .27
Weight in gms.

1,150

1,360

1,440

1,380

1,020

Clinical observations.

Paresis of hindquarters.

Found dead 28 days after inoculation.

Microscopic examination. The brain and spinal cord showed the presence of typical lesions.

Conclusion. Centrifugalization for even 15 miutes at 5,400 rev. per minute does not deprive the supernatant fluid of virulence. This fact, in addition to the properties of filterability and invisibility of the pathogenic agent suggests that the size of the infective element is excessively small. It is affected by centrifugalization in the same way as other filterable viruses such as those of foot-and-mouth disease, rabies, herpes, vaccinia, and poliomyelitis.

\section{Resistance to Glycerine.}

Moussu (1926) found that a portion of brain preserved its virulence at room temperature (July-August, Alfort) for 18 days, but that its pathogenic action was lost after 32 days. According to Zwick the brain of a rabbit preserved its virulence in glycerine for from 4 to 5 months, and in our experiments glycerinated virus kept in the cold room at $4^{\circ} \mathrm{C}$. was still virulent after 113,135 , and in one case 161 days.

To find the best conditions for keeping the virus in the cold room the following solutions were tried. (1) Pure glycerine, (2) pure glycerine covered with a layer of sterile paraffin oil, (3) glycerine mixed with an equal part of sterile physiological saline, (4) glycerine mixed with an equal part of phosphate saline $\mathrm{M} / 25, \mathrm{pH}$. 7.6. The brain of Rabbit $77 \mathrm{~A}$ (dead of Borna disease 48 days after inoculation intracerebrally with typical lesions in the C.N.S.) was taken aseptically and divided into four equal portions, and owe of the portions placed in each of the four media referred to above. At the end of a certain time a fragment of each portion was taken and an emulsion of it inoculated intracerebrally into rabbits to test its virulence. A table of results is given on page 18 .

The results recorded in the table on $\mathrm{p} .18$ show that the virus may remain virulent in the cold room at $4^{\circ} \mathrm{C}$. at least 113 days in a medium consisting of pure glycerine, glycerine diluted to 50 per cent. with physiological saline, or glycerine diluted to 50 per cent. with phosphate saline $\mathrm{M} / 25, \mathrm{pH}$. 7.6. In two further experiments under similar conditions the virus preserved in glycerine remained virulent for 135 days and 161 days respectively.

(1) An emulsion of the brain of Rabbit 25 (dead of Borua disease 35 days after inoculation) which had been kept in glycerine in the ice-chest for 135 days was inoculated intracerebrally into Rabbit $145 \mathrm{~A}$. 


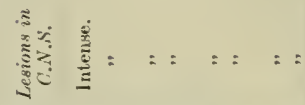

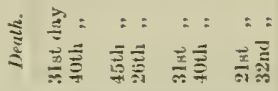

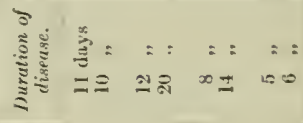

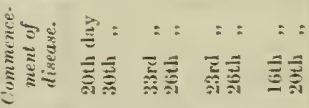

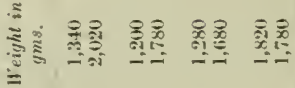

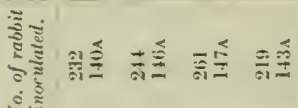
$\therefore$

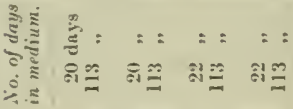

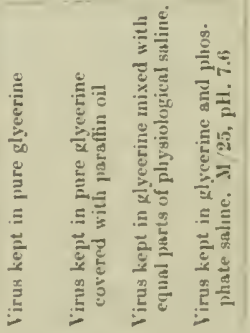


Rabbit $14.5 \mathrm{~A}$. Weight $2,500 \mathrm{gms}$.

$\begin{array}{ccc}\text { Date. } & \text { Weight in gms. } & \text { Clinical observations. } \\ 13.6 .27 & 2,500 & \text { Normal. } \\ 22.6 .27 & 2,500 & , " \\ 29.6 .27 & 2,500 & \text { First symptoms of the disease. } \\ 7.7 .27 & 2,320 & \text { Typical symptoms of the disease in an advanced } \\ 14.7 .27 & 1,900 & \text { stage. } \\ 19.7 .27 & 1,550 & \text { Died } 47 \text { days after inoculation. }\end{array}$

Cultures from brain. Negative.

Microscopic examination. Brain and cord showed presence of intense lesions.

(2) Virus (brain of Rabbit 100 dead of enzootic encephalo-myehtis on the 37 th day after inoculation) kept in glycerme 161 days in the chest, was inoculated intracerebrally into Rabbit $142 \mathrm{~A}$ on the 3.6 .27 .

Rabbit $142 \mathrm{~A}$. Weight $2,440 \mathrm{gms}$.

$\begin{array}{rcc}\text { Date. } & \text { Weight in gms. } & \text { Clinical observations. } \\ 13.6 .27 & 2,500 & \text { Normal. } \\ 22.6 .27 & 2.620 & . \\ 29.6 .27 & 2,440 & \text { Typical symptoms commencing. } \\ 7.7 .27 & 2,040 & \text { ". } \\ 14.7 .27 & 1,550 & \text { Died } 43 \text { days after inoculation. }\end{array}$

Cultures from brain. Negative.

Hicroscopically. Characteristic and intense lesions were present in the central nerrous system.

The have observed that certain of the rabbits infected intracerebrally with virus kept in glycerine succumbed to the disease at an earlier date than rabbits inoculated with an emulsion of fresh virulent brain as is indicated by the following experiment.

(3) Rabbit 275 was inoculated intracerebrally with a virus kept in pure glycerine for 48 days on 10.2.27.

$\begin{array}{rcc}\text { Date. } & \text { Weight in gms. } & \text { Clinical observations. } \\ 10.2 .27 & 2,100 & \text { No abnormal symptoms observed. } \\ 19.2 .27 & 2,150 & , \\ 23.2 .27 & 2,040 & , \\ 27.2 .27 & 1,940 & \text { Commencing paresis of the hind quarters. } \\ 5.3 .27 & 1,700 & \text { Paresis of hindquarters more adranced. } \\ 7.5 .27 & 1,520 & \text { Animal remained in corner of the cage hunched up, } \\ 9.3 .27 & - & \text { depressed. The paresis was still present. } \\ 12.3 .27 & 1,260 & \text { Intense salivation. Paralysis of the hind quarters. } \\ 13.3 .27 & 1,220 & \text { Died } 32 \text { days after the inoculation. }\end{array}$

The microscopic exomination of sections of brain and cord of Rabbit $112 \mathrm{~A}$ revealed the presence of intense and characteristic lesions.

The following table, which shows the chain of the series of passages of the virus from rabbit to rabbit, of which Rabbit 275 forms a connecting link, demonstrates the fact that although it weighed more than 2,000 gms. it died at an eartier date than the other rabbits of the same series. 


No. of Rabbit.
100
774
275
$2] 1$

212
Inoculated intracerebrally with

Fresh virus.

Fresh virus from Rabbit 100 .

Virus from Rabbis $7 \%$ A kept in glyeerine for 48 days.

Fresh virus from Rabbit 275.
Interial between inocula. tion and death.

37 days.

48 ,

$32 \quad$

42 "

A similar observation has been made a number of times in the course of our experiments, and this is recorded as a typical example. Levaditi, Harvier, and Nicolau record similar findings for the virus of herpes, and this has been confirmed more recently by Perdrau.

\section{T. Sexsitiveness to Heat and Desiccation.}

(a) Heat. Zwick and his collaborators found that cerebral emulsions heated for $5,10,15,20$, and 25 minutes respectively at $50^{\circ} \mathrm{C}$. preserved their virulence for the rabbit. In some instances a similar emulsion heated for 30 minutes at $50^{\circ} \mathrm{C}$. became arirulent. Heated for 30 minutes at $57^{\circ} \mathrm{C}$. or 10 minutes at $70^{\circ} \mathrm{C}$. in the water-bath the virulence of the emulsion was destroyed.

(b) Desiccation. Zwick found that a virulent emulsion of brain dried for 6 to 10 hours at $30^{\circ} \mathrm{C}$. proved to be avirulent when inoculated 1 or 10 days after such desiccation.

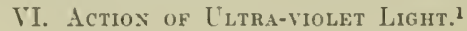

We proceeded in the following manner. A homogeneous emulsion of virulent brain was centrifugalized for 5 minutes. The supernatant Huid was carefully pipetted into a small quartz Hask and exposerl for 5 minutes to the rays from a mercury arc. Two mercury vapour lamps (K.B.B. type, 25 amperes, 210 volts D.C.) were employed 8 inches distant. The flasks were slowly rotated during the exposure so that a fresh thin film of Huid was constantly exposed to the lamp. The tlasks dipped periodically into cold water in a trough to prevent overheating during the experiment. The irradiated fluid was inocnlated into the brain of a rabbit. At the same time a portion of the non-irradiated emulsion was inoculated intracerebrally into two rabbits, which served as controls. The protocols of these ixperiments are recorded on page 21 .

The rabbit inoculated intracerebrally with the virus which ham beren subjected to the rays of the mereury are, dirl not show any symptoms during three months, while the controls died after 23 and 34 days respectively, showing that the virus subjected to the action of ultra-violet rays (radiations of wave-lengths 5,720-2,320 A.I.) is killed in a maximum of 5 minntes.

liabbit 16:3. was rinoculated, along with a control rabbit, No. $25 \mathrm{~A}$, with fresh passage virus 86 days later and died on the

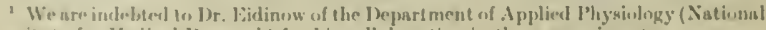
Instilute for Modiesl leesearch) fur his eollaboration in theso exprrinents. 
38 th day. The control rabbit succumbed to the injection on the 48 th day.

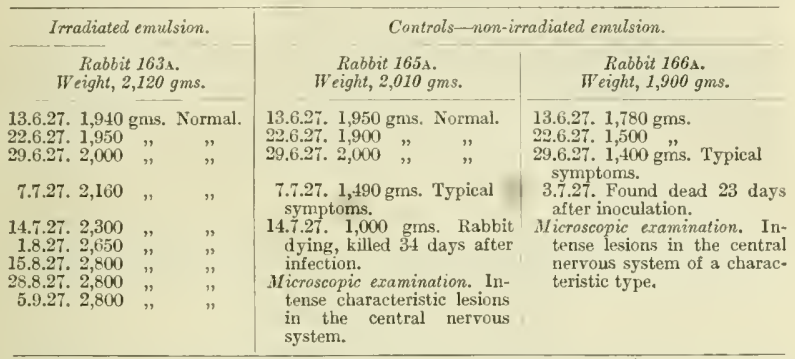

VII. The Action of Hexamethylenetetramine (Urotropine).

The experiments of Moussu (1926) show that when equal quantities of a virulent emulsion of brain and a 10 per cent. solution of urotropine are mixed and kept at room temperature for 12 hours, the virus can still be demonstrated in the mixture after this time.

\section{Action of Chloroform AND Ether.}

(a) Action of Chloroform. A thick emulsion of the brain of a rabbit dead of experimental Borna disease (Rabbit 182A, dead on the 40th day after cerebral infection) was mixed with five volumes of chloroform, and the mixture kept for 18 hours at room temperature. The fluid part of the misture was removed by evaporation in a vacuum over sulphuric acid. The dried brain residue was powdered in a mortar and suspended in physiological saline. This suspension was then inoculated intracranially into two rabbits (234A and 235 $\mathrm{A}$ ). Rabbit $219 \mathrm{~A}$, which was inoculated with an emulsion of the same brain not mixed with chloroform, served as control.

Five days later both Rabbits $234 \mathrm{~A}$ and $235 \mathrm{~A}$ received a further inoculation with the virus which had undergone similar treatment with chloroform.

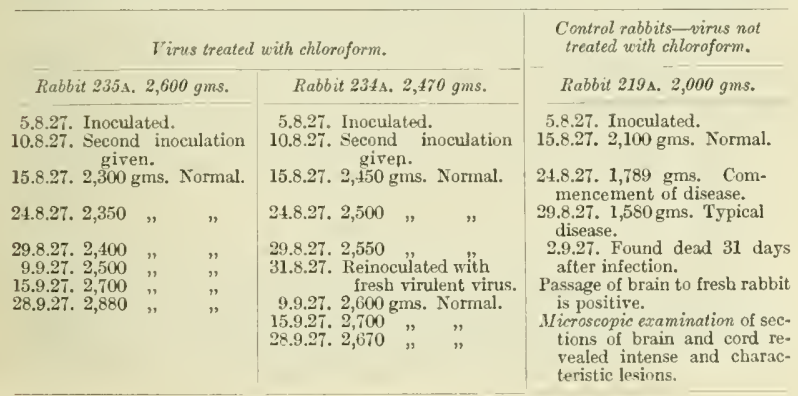


These experiments show that the virus is inactivated by contact with chloroform for 18 hours at room temperature.

(b) Action of Ether. The technique was similar to that employed in the above experiment with chloroform. Pabbit $231 \mathrm{~A}$, which received an intracerebral inoculation of ether-treated brain emulsion, was kept under obserration for 5 months. It never showed any srmptoms of Borna disease and gained $780 \mathrm{gms}$. in weight. The control rabbit, $219 \mathrm{~A}$, inocnlated with non-treated brain died in 31 days of a typical infection.

NoтE.-The experiments on the effect of chloroform and ether on the virus are onl preliminary. Obviously there are certain details in the technique used which will have to be controlled, and improved methods are now being emploved.

\section{Actios of Formalis.}

A bont one gramme of the brain of Rabbit 355. (which died 27 days after intracerebral inoculation with the passige virus of Borna disease) was emulsified in 15 c.cms. of a solution of formalin in physiological saline $(2: 1,000)$. The emulsion was rendered as lomogeneous as possible, and was then placed at the temperature of the laboratory for 18 hours. Subsequently rabbits were inoculated intracerebrally with the formolized emulsion. An emulsion of the brain of Rabbit $355 \AA$ in a similar dilution not treated with formalin was inoculated as a control into the brain of a rabbit.

Protocols. The inoculations were made 10.S.27.

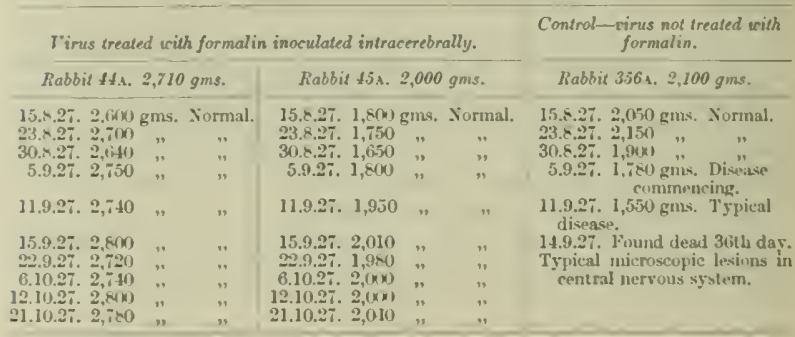

Conclusion. The conclusion arrived at is that formalin in a concentration of $0 \cdot 2$ per cent. inactivates the virus after 18 hours' contact at room temperature.

\section{Culture.}

All attempts at cultiration of the virus have remained negative up to the present.

\section{Xl. S'mustr.}

From the observations of the authors quoted and our own, it appears that the virus of Borna disease possesses the propert ies common to those of vaccinia, herpes, rabies, and polionyelitis which Jevaditi has gromped together under the mame "etodermoses neurotropes'. Ender favourable conditions it filters through bacteria-proof filters, 
although most of the virus is held back, and through a collodion ultrafilter which will allow colloidal particles of large dimensions to pass. The infectivity of the supernatant fluid cannot be removed by centrifugalization for 15 minutes at 5,400 revs. per minute. It is resistant to the action of glycerine, but sensitive to desiccation, ultraviolet light and heat. It is destroyed by ether, chloroform, and formalin. It has not been propagated outside the body.

\section{TRANSMISSION OF EQUINE STRAIN TO RABBIT AND FROM RABBIT TO SHEEP, AND VICE VERSA}

Moussu (1926) inoculated an emulsion of the brain of a rabbit preriously infected with the virus from a horse into the anterior chamber of the eye of a horse. The animal developed symptoms 3 days after the inoculation and died in 8 days. The lesions found in the brain were very intense, infiltrative, and haemorrhagic. A rabbit inoculated with an emulsion from the brain of this horse died 4 days later. ${ }^{1}$ This same anthor failed to infect horses with virulent material from rabbits by subcutaneous inoculation or per os. Zwick and his collaborators (1926) inoculated a horse intracerebrally with the brain of a rabbit suffering from experimental Borna disease. The virus had been passaged in this species of animal nine times. The horse fell ill 53 days after the inoculation. For 11 days it showed the typical symptoms of encephalo-nyelitis and death followed 64 days after the inoculation. The lesions of the nervous system were characteristic of Borna disease. The intranuclear corpuscles of Joest-Degen were demonstrated in the ganglion cells of the Ammon's horn.

We have referred previously to the experiments of Beck and Frohböse (1926), Moussu (1926), Miessner (1926), and Ernst and Hahn (1927), which showed that the virus of eucephalo-myelitis originating from sheep can be transmitted to rabbits by experimental inoculation. Moussu and Marchand (1924) succeeded in passing the disease from sheep to sheep. Zwick and his collaborators (1926) failed to transmit the disease to adult sheep by intracerebral inoculation with a strain derived from a horse and passed through rabbits. Using the same strain of virus they succeeded, however, in conferring the disease on young lambs. Death followed 88 days after the inoculation and typical cerebral lesions were revealed.

Direct inoculation from horse to lamb was also successful. The lamb showed characteristic symptoms and died 92 days after infection. Inoculation of the brain of this lamb to a rabbit gave a positive result, but inoculation of the cord gave a negative result. Beck and Frohböse (1926) did not succeed in infecting the lorse by the intracerebral route with virus from sheep dead from the spontaneous

\footnotetext{
1 The experiments of Moussu and Marchand have been eriticized since his inoculated animals succumbed very early, and also hecause the lesions of the brain were surprisingly acute when compared with those found in the classical disease occurring spontaneously or in animals infected with the viruses isolated by the German school. We had the intention of comparing their strain with those of Zwick and Miessner, but Moussu has informed us that his strain is not now available.
} 
disease. On the other hand, they succeeded in infecting sheep with virus obtained from horses.

From the foregoing résumé of the literature the following conclusions may be drawn:

(1) The virus originating from horses passaged through rabbits can be transmitted back to the horse.

(2) The virus taken directly from the horse or subsequently passaged through rabbits is pathogemic for lambs.

(3) Attempts at transmitting the disease from sheep to horses have so far been unsuccessful.

\section{EXPERIMENTAL DISEASE IN THE RABBIT}

\section{Experimental Traxsmissiox of the Disease to the RABBIT}

Ioussu (1926) inoculated an emulsion of the brain of a borse dead of encephalo-myelitis into the anterior chamber of the eye of the rabbit. In one experiment three animals were inoculated by this route. One died on the 9 th day; the two others survived; the rabbit which died constituted the head of the series of passages that the author continued until he obtained a 'fixed' virus which lilled the rabbits infected by the intraocular route in 4 to 6 days. In another experiment using similar material one out of five animals inoculated intraocularly died 11 days after receiving the injection; the other four survived. In the majority of cases a marked excitability was a characteristic symptom. Moussu states, howerer, that certain rabbits die 'following an infection with a slower evolution, lasting more than a fortnight'.

Zwick inoculated rabbits intracerebrally with the cerebral substance (Amnon's horn, caudate nucleus, and cerebral cortex) taken from the brain of a horse dead of Borna clisease. He observed trpical symptoms of the disease after a period of about 4 weels, and the lesions were analogous to those described previously in the horse. Passage from rabbit to rabbit was effeeted, the period of incubation after inoculation being about 3 weeks.

/wick and his collaborators (1926) succeeded in infecting rabbits with the virus from 16 ont of 21 cases of horses dead of Borna disease which was rerified histologically. The incubation period of the disease in such rabbits infected by the intracerebral ronte was from 3 to 4 weeks. Death ensued 8 to 14 days after the appearance of the characteristic symptons.

Beck and Frohböse (1926) also infected rabbits with the rirus from horses and sheep. Miessner (1926) with sheep virus, and Ernst and Hahn (1927) with viruses from horses, sheep, and enttle.

\section{Autuors' Observations.}

The virus of encephalo-myelitis of equine or ovine origin isolated by the freman workers does not become 'fixed' when passaged through rablits. The period of incubation varies from 15 to 50 days, and we have also observed recurrent forms of the disease in rabbits. 
We have inoculated more than 200 rabbits by the intracerebral route with the virus originating from horses or sheep. In Table I the period of incubation and the time between the onset of the disease and death is recorded for a total of 50 rabbits used for passaging a virus originally obtained from a horse and sent to us by Professor Zwick.

TABLE T.

\begin{tabular}{|c|c|c|c|c|c|c|}
\hline $\begin{array}{l}\text { Number } \\
\text { of } \\
\text { rabbit. }\end{array}$ & $\begin{array}{c}\text { Weight in } \\
\text { gms. }\end{array}$ & $\begin{array}{c}\text { Commence- } \\
\text { ment of } \\
\text { disease. }\end{array}$ & $\begin{array}{l}\text { Duration } \\
\text { of the } \\
\text { disease. }\end{array}$ & Death & & $\begin{array}{c}\text { Lesion.s in } \\
\text { C.N.S. }\end{array}$ \\
\hline 25 & 2,160 & 2lst day & 14 days & 35 th d & day & Intense. \\
\hline 22 & 2,000 & 20th ," & $4 \quad$, & 24 th & & Positive. \\
\hline 24 & 1,420 & $21 s t$ & 19, & 40 th & , & , \\
\hline $10 \mathrm{D}$ & 2,500 & 27 th , & $10 "$ & 37 th & , & Intense. \\
\hline 110 & 1,000 & 17th ", & 10 & $27 \mathrm{th}$ & , & \\
\hline$* 93 \mathrm{~A}$ & 1,520 & 7 th , & , & 8th & ", & Sbight. ${ }^{1}$ \\
\hline $68 A$ & 1,150 & 20 th , & $"$ & 25 th & , & Intense. \\
\hline $50 \mathrm{~A}$ & 1,620 & 40th ., & 13 & 53rd & ", & , \\
\hline $77 \mathrm{~A}$ & 1,570 & 38 th , & 10 & $48 \mathrm{th}$ & $"$ & $"$ \\
\hline 80 & 1,350 & 2 lst & 7 & $28 \mathrm{th}$ & , & , \\
\hline $51 \mathrm{~A}$ & 1,350 & 20 th & ," & $28 \mathrm{th}$ & , & , \\
\hline 34 & 2,000 & $43 \mathrm{rd}$, & 14 & $57 \mathrm{th}$ & , & , \\
\hline 298 & 820 & 25 th , & 14 & 39 th & ", & ", \\
\hline 275 & 2,100 & 25 th, & 7 & 32 nd & ", & , \\
\hline 202 & 1,050 & 29 th & $"$ & 32nd & ," & ," \\
\hline 282 & 1.040 & 27 th & ," & 31st & ", & ", \\
\hline 244 & 1,200 & 33 rd ", & 12 & 45th & ", & $"$ \\
\hline 261 & 1,280 & 23rd ," & 8 & 31 st & ", & ", \\
\hline 232 & 1,340 & 20 th & 11 & 31 st & $"$ & , \\
\hline 219 & 1,820 & 16 th, & , & $21 \mathrm{st}$ & ", & $"$ \\
\hline 295 & 1,300 & 9 th ," & 10 & 19 th & , & Very intense. \\
\hline 211 & 1,580 & 3lst ," & 11 & 42 nd & , & , \\
\hline 212 & 1,400 & 3 lst ," & 13 & 44 th & $"$ & ", \\
\hline 220 & 1,500 & 31 st ", & 8 & 39 th & ", & " \\
\hline 222 & 1,540 & 35 th ," & 13 & 48th & ", & , \\
\hline 224 & 1,150 & 32 nd , & 13 & 45th & , & ", \\
\hline 226 & 1,150 & 24th ", & , & 28 th & " & Positive. \\
\hline 70 & 1,700 & 20 th , & , & 22nd & 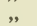 & Intense. \\
\hline 56 & 1,400 & 20 th , & , & $26 \mathrm{th}$ & , & , \\
\hline 61 & 1,500 & 24 th , & , & 30 th & , & , \\
\hline 251 & 1,280 & $18 \mathrm{th}$, & ", & 27 th & , & , \\
\hline 237 & 1,680 & 18th, , & 13 & 3lst & ", & , \\
\hline 255 & 1,920 & 35 th ," & 7 & 42nd & ", & ", \\
\hline 256 & 1,860 & 32 nd ," & 15 & 47 th & ", & , \\
\hline 30 & 1,120 & 28 th & 8 & 36 th & $"$ & $"$ \\
\hline 44 & 1,350 & 26 th , & ", & 33rd & ", & " \\
\hline 58 & 1,000 & $27 \mathrm{th}$, & 7 & $34 \mathrm{th}$ & , & Positive. \\
\hline$* 291$ & 950 & No sympt. & - & i5th & , & Slight. ${ }^{1}$ \\
\hline $85 \mathrm{~B}$ & 1,500 & $32 n d$, & 6, & $38 \mathrm{th}$ & $"$ & Very intense. \\
\hline$* \$ 3$ & 1,020 & No sympt. & - & 12 th & , & Slight. \\
\hline 60 & 1,800 & 30 th , & 7 & 37 th & ", & Intense. \\
\hline 62 & 1,610 & 22 nd ," & 17 & 39 th & , & ," \\
\hline 271 & 1,220 & 31st ." & 10 & 41 st & , & \\
\hline$* 80$ & 820 & No sympt. & - & 7 th & ", & Slight. \\
\hline 269 & 2,200 & 19 th & 2 & 21 st &, & Positive. \\
\hline$* 775$ & 1,780 & No sympt. & -.." & 13 th & , & Positive. ${ }^{1}$ \\
\hline 296 & 2,900 & $26 \mathrm{th}$ & 7 & $33 \mathrm{rd}$ & $"$ & Intense. \\
\hline 277 & 2,100 & 13 th , & 11 & $24 t h$ & ", & ," \\
\hline $78 \mathrm{~s}$ & 1,700 & 24 th & 8 & $32 n d$ & , & ", \\
\hline $116 \mathrm{~A}$ & 1,700 & 18th, & $4 n$ & 22nd & $"$ & , \\
\hline
\end{tabular}

1 When the brain of these rabbits was passaged, positive results were obtained. Rabbits inoculated with passage of virus from the brain of Rabbit No. 93. died in 
Of 50 rabbits inoculated in the brain:

23 died between 21 and 33 days after inoculation.

6 died in less than 21 days.

21 died in more than 33 days.

Only exceptionally did the rabbit die in less than 3 weeks when infected by the intracerebral route. The detailed histopathological study of each case showed that the rabbits dead 7 to 8 days after inoculation had minimal infiltrative lesions in the central nerrous system. The presence of virus in the brain was proved by subsequent passage and in all cases complete autopsies were made to exclude the possibility of death from other causes.

The animals which died between 21 days and 57 days presented the characteristic lesions in the nerrous system, which are described in full in the chapter dealing with the histopathology of the disease. The intensity of the lesions was not in direct relationship with the duration of the nialady. As has also been observed by Zwick the incubation period was longer in larger animals. Generally, rabbits weighing less than 1,500 gms. were more susceptible to infection than older rabbits. Excluding the five animals in Table I marked with an asterisk, all of which died in 15 days or under, the average time which elapsed between the intracerebral inoculation and the death of the animals in our experiments was 20 days in rabbits of less than $1,500 \mathrm{gms}$. and 36 days in rabbits orer this reight at the time of infection.

TABLE II.

\begin{tabular}{|c|c|c|c|c|c|c|c|}
\hline $\begin{array}{l}\text { Number } \\
\text { of } \\
\text { rabbit. }\end{array}$ & $\begin{array}{l}\text { Weight in } \\
\text { gms. }\end{array}$ & $\begin{array}{c}\text { Commence. } \\
\text { ment of } \\
\text { disease. }\end{array}$ & $\begin{array}{l}\text { Dure } \\
\text { of dis }\end{array}$ & $\begin{array}{l}\text { tion } \\
\text { ease. }\end{array}$ & Deal & & $\begin{array}{c}\text { Lesions in } \\
C . I^{*} . S \text {. }\end{array}$ \\
\hline 164 & 1,220 & $21 \mathrm{st}$ day & 81 & ay's & 29th d & lay & Intense. \\
\hline 18 & 1,240 & 2ith .. & 9 & . & 35th & $"$ & .. \\
\hline 246 & 1,380 & $28 t h \quad .$. & 10 & , & $3 s t h$ & " & \\
\hline 234 & $1,+20$ & Tth , & & & Fth & ". & Slight. \\
\hline 243 & 1,420 & $20 t h$." & 2 & .. & 22nd & .. & Intense. \\
\hline 235 & $1,5(x)$ & 22 nd .. & 9 & " & $33 \mathrm{rd}$ & " & ," \\
\hline 262 & 2,220 & 40 th. & 8 & ". & $48 t h$ & $"$ & ". \\
\hline Q30 & $3,6+1$ & 23rd , & 12 & $\checkmark$ & 35 th & $"$ & ." \\
\hline 10 & 2,140 & 18th ., & 9 & " & $2 \pi$ th & " & $"$ \\
\hline 9] & 1.620 & 19th & 8 & " & $27 \mathrm{th}_{2}$ & " & $\bullet$ \\
\hline 274 & 1,770 & J8th ", & 10 & $"$ & 2 sith & " & " \\
\hline 28 & $1,9(k)$ & 23rd " & 14 & "• & 37 th & $"$ & $"$ \\
\hline Sti & $1.8110)$ & 20th " & 12 & " & 32 nd & " & $"$ \\
\hline 63 & 1,6041 & $20 \mathrm{Hh}$, & 8 & " & $2 s t h$ & " & $"$ \\
\hline $162 \mathrm{~A}$ & 2.180 & 2lst " & 12 & $"$ & 33rd & ," & $"$ \\
\hline Jiti A & 2,420 & 22nd! ,. & 7 & 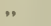 & 29th & $"$ & $"$ \\
\hline 178 & 3,770 & 25th ." & 9 & "P & $3 \cdot t$ th & $"$ & Wïl marliod \\
\hline $207 \mathrm{~A}$ & 840 & lith ., & 2 & " & $21 \mathrm{st}$ & ". & W (') marked. \\
\hline $181 \mathrm{~A}$ & $2, I(k)$ & 2tith ". & 6 & " & $32 \mathrm{nd}$ & 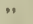 & $\because$ \\
\hline (is) & 1,6700 & 2tith ," & 7 & .. & 33 ral & .. & " \\
\hline $1 \times()_{A}$ & $1,890)$ & 27 th & 12 & $\bullet$ & $3 ! n \mathrm{~h}$ & $"$ & $"$ \\
\hline $179 \mathrm{~A}$ & 2,2211 & $26 t h$. & 6 & " & $32 n d$ & " & $"$ \\
\hline
\end{tabular}

T'able II sets forth similar observations in the case of 22 rabbits

83 disys; from Xn, 2yl, in 38 dnys; from Xo. 77 in 21 days, Intense lesions wero found in the C.X.S. of these lutter rabbits. 
inoculated with a strain of orine origin kindly sent to us by Professor Miessner. The arerage time between inoculation and death was 33 days for the 15 rabbits weighing more than $1,500 \mathrm{gms}$. and 28 days for the 6 rabbits weighing less than 1,500 gms.

\section{Symptomatology of the Disease in the Rabits.}

Observations hare been made on over 200 rabbits. During the first 2 to $t$ days following the injection the reight of the animal decreases shightly, to return later to the normal. Once the period of traumatic shock has subsided the animal puts on weight and no morbid symptoms are seen during 15 to 20 days. Subsequently it becomes slow in its morements and appears depressed; the weight decreases progressively and the first characteristic symptom develops. When the rabbit is placed on its side it makes efforts to recorer its feet, beating the air with its hind legs before erentually recorering the normal position. While the depression referred to above suggests modifications in the meninges and cerebrum, the symptoms described later point to changes in the spinal cord.

The animal assumes a characteristic attitude in the cage with the head in the angle formed by tro walls; it appears somnolent and the somnolence lasts till the end of the disease. The symptoms of nervous origin become intensified gradually; among these are those of amaurosis. Then the animal is allowed to run towards an object it runs into it as if it had not seen it. Grinding of the teeth is observed, sometimes with increased salivation. There is paresis of the ears, which fall to the right and left of the head. The head itself is depressed. When the animal is placed at the edge of a table it hangs its head over the edge below the level of the rest of the body. Trismus may occur. The symptoms of a myelitic character become exacerbated. Taken from the cage and placed on its side, the rabbit makes vain efforts to rise. At this stage its position at rest is characteristic; it remains hunched up in a corner, the head is dropped as if it was no longer capable of supporting it (Fig. 1), and sometimes the back is humped. The muscles of the back become soft and flaccid. Attempts to resist with the hind legs when the animal is held by the skin of the back are feeble or absent. Finally paralysis of the hind quarters occurs, which spreads later to the fore-himbs. The amimal ceases to feed, either from loss of appetite or difficulty in deglutition, and loses weight'. In certain cases the loss of weight may be the dominant feature of the disease. Very often rabbits at the end of the disease have lost nearly half of their original weight (Charts I and II).

The have never observed excitement in our experimental animals, but always depression.

The study of the blood has given inconstant results. In certain animals a slight hyperleucocytosis has been observed with a slight increase in polymorphonuclears. In others the lencocytosis 16,000 to 18,000 per c.mm. was accompanied by lymphocytosis. In the 


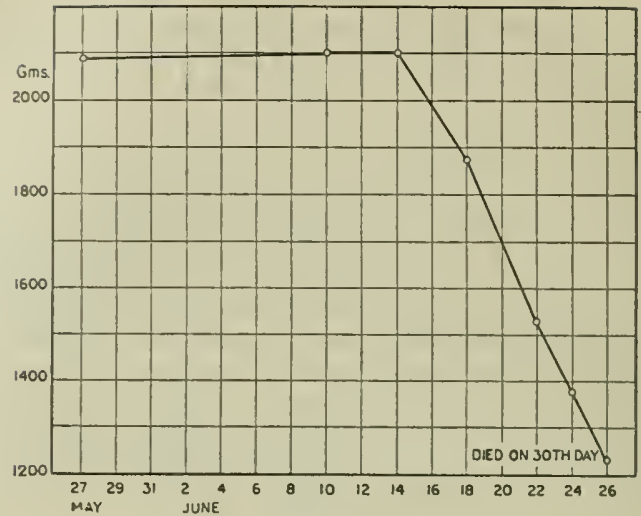

Chart I.

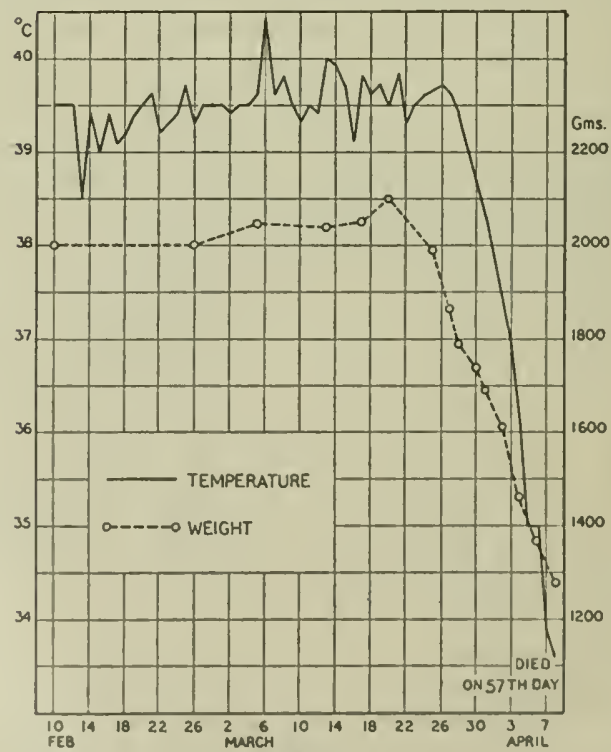

Chart II. 
terminal stage a marked increase in polymorphonuclears is the rule. The number of erythrocytes remains unchanged, and they show no morphological changes.

Chart III shows the parallelism between the augmentation of the number of leucocytes per c.mm. and the number of lymphocytes obtained from the leucocytic count. This modification of the number of lencocytes is not constant.

No fever exists during the course of the disease in the rabbit. This fact was noted constantly when the temperature of a series of rabbits

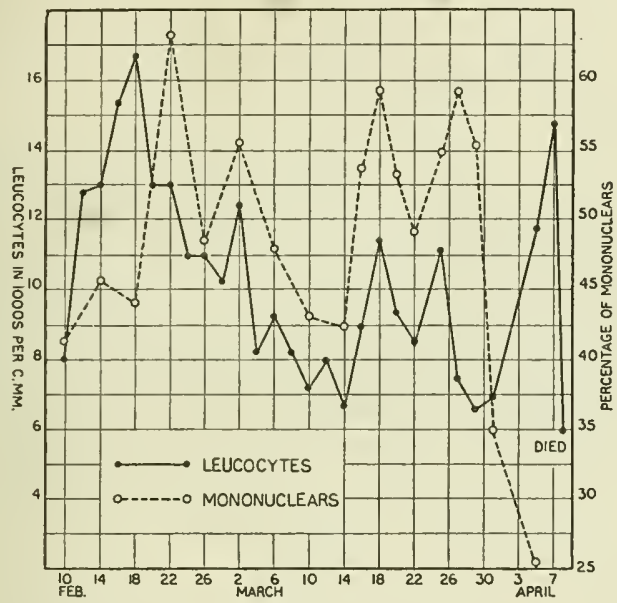

Chart III.

inoculated intracerebrally was taken daily at the same hour. Death takes place in coma-the temperature being hypothermic $\left(35^{\circ} \mathrm{C} .-\right.$ $34^{\circ} \mathrm{C}$.: see (lhart II).

\section{Routes by which Rabbits can be Infected.}

\section{Intracerebral.}

Intracerebral inoculation produces the disease in a constant manner, followed by death.

\section{Intrathecal.}

Beck (1925) infected by introducing virus intrathecally, and we have also succeeded in infecting rabbits by this route.

Experiment 1. Rabbit 207 , weighing 780 gms, was inoculated intrathecally in the lumbar region with $0.5 \mathrm{c.cm}$. of a virulent emulsion of brain diluted 1:10 in physiological saline. Forty-three days 
after the inoculation the condition of the animal was such that when taken out of the eage it walked with its legs spread out from the bodr. Paresis of the hind quarters was well marked, and inereased gradually. The animal wasted and died 66 days after the inoculation. Examination of the brain revealed the presence of characteristic lesions, and a passage of this brain to a healthy rabbit gave a positive result.

\section{Sciatic Nerce.}

Introduction of several drops of a virulent emulsion of the virus into the sciatic nerre did not infect animals with encephalo-myelitis in the experiments of Moussu (1926), and Zwick and his collaborators (1926). We have, however, suceeded several times in producing Borna disease in rabbits inoeulated by this route.

Experiment 2. The right sciatic nerve of Rabbit 208, weighing \$.50 gms., was exposed by incision and 2 or 3 drops of a virulent emulsion of the brain of a rabbit infected with encephalo-myelitis was injected into the substance of the nerve-trunk. The point of introduetion of the needle was seared to prevent the exit of Huid into the surrounding tissues. The operation was carried out aseptically and the incision healed by first intention. The animal showed no morbid symptoms for 35 days and put on weight, reaching 1,350 gms. Subsequently it became prostrate, wasted progressively, and sliowed marked inco-ordination, which beeame accentuated later; the animal died on the 4thth day. The brain was proved to be bacteriologieally sterile, and no lesions were found which might serve to explain the cause of death, other than those in the central and peripheral nervous system. These were of an intense character, and were found in the brain, in the spinal cord (ecrical, thoracie, dorsal, and lumbar regions), and also in the inoculated nerve.

Emulsions from the brain and also the dorso-Jumbar part of the spinal corl were inoeulated into the brain of fresh rabbits. These inoculations producel the disease, showing that the virus was present both in the brain and cord of rabbits inoculated into a peripheral nerve.

Rabbit 2\%0 was also inoculated into the seiatie nerve by the same method as recorded above for Rabbit 20 s. This rabbit $(270)$ showed, (i.) days after the inoeulation, paralysis of the leg into the sciatic nervet of which virus had been inoenlated. Paralysis of the hind quarters followed, with grinding of the tceth, and other typienl symptons. The animal was found dead on the Tsth tay. Lesions were demonstrated throughunt the nervons system (brain, mesencephalon, cord in all regions, inoculated nerve, the seiatic of the opposite siule (noninveulated), as well as in the braelial nerves).

The detailed deseription of these lesions will be given later.

liabbit 2ifj was inoculated into the right sciatic with the same technique as before. "The leg on the side of inoculated nerve becane useless after 24 days, and the animal died 8 days later with lesions in the central and peripheral nervous system. 
Anterior Chamber of Eye.

Moussu (1926) and also Zrick (1926) have shown that it is possible to infect the rabbit by inoculation of a virulent emulsion of the brain of the horse into the anterior chamber of the eye, and we have confirmed the possibility of infection by this route.

Rabbit 206 received several drops of the supernatant fluid from a virulent emulsion of brain into the anterior chamber. The point of inoculation was carefully seared. During the period immediately following the inoculation a coagulum of fibrin could be seen in the eye, but this was absorbed later. The animal died 23 days after the inoculation, and lesions characteristic of Borna disease were found in the central nervous system; these, however, were not very acute.

The control rabbit inoculated intracerebrally with the same emulsion died in the average time with well-marked lesions in the central nervous system.

Rabbits $S 6$ s and $\$ 9$ s inoculated in the anterior chamber with an emulsion containing virus fell ill 29 and 36 days respectively after infection, and died on the 34 th and 51 st day with typical symptoms in the central nervous system. The control rabbit (intracerebral route) died 37 days after inoculation.

A fourth rabbit inoculated intraocularly with the virus survived without baving shown any symptoms.

Thus, of four rabbits inoculated in the anterior chamber three became infected and died of the disease, while the fourth showed no morbid svmptoms and survived. These results are in accordance with those of Zwick who had five positive results in six attempts to infect rabits by the intraocular route.

No macroscopic modification of the cornea followed the introduction of the virus, but microscopically there was slight infiltration with lymphocytes between the corneal laminae. In one case an interstitial infiltration with mononuclear cells of the optic nerve was found.

Corneal Scarification.

Zwick (1926) has stated that infection by comeal scarification causes the disease only rarely. We have inoculated four rabbits by scarification of the cornea; none became infected, nor was there any visible keratitis. However, one of the rabbits (Rabbit $81 \mathrm{~s}$ ) which was subsequently reinoculated intracerebrally with a virulent emulsion of brain 110 days later remained well, whereas a control rabbit which had received a cerebral inoculation with the same emulsion died 48 days later after showing typical symptoms of the disease, and with the characteristic lesions. The corneal inoculation may have rendered the rabbit refractory to infection by the intracerebral route.

\section{Conjunctival Sac.}

Instillation of a virulent emulsion into the conjunctival sac of the eye produced no effect.

Nasal Mucosa.

The nasal mueosa appears to be a possible portal of entry of the virus, and Joest (1927) has suggested that natural contagion in the 
horse is effected by this route. The results of attempts by Zwick (1926), Beck and Frohböse (1926) to infect rabbits by this route have, however, been inconstant.

\section{Scarified Skin.}

Zwick applied a virulent emulsion of brain to the scarified skin without result. Our results ${ }^{2}$ confirm those of Zwick. As, however, the experiments of Flexner and Amos (1917) with poliomyelitis, and of Levaditi and Nicolau $(1922,1923)$ with herpes and neurovaccinia show that previous injection of substances like physiological saline, bonillon, or normal serum into the brain may increase susceptibility, we introduced physiological saline either into the brain or intrathecally in rabbits which had received an application of the virus on to the depilated, shaved, and scarified skin. The animals prepared by the inoculation of saline intrathecally did not show any symptoms of the disease, while those which had been subjected to an irritation of the brain with saline subsequently contracted the disease, and died. Typical lesions were found in the central nervous system, and passage of the brain to new rabbits by the imtracerebral ronte gave positive results. This experiment shows that when the nervous system is in a state of special receptivity due to the diminntion of the normal power of defence, infection can take place from the skim. The virus probably reached the brain by way of the intercostal nerves, thus being protected from the action of leucocytes circulating in the blood. This interpretation is supported by the following experiments. Four rabbits were inoculated with $\mathbf{1 . 5}$ c.cms. of a centrifugalized emulsion of virulent brain into the marginal vein of the ear. Two of the rabbits inoculated intravenously received simultaneously $0.3 \mathrm{c}$.cm. of physiological saline into the brain, but neither of these amimals contricted the disease, nor did the two which received only the intravenous inoculation. Two months later the immunity of these four rabhits was tested by intracerebral inoculation, and all proved susceptible to infection. The virulence of the emulsion used to infect the four rabbits intravenously was proved by the intracerebral inoculation of two controls. So that it would appear that the virus was destroyed in the blood-stream, or in the tissues before it reached the brain.

Uur further attempts to infect by the intravenous route gave us negative results, but '/wick (1926) succeeded exceptionally when 4 intravenous injections were given at intervals. Positive results lave also been obtained by Emst and Hahn (1927). Usually, howevor. they found that repeated inoculations by the intravenons route instead of conferring the malady produeed solicl resistanee. 'I'his will be discussed in the chapter draling with immunity.

\section{Subcutaneous.}

Subeutaneous inoculation may, exceptionally, lead to a fatal (nIcephalo-myelitis. '/wick and his collaborators (1926), who cuployed repeated injections of the virus, produced the discase with a greater

' At no lime did the skin stow any macroseopic changes which could be als ribuled so the virun. 
frequencr. They obtained similar results by inoculation of the rirus intraperitoneally; intramuscular injections with the virus did not confer the disease in their experiments.

\section{Intratesticular.}

According to the latter investigators the introluction of virus by the intratesticular route did not produce infection in rabbits, but in our experiments it has done so.

Rabbit 209. weighing $1.950 \mathrm{gms}$, was inoculated under anaesthesia into both testicles with a virulent emulsion of the brains of four rabbits dead of experimental Borna. The dilution of the emulsion of brain substance in physiological saline was $1: 20$. During a period of 43 days the animal showed no morbid spmptoms and its weight increased to $2.240 \mathrm{gms}$; then, withont other symptoms, wasting commeneed; 19 days later the weight had fallen to 1.860 gms. $(680$ gms. loss), and inco-ordination with slight paresis of the hind quarters was noticed. Paresis became accentuated and other srmptoms characteristic of the disease became manifest. On the $i$ ist das after the inoculation. 20 days after the first loss of weight was recorded and 8 days after the first climical symptom, the animal died, weighing only 1,480 gms. The lesions found in the central nerrous srstem were characteristic and rere especially intense in the lumbar region. The topography of the lesions in the cord indicated that the virus had spread from the point of inoculation to the brain through the cord centripetally. The intranuclear inclusions of Joest-Degen were found.

The passage of the brain and cord of Rabbit 209 to fresh animals gave positive results, indicating the presence of virus in both. The control rabbit inoculated intracerebrally with the emulsion of brain which served to infect Rabbit 209 died 32. dars after inoculation.

Rabbit 2S9, weighing 1.720 gms., was inoculated into the right testicle with a virulent emulsion of brain. During 60 days it put on weight, reaching 2.320 gms. This weight was maintained for 11 days, when wasting began. On the 90 th day after inoculation paresis of the hind quarters was observed. The animal died 105 days after inoculation.

Rubbit 273 inoculated into the right testicle at the same time showed no srmptoms and survived, while the control rabbit inoculated intracerebrally died after 37 days with the typical symptoms and lesions characteristic of the disease.

\section{Intratracheal.}

TVe have made two unsuccessful attempts to infect rabbits by intratracheal inoculation. In the first attempt two rabbits received each $0.3 \mathrm{c.cm}$. of a thick emulsion of brain containing virus into the trachea, which had been exposed by incision; both these rabbits survired without having shown any symptoms, while the control which had received an intracerebral inoculation with the same virus succumbed to the infection. In the second experiment four young rabbits, between 670 and $s 60$ gms., were inoculated. Each received $0.5 \mathrm{c.cm}$. of a thick emulsion of the brain of a rabbit, dead of Borna disease, 6109 
dihted $1: 5$. Fept under obserration more than six months ther maintained their normal state of health, more than doubling their weight. The controls of this experiment inoculated intracerebrally died of a typical encephalo-myelitis on the $42 \mathrm{nd}$ and 44 th day after injection.

$\operatorname{Per} 0$ s.

Attempts at infecting rabbits per os are of special interest for the interpretation of natural infection in horses, cattle, and sheep. Zwick and his collaborators (1926) succeeded in infecting rabbits by mixing virulent brain with the food. He refers to this as infection by the intestinal route, but as the virus was administered by the moutli witl the food, the pre-existence of small traumatic lesions in the mouth might permit the implantation of the virus. As infection by the nusal mucosa has been shown to be possible, one cannot exclude the possibility that infection took place by the buccal nucous membrane, especially when one consillers the existence of nerrous tissue immediately below the mucons membrane covering the tongur (Manouelian and Fiala, 1926). Supposing the virus to have been implanted in such nervons tissue, it is quite easy to conceive how it might ultimately reach the brain.

Attempts to infect rabbits by cohabitation have been unsuccessful.

\section{ACTHORS EXPERIMENTS ON THE TRANSIISNION ON THE DISEASE TO MONKEYS (MACACUS RHESUS), A.TD SYMPTOMS OCCURRISG IN THESE ANIMALS}

Monkey . I. I. A fine specimen of Macacus rhesus weighing 3,500 gins. was kept under observation during 16 days prior to inoculation. The animal's temperatnre varied very little.

On 15.3.2T it was inoculated intracerebrally muler annestluesia with 1.5 c.cuns. of a virulent emulsion of the lirain of a rabbit diluted $1: 5$. Two cont rol rabbits were inoculated intracerebrally at the sams time as the monkey; they dereloped typical symptoms on the 24 th and 31 st day, and died of Borna disease on the 42 nd and 44 th day.

Between 15.3.27 and 11.5.27, a perioel of 57 days, the monkity slowed no srumptoms and the temperature remained normal.

15.3.27. Weight $3,800 \mathrm{gms}$. Temperature $38 \cdot 9^{\circ} \mathrm{C}$. Received inoculation with the lirain emulsion from Rabbit 275 .

11.5.27. Fifty-seven days after inoculation the monkey appen rexl depresued. 'Teun. perature $35 \cdot 4^{\circ} \mathrm{C}$. Slight dinrrhoea.

12.5.27. Same condition.

14.5.27. Temperature 385 C. No oliarrhoen. IAse lively than usmal, apprarev 10 prefer to remain with the lonck to the light (photophobin?).

15.5.2\%. I'ondition unchangerl.

]6.5.27. Photophohia well marked. The monkey hid its head under the strun of the eage and would not move when disturberl. It allowerl itsilf to be caught easily and defended itself when approched nimost exclusively with the luft hand and foot. Slight paresis of the right arm was detereter. The pupils were eyual and reacterl normully to light.

18.5.27. Weight 3,241$)$ gms. Timperature $3 \times .2^{\circ}$ (?. Animal foeding normally. It remninivl in a enrner of the eage with the hind lroplyerl like that of a 
rabbit ill from Borna disease. It allowed itself to be caught easily, offering but little resistance and with the left arm only. It was found possible to introduce the thermometer into the rectum without bolding the legs, which fell practically inert. When the monkey was put on the ground it moved much more slowly than normally, dragging the right leg, which showed paresis. Paresis was less evident in the left leg. The animal could grip the eage with the left hand, the only limb which preserved its normal function. The right leg and arm did not grip or gripped only badly. The animal attempted to climb, but fell exhausted by the effort. It was roused with difficulty. There appeared to be no trouble in preserving equilibrium. The animal appeared to be able to see. The diarrhoea was replaced by constipation.

19.5.27. Temperature $38.5^{\circ} \mathrm{C}$. Same symptoms as on the preceding day. On opening the cage the monkey did not move or try to get out. When taken out and left to run it fell on the right side, of which the paralysis was more accentuated. When the monkey was held by the skin of the neck, the legs, which showed a marked flaccidity, fell inert without any resistance (Fig. 2). If a finger was presented, the monkey gripped it with the left hand only, the right hand showed paralysis of the flexors of the digits.

20.5.27. Temperature $38 \cdot 5^{\circ} \mathrm{C}$. Same condition.

21.5.27. Temperature $38 \cdot 1^{\circ} \mathrm{C}$. Weight $3,280 \mathrm{gms}$. Animal still feeding. When taken out of the cage it was found to tire quickly, and after a feeble effort at escaping it remained on the ground immobile for several minutes.

23.5.27. Temperatıre $38.0^{\circ}$ C. Hotor disturbances were accentuated. Monkey remained hunched up in a corner of the cage (Fig. 3).

24.5.27. Temperature $37 \cdot 5^{\circ} \mathrm{C}$. Same condition.

25.5.27. Temperature $37 \cdot 3^{\circ} \mathrm{C}$. Complete paralysis of the legs. When making movements, it supported itself especially with the left arm and dragged the paralysed legs. For the most part it preferred to remain hunched up in the corner of the cage.

26.5.27. Found procumbent. Weight $3,180 \mathrm{gms}$.

27.5.27. Temperature $36 \cdot 5^{\circ} \mathrm{C}$. Animal procumbent, the respirations were irregular and infrequent. Incontinence of urine, no grinding of the teeth, no ocular symptoms, no hypersalivation, both legs paralysed. As the animal was dying it was killed by means of chloroform at 6 o'clock in the evening 73 days after the inoculation, 16 days after the first symptoms were observed.

Autopsy of Monkey 1.

The dura mater. pia mater, and the brain substance appeared normal.

The cord was slightly hyperaemic, but no haemorrhagic areas were found.

The buccal epithetium and tongue showed desquamation of the epithelium and redness.

The parotid gland. Normal in aspect.

Lung. Normal.

Spleen, liver, and gall bladder. Normal.

Kidney. Congested in both the cortical and medullary zones.

Adrenal. Normal.

Peritoneal cavity, bladder, and intestines. Normal.

Cultures made from the brain, spleen, and blood proved to be bacteriologically sterile.

Note. A study of the blood, made during the course of the infection, indicated no decided changes; the leucocytic formula remained normal, except for a slight increase in the number of polymorphonuclears in the last stages of the disease. 
Passages into rabbits made with emulsions from various parts of the central nervons system of this monkey gare positive results (see p. 45).

An emulsion of the brain of M. 1 was likewise inoculated into two monkeys of the same species by the intracerebral route (Monkey M. 2 and II. 3) on the 28.5.2T.

\section{Monkey M. 3 (Macucus rhesus). Weighed 3,150 gms.}

During a period of 71 days after the inoculation, the animal remained free from all anorbid symptoms, and the temperature remained normal. On the 7 .nd day the monkey was found procumbent, although the day before there was no obvious illuess. It was paralysed in the legs and arms, and it could not assume an upright position. Slight ptosis of the right eyelid was obstrved. The temperature was subnormal. The following day the respirations were irregular, gasping, and moist râles were heard. Is the animal was in comvlsions it was killed. The findings on antopsy were the same as for Monkey .I. 1. Rabbits inoculated with emulsions of rarions parts of the nervous sytem died of Borna disease with characteristic lesions.

Monkey M. 2 (Macacus rhesus). The evolution of the lisease in this monkey was entirely differtnt.

28.5.27. Animal inoculated. Weight 3,200 gms. Temperature $38.5^{\circ} \mathrm{C}$. During a periol of 33 day's after the inoculation the blood, the body-weight, and the temperature eurve showed no marked changes, and there was no eridence of any symptoms.

30.6.27. Temperature $3 \mathrm{~s} \cdot 2$ C. Weight 3.100 gnus. When a stiek was given to the animal it could not seize it with the right hand, and if irritated it defended itself with the left hand. The monkey was able to run nnd elimh normally.

1.7.27 and 2.7.27. No elange in eondition.

3.7.2\%. In addition to the paresis of the right arm the animal showed lassitude and appeared less agile.

From the 3.7 .27 to the 11.7 .27 . the condition remained unchanged.

14.7.27. Forty-seven days after the inoculation. Weight $2.790 \mathrm{gms}$. When taken out of the eage the animal ran and elimber with difticulty. The paresis of the right arm was amelioraterl, but there was paresis of the legs, more accentuated on the left side. The left arm also showed slight paresis.

14.7.27. The left eye was eloserl completely, due to ptosis of the upper evelid (Fig. 4). The face was drawn to the right side. The paresis of the arm and legg on the left side was now easily discernible. If the animal wh'n seated was gently pushed it fell on to the left sille. It uttered a plaintive ery from time to time. No lesions cubld be seen on the cornes or eonjunctiva.

211.7.27. Markirl exeitation was olserverl. The animal appenred to have hallueinations. It threw itself at imaginary objects, attempted to bite fre. quently, and strugglexl and fell as if in a tit. There was nearly complete prarulysis of the left side and ptosis of the left evelist.

22.27.27. The symptoms appenresl to be ameliorated. The animal was mueh ealmer and the eye could be opened partially:

25.7.27. Eye noarly eompletely open. Animal atill nggressive, uttervd cries from time to time, paralysis less noticeable. 
28.7.27. Eye appeared normal, and the condition of the monkey practically normal.

1.8.27. Ptosis of the right eyelid. Slight paresis of the hind quarters, which, however. was not sufficient to prevent the monkey from climbing. It became fatigued easily, however, and remained in a corner of the cage crying out from time to time.

3.8.27. Paralysis of the right side of the face (see Fig. 5) was observed. Animal could still run and climb.

5.8.27. Same condition. Weight 3.170 gms.

8.8.27. Paralysis of face diminished. Animal irascible.

12.8.27. Spasmodic contractions of muscular groups of the back and shoulders were the only signs of the animal being other than normal.

13.8.27. Left eye deviated to the internal canthus. Tendency to remain hunched up.

14.8.27. Arimal decidedly ill. Head hanging over on to right shoulder: internal strabismus still present and left pupil dilated. Right eye mobile. Pupil of this eye reacted to light. Nystagmus present. The amimal had periods of excitement.

15.8.27. Monkcy uttering cries with a low feeble raucous voice. Mouth opened after showing dragging to the right side. Internal strabismus on the left side, pupil on this side also dilated. Nystagmus exacerbated. Paralysis of muscles of left shoulder, head falling over on to the right shoulder.

17.8.27 and 21.8.27. Condition unchanged.

27.8.27. Until 27.8.27 animal appeared normal. On this date the animal had complete aphonia (probably paralysis of the recurrent nerve). The head hung over the right side and the monkey showed signs of cerebral disorder. Strabismus was less, face was drawn to the right side, and there was frequent spasmodic contraction of the facial muscles ("tic). The pupils were unequal in size. The animal carried out movements of mastication without the teeth coming in apposition, for this reason it fed with difficulty. Deglutition was not carried out easily, and the animal appeared to have difficulty in orientation. Taken out of the cage it could not co-ordinate its movements in the direction desired.

29.8. 27. Weight $2,900 \mathrm{gms}$. Animal still made movements of mastication continually, and twitching of the muscles of the mouth was present. There was internal strabismus, as well as aphonia and weakness of the muscles of the neck on the left side. The monkey remained hunched up, or had periods of excitement which were increased by noises, movements, \&c.

31.8.27. Condition unchanged.

2.9.27. Weight 2,820 gms. Spastic contractions of divers muscular groups were produced hy noises. The tongue was drawn to the right side. The animal fed no more owing to the impossibility of swallowing. 'Tie' of the mouth persisted, also the strabismus and the inequality of the pupils.

4.9.27. The left eye appeared practically normal and the pupils equal in sizc. The animal, however, still trembled at times and bit at imaginary objects; frequent 'tic' was observed with aphonia. The animal, however, fed well.

9.9.27. The condition of the animal had not changed.

16.9.27. The cry appeared more normal, ocular disturbances were ahsent, although 'tic' and champing of the jaws was still observed. The head was hung over the right shoulder, and the animal showed increased salivation.

20.9.27. The condition of the amimal was unchanged; to a certain degree the syndrome in this monkey might be compared to that exhibited by a man affected with post-encephalitic Parkinsonism.

22.9.27. Same condition. Weight $3,000 \mathrm{gms}$.

5.10.27. Up to this date the monkey remained in a similar state, this being the 130 th day since the inoculation. At this time the animal was inoculated with the virus of polio-myelitis. The result is given in the chapter dealing with immunity. 
These three monkeys showed three different forms of the disease. In all three cases the incubation period was very long, but the duration of the morbid symptoms raried. Monkey 3 had an acute attack which lasted only 2 days. In Monkey 1 the evolution was slower. the time between the onset of symptoms and death being 16 lays. Monkey 2 had recurrent attacks during a periorl of 97 days (see subsequent history, p. 80).

The virus after passage through monkeys had not lost its virulence for the rabbit or guinea-pig.

In the chapter dealing with histopathology the lesions in the nervous sytem will be described in full. We may, however, anticipate here by the statement that we found lesions of an intense eliaracter. in the brain, and of a more discrete character in the cord. Lesions were also found in the spinal ganglia, posterior nerve-roots, and peripheral nerves. Both chinically and pathologically the disease may be described as an encephalo-myelitis complicated with a ganglioradiculitis and peripheral neuritis. The virus when introdnced into the brain evidently spreats not only to the cord, but also to the peripheral nerves, for not only have we found lesions in these, lint we have also been able to demonstrate the presence of virus.

\section{Discussios.}

The pathogenicity of the virus for the monkey, and the clinical features presented in this animal, raise the question of the relition between enzootic encephalo-myelitis of domestic animals and polio myelitis in man. There are marked resemblances in the clinieal aspects as well as in the alterations in the cord and spinal ganglia in the two diseases. The former virus is, however, pathogenic for the rabbit, while the latter is generally considered not to be so. The incubation period of experimental encephalo-myclitis in the monkey is longer than in the disease prodnced by the virus of polio-myelitis.

Another question is whether the virus of encephalo-myelitis is pathogenic for man, and if such is the case, whether some luman clisease of the nervous system at present of mknown orjgin may possibly be due to it. It is a common observation in clinical medicine that exposure to cold may determine an attack of facial neuritis or seiatica. Conceivably, such attaeks might be the expression of an unrecognized infection by some virns, akin to rmzootic enerphalomyelitis, which in the first place caused only slight, if any, generul symptoms of disense and then proceederl down into the peripheral nerves, where it remained latent until the added fictor of cold determined the loeal ineilenee of paralysis or pain. Similar views may be argued with regard to herpes zoster, recurrent herpes, or the so-culled peripheral forms of epiclemic enceplatitis. An unalogons action of cold was recorded by l'asteur, when certain rubbits that were resistant to the inoeulation of an uttemated ralies virus, at one showed paralytic symptuns after exposure to severe colel.

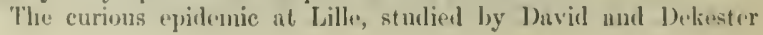


(1926), has suggested that a certain form of sciatica, at least, is an infectious disease; and there are many human cases on record of myelitis associated with peripheral neuritis, apparently of a contagious type, in some of which, as in the instance of the child described by Péhu and Dechaume (1927), there were in the peripheral nerves inflammatory lesions closely resembling those described by us in monkeys and rabbits infected with Borna disease.

We give below a résumé of Péhu and Dechaume's case in some detail because the symptoms resemble in certain respects those which our Monkey M. 2 showed after inoculation with the virus of Boma disease. The child, 20 months old, was in perfect health up to the day when it showed some lassitude three months before going to hospital. The temperature did not exceed $36^{\circ} 5^{\circ} \mathrm{C}$. Two montlas later it could no longer walk and had lost power in the arms. At the time of entering the hospital it showed tlaceidity and paralysis in the lower extremities without Babinski's sign. There was also slight paresis of one arm. The following day the child collapsed although not losing consciousness. There were no cerebral synptoms, nor vomiting, neither did sommolence exist, but the pulse was rapid and irregular. The condition lasted 11 days and the child died suddenly without convulsions. The case was diagnosed as a peripleral form of epidemic encephalitis, referred to as pseudo-myelitic.

On autopsy there were no macroscopic changes. On microscopic examination of sections, discrete lesions, for the most part exudative, were found in the cord, especially in the lumbar region. Perivascular infiltrations occurred in the brain. No neuronophagia was recorded, and the spinal ganglia were not examiner. The lesions found in sections of the median nerves, sciatic nerve, and posterior tibial nerves were comparable to those described by us in the sciatic and brachial nerses of rabbits and monkeys inoculated intracerebrally with the virus of Borna disease (see pages 61 and 67 ).

Péhu and Dechaume suggested that the presence of lesions in the peripheral nerves might be coexistent with the presence of virus. In the case of Borna disease we have proved that the presence of virus is coexistent with the existence of lesions in the peripheral nerves (see page 45).

\section{PATHOGENICITY OF THE VIRUS OF ENZOOTIC EN- CEPHALO-MYELITIS FOR THE GUINEA-PIG, RAT, MOUSE, AND FOWL}

\section{Guinea-pig.}

The introduction of virus intracerebrally into guinea-pigs may produce the disease. The incubation period varies in individual cases and death is inconstant. Zwick and his collaborators (1926) were the first to transmit the disease to guinea-pigs, and to make passages in series from brain to brain. Some guinea-pigs proved to be resistant to infection. According to their experiments death followed infection in 
from 3 weeks to 13 months. They also succeeded in infecting rabbits with the virus passaged through guinea-pigs.

In Table III we give the period of incubation and the duration of the disease in a batch of guinea-pigs which in our experiments proved to be susceptible to the virns inoculated intracranially.

TABLE III.

\begin{tabular}{|c|c|c|c|c|}
\hline $\begin{array}{c}\text { No. of guinea- } \\
\text { pig. }\end{array}$ & $\begin{array}{l}\text { Weight in } \\
\text { gms. }\end{array}$ & $\begin{array}{c}\text { Commencement } \\
\text { of disease. }\end{array}$ & Death. & $\begin{array}{l}\text { Lestons in } \\
\text { brain. }\end{array}$ \\
\hline $85 E$ & 470 & 73rd day & 83rd day & Inteuse. \\
\hline$S+k$ & $f(M)$ & 107th ," & $132 \mathrm{nd}$ & . \\
\hline $9+\varepsilon$ & $5(x)$ & $23 r d$. & IIfth .. & \\
\hline $95 k$ & $\delta(x)$ & $58 \mathrm{th} \quad$, & $65 \mathrm{l} h \quad .$. & Discrete. \\
\hline $93 k$ & 430 & 4i)th .. & $58 t h$. & Average. \\
\hline $98 \mathrm{k}$ & 4511 & $57 \mathrm{lh}$ & $64 t h$.. & .. \\
\hline $99 \mathrm{~K}$ & 580 & $181 \mathrm{~h}$ & 19 th. & Intense. \\
\hline $100 \mathrm{~K}$ & 560 & $58 t h$." & 182nd .. & ., \\
\hline
\end{tabular}

We have also made experinents to determine the relative susceptibility of guinea-pigs to infection. Forty-five guinea-pigs of about the same size ( $400-600 \mathrm{gms}$.) were divided into three lots of 15.

Lot A were injected with an emulsion of the brain of a rabbit dead of Borna disease diluted $1: 10$.

Lot $B$ were injected with the same emulsion diluted $1: 100$.

Lot (1 were inoculated with the emulsion diluted 1: 1.000.

The results were as follows:

In Lot $A$ all the gnimea-pigs died after showing typical symptoms of the disease. $52,55.74,138,134,139,139,141,141,143,148,150$, 153,156 . and 176 day's after the inoculation. Lesions characteristic of enzootic encephalo-myelitis were found in sections of the brain and spinal cort of these animals; moreover, the corpusches of JoestDegg'n were demonstrated.

'TABLE IV.

Lot A.

\begin{tabular}{|c|c|c|c|c|c|c|}
\hline $\begin{array}{l}\text { Dilution of } \\
\text { emulsion of } \\
\text { l,rain inncu- } \\
\text { lated. }\end{array}$ & $\begin{array}{l}\text { So. of } \\
\text { guinea-pig. }\end{array}$ & \multicolumn{2}{|c|}{$\begin{array}{l}\text { Inimal } \\
\text { died. }\end{array}$} & \multicolumn{3}{|c|}{ Obsermations. } \\
\hline $1: 10$ & IA & \multicolumn{2}{|c|}{52 nd day } & \multicolumn{3}{|c|}{ Inlense lesions in cenl ral nervous syslem. } \\
\hline , & $2 \boldsymbol{A}$ & $5 x+h$ & $"$ & . $\quad$ * & " & $\because$ \\
\hline$*$ & $3 \mathbf{A}$ & $7+1 \mathrm{~h}$ & ", & ". & *. & ". \\
\hline •" & $4 x$ & I3:3rd & ". & & & \\
\hline " & is & $13 \# 1 \mathrm{~h}$ & $"$ & \multirow{2}{*}{\multicolumn{3}{|c|}{$\begin{array}{l}\text { Very intenue lesion in C.N.S. } \\
\text { Dimrete lesions in C.X.S. }\end{array}$}} \\
\hline ,. & lis & I39th & .. & & & \\
\hline .. & iA & $1391 \mathrm{~h}$ & , & \multicolumn{3}{|c|}{ Intenne lesions in C.N.S. } \\
\hline$\because$ & $8 A$ & $1+1 \mathrm{nt}$ & $"$ & \multirow{2}{*}{\multicolumn{3}{|c|}{ Mild lesions in C.N.S. }} \\
\hline . & Si. & $1.11 \times 1$ & . & & & \\
\hline$"$ & $16 \mathrm{~A}$ & I.13r| & $\bullet$ & \multicolumn{3}{|c|}{ Intense lesions in C.N.S. } \\
\hline " & $11 \mathrm{~A}$ & $1451 / 1$ & " & \multicolumn{3}{|c|}{ ". $\quad "$} \\
\hline . & $12 \mathrm{~A}$ & $1501 \mathrm{~h}$ & $n$ & & & \\
\hline .. & 13. & |5:Ird & .• & \multirow{2}{*}{\multicolumn{3}{|c|}{$\begin{array}{l}\text { lery intentue lexiens in ('.N.S. } \\
\text { Jutense lesions in C.N.S. }\end{array}$}} \\
\hline ". & 14 & lotith & . & & & \\
\hline ", & 15.4 & $1761 \mathrm{~h}$ & ", & •. & & \\
\hline
\end{tabular}


In Lot B two of the guinea-pigs succumbed to an intercurrent infection. The thirteen others died 58, 105, 130, 130, 135, 137. 138, $140,140,140,147,149$, and 153 days after infection.

TABLe $Y$.

Lot $B$.

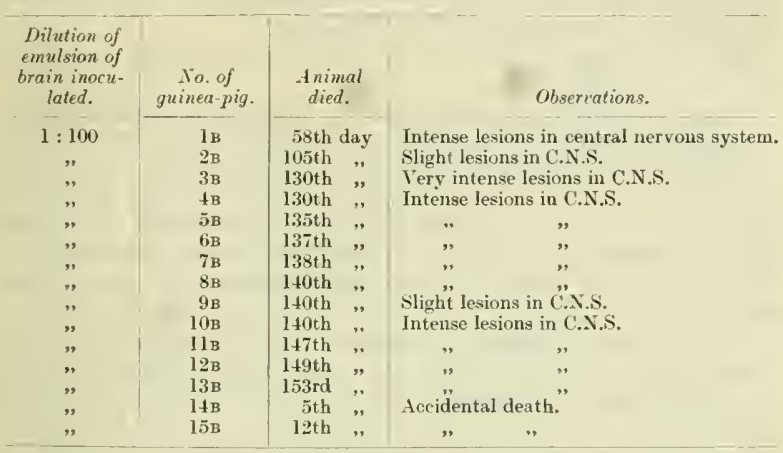

In Lot $\mathrm{C}$ five of the animals died of an intercurrent infection, the ten remaining died $70,90,96,101,140,141,141,147,149$, and 150 days after intracerebral inoculation.

TABLe VI.

Lot $C$.

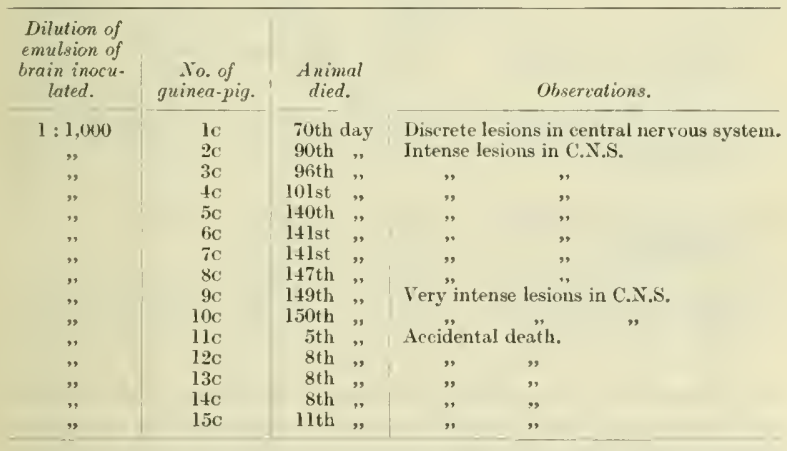

As in the case of the guinea-pigs of Lot A, the symptoms in guineapigs of Lot $\mathrm{B}$ and $\mathrm{C}$ were characteristic, and sections made from the 
central nerrous system showed the typical changes produced by the virus of Borna disease in other animals.

These results, while demonstrating the variation in individual sus ceptibility, also point to the fact that resistance to infection in the guinea-pig is not so marked as it appeared to be from the results obtained by Zwick, since of thirty-eight guinea-pigs inoculated in our experiments thirty-eight succumbed to the disease (the seven guineapigs dead from other causes are not included).

The virus passaged through guinea-pigs still preserved its pathogenicity for the rabbit.

The disease in the guinea-pig is similar to that of the rabbit. After a variable period the animal appears depressed, there is marked somnolence, and abstention from food. Characteristic nervous symptoms follow, those inclicating affection of the cord being especially well nuarked. The syndrome is as deseribed in the rabbit. The hind legs become paralysed (Fig. 6) and the fore legs are involved later (Fig. 7). The loss of weight is less marked than in the ease of the rabbit.

From the four following experiments the susceptibility of the guinea-pig after the virus is inoculated would appear to be diminished by a simnltaneons inoculation of the same material intramuscularly.

An emulsion of virulent brain originating from a rabbit dead of experimental Borna disease was inoculated into the brain of eight guinea-pigs, and at the same time 1 c.cm. of the same enulsion was inoculated into the quadriceps group of museles of four of them. The results of these four experiments are tabulated below:

TABLE VII.

\begin{tabular}{|c|c|c|c|c|}
\hline & & $\begin{array}{l}\text { No. of } \\
\text { guinea-pig. }\end{array}$ & $\begin{array}{l}\text { Guinea pig } \\
\text { died. }\end{array}$ & Lesions in the bresin. \\
\hline \multirow{2}{*}{\multicolumn{2}{|c|}{$\begin{array}{l}\text { 1. Incoulated into the brain } \\
\text { Incoulated into the brain } \\
\text { and inusele. }\end{array}$}} & $9.5 \mathrm{~K}$ & 651 h dny & \multirow{2}{*}{$\begin{array}{l}\text { Diserete. } \\
\text { Intense. }\end{array}$} \\
\hline & & $97 \mathrm{~B}$ & 13Ist . & \\
\hline \multirow{2}{*}{\multicolumn{2}{|c|}{$\begin{array}{l}\text { 11. Inoculated into the brain } \\
\text { Inoculated into the brain } \\
\text { and muscle }\end{array}$}} & $93 \kappa$ & 58 th & Of average intensity. \\
\hline & & 91 ก & I16th ." & " \\
\hline \multirow[t]{2}{*}{111.} & Inoculated into the brswin & $99 \mathrm{k}$ & $19 t h$ dny & \multirow[t]{2}{*}{ Intense. } \\
\hline & $\begin{array}{l}\text { Inoculated into the brain } \\
\text { and nuscle }\end{array}$ & 9tius & Survived & \\
\hline \multirow{2}{*}{ 11. } & Ineculated into the brain & $98 \mathrm{~K}$ & (b)th day & \multirow{2}{*}{$\begin{array}{l}\text { () average intensity. } \\
\text { Jntense. }\end{array}$} \\
\hline & $\begin{array}{l}\text { Inoculated intu the brain } \\
\text { and nuscle }\end{array}$ & $2(k) \mathrm{s}$ & $18+t 1$, & \\
\hline
\end{tabular}

This observation is comparable to that of Erust and Hahu (1927), who found that when rabbits inoculated intrnecrebrally with virulint enulsion received, rither at the same time or subsequently, injections of virus into the veins, they did not develop a fintal "ncephlinlitis. 
Attempts at infecting the guinea-pig by intradermal inoculation of an emulsion of virulent brain into the metatarsal pad (following the technique nsed by Waldmam and Pape (1921) in foot-and-mouth disease, and by Gildemeister and Herzberg (1925) in experinental herpes) did not succeed. The guinea-pigs inoculated raried in weight from 100 gms. to $750 \mathrm{gms}$., and were kept under observation for over seven months, but no symptoms were seen at any time during this period.

\section{Rat.}

Zwick, Seifried, and Witte (19:26) infected rats with the virus of Borna disease by intracerebral inoculation. Death supervened 40, 53, and 62 days respectively, after infection. Some rats slowed no symptoms and survived. The virus passaged throngh the rat had not lost its pathogenicity for the rabbit.

In our experiments large rats appeared to be more susceptible to the disease than young animals. Four rats (three old and one young) were inoculated intracerebrally with an emulsion of the brain of rat No. I which died 67 days after infection. (Typical lesions of Borna disease were found in sections of the brain of rat No. 1.) The three large rats died 22,37 , and 74 days respectively after inoculation. They all developed typical symptoms, and sections of the brain showed the presence of characteristic lesions microscopically. The young rats kept under observation for six and a half months remained perfectly normal.

The control rabbit inoculated with the same emulsion of brain from Rat 1 died on the 27 th day of a typical infection.

Subsequently four rats (two large and two small) were inoculated with an emulsion of one of the brains of one of the large rats mentioned above (that dead on the 37th day). The two older rats died on the 40th and 82nd day after infection, while the two younger animals survived 124 days, succumbing later to an intercurrent infection. In all, we have inoculated twenty-eight rats; of these only the older rats contracted the disease.

The symptoms in the rat are similar to those in the guinea-pig. They commence with motor disturbances, inco-ordination, and difficulty in maintaming equilibrium. Paralysis, coma, eachexia, and death follow later.

Up to the time of writing we have succeeded in making at least four passages in this species. The rats in the series died $67,37,82$, and 47 days respectively, after inoculation, showing that the course of the disease in the rat is as variable as in the guinea-pig. It would appear that virus passaged through rats when inoculated intracerebrally into rabbits produced the disease after a shorter incubation period than when the virus was passaged in series through rabbits.

In sections of the brain of our experimental rats the corpuscles of Joest-Degen were found. Zwick (1926), however, failed to find them in the brain of rats inoculated with the virns of Borna disease. 


\section{Mouse.}

We have been able to infect mice by the intracerebral route, but this species of rodent is apparently less susceptible to the infection. As in the rat, age appears to have an important bearing on the sus. ceptibility of the mouse to the disease. Yice weighing more than 20 gms. generally contracted the discase and died, while smaller mice survired without showing symptoms. In our experiments mice died on the $37 \mathrm{th}, 52 \mathrm{nd}, 81$ st, and 126 th day respectively, after inoculation.

These mice wasted considerably, walked with tortoise-like movements, and showed other motor disturbances. Typical lesions were demonstrated in the brains of the mice and the intranuclear 'inclu. sions ' of Joest-Degen were present in the Ammon's horn.

\section{Fowl.}

Zwick, Seifried, and Witte (1926) found the fowl to be susceptible to intracerebral inoculation. In one case the imculation period was 37 days, and death followed $\mathbf{1 5}$ days later. Passage from fowl to rabbit gave a positive result.

\section{ANIMALS WHICH HATE BEEN FOUNI) TO BE RESIS- TANT TO INFECTION WITH THE VIRUS OF EXZOOTIC ECEPHALO-MYELITIS}

\section{Dog.}

According to Zwick, Seifried, and Witte (1926) the dog appears to be resistant to infection with the virus of Borna disease. This fact obviates up to a certain point confusion with the virns of rabies. A greater number of experiments require to be done, however, before the dog ean be definitely classed among the animals resistant to infection.

\section{PIGEON.}

These same anthors demonstratel that the pigeon is resistant to intracerebral infection with the virus.

\section{Ferret.}

We inoculated six ferrets, three young and three adults, by the intracerebral ronte and kept them under obsecvation for seven months, but no morbid symptoms developed.

\section{i. DISTRIBUTION OF THL VIRUS OF BORNA DISEASE IN THF ANIMAL, BODY}

I. Pagracie of Vime throvih the Placenta.

Krnst and Haln (1927) showed that the virus is capable of passing the placenta of the suare and infecting the foetus during intrauturine life. In two casus the virus was demonstrated by inoculation 
of rabbits intracerebrally with the brain of foals born of mothers ill with enzoot ic encephalo-myelitis. Further, they demonstrated lesions characteristic of Borna in the sections of the brain of both the foals and the mothers in these cases.

\section{Distribution of the Virus in Various Organs and \\ Tissues}

Zwick, Seifried, and Witte (1926) tested four samples of blood from infected rabbits, three samples of blood, two of spleen, two of kidney, and two of liver, from horses ill from Borna disease, but failed to find the virus. Ernst and Hahn (1927), on the other hand, proved the blood to contain the virus during some stages of the illness of a rabbit suffering from Borna disease.

Similar apparently contradictory results have been obtained in experimental infections produced by other filterable viruses where the virus may sometimes be found in the blood, e.g. rabies, vaccinia, herpes, and foot-and-mouth disease.

Ermst and Hahn (1927) found the vitreous body of the eye infective after a rabbit had been inoculated intracerebrally. The virus has also been demonstrated by Zwick and his collaborators (1926) in the submaxillary sahvary gland in inoculated rablits.

\section{Presence of Vires in the Peripheral Nerves of Rabbits Ixocllated Intracerebrally.}

The present writers have demonstrated the virus in the peripheral nerves of rabbits infected by the intracerebral route in which infiltrating lesions in the nerve occurred.

Experiment 1. A portion of both seiatic nerves taken from $1 \mathrm{~cm}$. below their emergence from the greater sciatic forameu to the popliteal region was removed aseptically from Rabbit $130 \mathrm{~A}$, which died 50 days after intracerebral inoculation. An emulsion of these two portions of sciatic nerve was made in physiological saline and inoculated into the brain of Rabbits $213 \mathrm{~A}$ and $214 \mathrm{~A}$.

\section{Rabbit 213A.}

\section{Weight $2,000 \mathrm{gms}$.}

14.7.2\%. Intracerebral inoculation with emulsion of sciatic nerve.

1.8.27. Animal normal. 2,000 gms.

7.8.2\%. Animal normal.

15.8.27. Commencement of paresis of the hind quarters. $2,000 \mathrm{gms}$.

24.8.27. Typical symptoms of the disease. 1,600 gns.

29.8.27. Animal very ill. $1,350 \mathrm{gms}$.

29.8.27. Died the 46 th day after the inoculation.

Autopsy. All organs macroscopically normal. Cultures from the brain negative.

Sections. Intense lesions of a characteristic type in the central nervous system.

The corpuseles of Joest-Degen were also denonstrated. 


\section{Rabbit 214 A.}

Weight $2,100 \mathrm{gms}$.

14.7.27. Intracerebral inoculation with an emulsion of the sciatic nerve.

1.8.27. Normal. $2.250 \mathrm{gms}$.

7.8.27. Animal normal.

15.8.27. Typical symptoms of the disease. Head depressed; placed on its side the animal showed the characteristic myelitic syndrome. 1,800 gms.

20.5.27. Animal rerv ill. $1,600 \mathrm{gms}$.

22.8.27. Found dead 39 days after the inoculation.

Autopsy. No lesions in organs. Cultures from the brain negative.

Sections. Intense lesions characteristic of Borna disense were demonstrated throughout the cent ral nervous systen.

Passage. The brain of this rabbit uras passaged to Rabbit $291 \mathrm{~A}$.

\section{Rabbit 291..}

24.8.27. Intracerebral inoculation with an einulsion of the brain of Rabbit 2141. 15.9.27. Typical symptoms of the disease. $1,590 \mathrm{gms}$.

21.9.27. Found dead the 28 th day. $1,150 \mathrm{gms}$.

Characteristic intense lesions were found in the central nervous system, and the corpuscles of Joest-Degen were demonstrated.

The two rabbits died after showing typical symptoms of the disease. Lesions of a characteristic type were demonstrated throughont their central nervous system, and moreover, the virus was clemonstrated in their brain.

Experiment 2. In a second experiment the virus was sought for also in the brachial nerve of a rabbit which had succumbed 31 days after inoculation into the brain. The nerves were removed aseptically and emulsitied in sterile mortars. The emulsions were then inoculated int racerebrally into rabhits. The results of the inoculation are given below.

\section{(1) Brachial Nerie.}

Rabbit $36 \mathrm{~A}$. II'eight $2,570 \mathrm{gms}$.

15.9.27. Inoculated intracerebrally with an enulsion of the brachial nerre of Rabbit 252.

22.9.27. No symptoms. $2,850 \mathrm{gms}$.

2S.9.27. Animal normal. $2,700 \mathrm{grms}$.

6.10.27. Animal normal. $2,620 \mathrm{gms}$.

10.10.27. Commencement of paresis. 2,350 gms.

12.10.27. Typical aymptoms of the disease. $2,150 \mathrm{gms}$.

14.10.27. Animal dierl 3ith day after inoculation. 1.81M) gms.

Autopsy. All organs appeared normal.

r'ullures of the brain. Negative.

Microscopic exumination of seetions of the brain and other parts of the eentral nervous aystem showerl the presence of typical lesions.

\section{(2) Sciatic Verte.}

\section{Rabbit 35s. Weight 1,200 gms.}

15.9.27. Inoculated intracerebrally with an emulsion of the seiatic nerve of liabbit $252 \mathrm{~A}$.

22.9.27. Animal normal. 1,050 gms.

28.9.27. Arumal normal. 1,020 gms.

15.10.27. Animal normal. I, $100 \mathrm{gms}$. 
10.10.27. Commencement of paresis. $1,150 \mathrm{gms}$.

12.10.27. Typical symptoms of the disease. $1,050 \mathrm{gms}$.

14.10.27. Typical symptoms of the disease. $960 \mathrm{gms}$.

15.10.27. Found dead 37 days after infection.

Autopsy. All organs normal.

Cultures of the brain. Negative.

Typical lesions were found on microscopical examination of sections from the central nervous system.

This second experiment shows that when the virus is introduced into the aninal organism by the intracerebral route, it may subsequently be found in the brachial as well as the sciatic nerves.

In a third experiment Rabbits $27 \mathrm{~A}$ and $30 \mathrm{~A}$ were inoculated intracerebrally with an emulsion of the sciatic nerve taken as in experiment 1 .

Rabbit 2ĩ.

Rabbit $27 \mathrm{~s}$. Weight $1.690 \mathrm{gms}$.

6.9.27. Date of inoculation.

15.9.27. Animal normal. $1,750 \mathrm{gms}$.

22.9.27. Animal normal. $1,900 \mathrm{gms}$.

28.9.27. Animal normal. $1,870 \mathrm{gms}$.

6.10.27. Animal normal. $1,850 \mathrm{gms}$.

10.10.27. Commencement of the disease. $1,850 \mathrm{gms}$.

12.10.2-. Typical symptoms of the disease. $1,700 \mathrm{gms}$.

15.10.27. Animal in agonal stage of death. $1,450 \mathrm{gms}$. Found dead later, 39 th day after infection.

Autopsy. No macroseopic lesions.

\section{Rabbit 30A.}

Rabbit $30_{\mathrm{A}}$. Weight $1,7.50 \mathrm{gms}$.

6.9.27. Date of inoculation.

15.9.27. Animal normal. $1,750 \mathrm{gms}$.

22.9.2\%. Animal normal. $1.820 \mathrm{gms}$.

28.9.27. Animal normal. 1,900 gms.

6.10.27. Animal normal. 2,000 gms.

10.10.27. Slight paresis of hind quarters, $2,050 \mathrm{gms}$.

12.10.27. Slight paresis of hind quarters. $2,000 \mathrm{gms}$.

21.10.27. Typical symptoms of the disease present. $1,900 \mathrm{gms}$.

All these eight rabbits inoculated intracerebrally with emulsions of either the brachial nerve or sciatic nerve of rabbits dead of experimental enzootic encephalitis contracted the disease and died. The presence of lesions, and of the corpuscles of Joest-Degen in the central nerrous system of these eight rabbits, as well as the positive passage made with the brain of one of them, indicates that the virus of Borna disease generalizes into the peripheral nerrous system centrifugally. The lesions occurring in the peripheral nerves are described later (see p. 61). 
IV. Disthibution of the VIRUS IN VARIOUS ORGaxs AND Tissues of the MoNkey.

Wie have studied the distribution of the virus in the animal organism of Monkey M. 1 (Macacus rhesus) (see p. 34) which died of Borna disease 73 days after infection.

Experiment 1. Two rabbits were inoculated intracerebrally with emulsions of the cerebrum, medulla oblongata, spinal cord (dorsolumbar), parotid, spleen, testicle, blood, and adrenal glands.

The results are set forth in Table VIII.

\section{' lable VIII.}

\begin{tabular}{|c|c|c|c|c|c|c|}
\hline Organ. & $\begin{array}{l}\text { No. of } \\
\text { rabbit. }\end{array}$ & $\begin{array}{l}\text { Ileight } \\
\text { in gins. }\end{array}$ & $\begin{array}{l}\text { First appearance } \\
\text { of disease. }\end{array}$ & Deuth. & Lesions. & P'ussage. \\
\hline C'erebrum & $\begin{array}{l}1] 5 \mathrm{~A} \\
126 \mathrm{~A}\end{array}$ & $\begin{array}{l}1,700 \\
2,100\end{array}$ & $\begin{array}{l}22 \text { nd day } \\
23 \text { rd }\end{array}$ & $\begin{array}{l}3 \text { ith day } \\
30 \text { h .. }\end{array}$ & + & $\begin{array}{l}+ \\
+\end{array}$ \\
\hline $\begin{array}{l}\text { Medulla } \\
\text { oblongata }\end{array}$ & $\begin{array}{l}117 \mathrm{~A} \\
123 \mathrm{~A}\end{array}$ & $\begin{array}{l}2,280 \\
1,2100\end{array}$ & $\begin{array}{l}\text { loth ". } \\
22_{\text {nd }} \text {," }\end{array}$ & $\begin{array}{l}27 \text { th } . \\
371 h \quad,\end{array}$ & + & $\begin{array}{l}+ \\
+\end{array}$ \\
\hline Spinal cord & $\begin{array}{l}109 \mathrm{~A} \\
124 \mathrm{~A}\end{array}$ & $\begin{array}{l}1,(140) \\
1,(640\end{array}$ & $\begin{array}{l}20 u h \quad " \\
20 t h \quad "\end{array}$ & $\begin{array}{ll}27 \mathrm{hh} & = \\
30 \mathrm{hh} & .\end{array}$ & + & $\begin{array}{l}+ \\
+\end{array}$ \\
\hline ]'arutid gland & $\begin{array}{l}121 \mathrm{~A} \\
130 \mathrm{~A}\end{array}$ & $\begin{array}{l}2,060 \\
1,860\end{array}$ & $\begin{array}{l}\text { Dead acciclentally } \\
3+1 l_{1} \text { day }\end{array}$ & $\begin{array}{l}12 \mathrm{th} \\
5 \mathrm{st}\end{array}$ & $\begin{array}{l}1 \\
+\end{array}$ & $\overline{+}$ \\
\hline Spleen & $\begin{array}{l}125 \mathrm{~A} \\
127 \mathrm{~A}\end{array}$ & $1,(1)($ ) $)$ & $\begin{array}{l}\text { Death due in olher } \\
\text { causes Ith day } \\
\text { survived }\end{array}$ & - & 0 & - \\
\hline Testicle & $\begin{array}{l}131 \mathrm{~A} \\
132 \mathrm{~A}\end{array}$ & $\begin{array}{l}2,100 \\
1,7(k)\end{array}$ & $\begin{array}{l}\text { Survived } \\
\text { Survived }\end{array}$ & & & \\
\hline $\begin{array}{l}\text { Adrenal } \\
\text { gland }\end{array}$ & $\begin{array}{l}119 \mathrm{~A} \\
133 \mathrm{~A}\end{array}$ & $\begin{array}{l}2,10(10) \\
1,160)\end{array}$ & $\begin{array}{l}30 t h \text { day } \\
2 t i t h \quad "\end{array}$ & $\begin{array}{l}40 t h \quad, \\
55 \text { th } \quad .\end{array}$ & + & $\begin{array}{l}+ \\
+\end{array}$ \\
\hline $\begin{array}{l}\text { Ifeart Blund } \\
\text { (clelibrinaled) }\end{array}$ & $\begin{array}{l}120 \mathrm{~A} \\
1+2 \mathrm{~A}\end{array}$ & 2,1660 & $\begin{array}{l}\text { Death die fo ollier } \\
\text { causes } \\
\text { Survived }\end{array}$ & & 0 & - \\
\hline
\end{tabular}

The virus was demonstrited in the brain, medulla oblongata, spinal cord, parotil, and adrenal glunds; it was not demonstrated in the spleen, testicle, or bloou.

The observations were repeated with the organs of Monkey M. 3 (spe p. 36), and the results are given in thable 1.5 . 
TABLE IX.

\begin{tabular}{|c|c|c|c|c|c|c|}
\hline Organ. & $\begin{array}{l}\text { No. of } \\
\text { rabbit. }\end{array}$ & $\begin{array}{l}\text { Weight } \\
\text { in gms. }\end{array}$ & $\begin{array}{c}\text { First } \\
\text { appearance } \\
\text { of disease. }\end{array}$ & Death. & Lesions. & Passage. \\
\hline \multirow[t]{2}{*}{ Cerebrum } & $252_{\Delta}$ & 1,370 & 20 th day & 31st day & $\div$ & $\begin{array}{l}\text { No passage } \\
\text { made. }\end{array}$ \\
\hline & $258 \mathrm{~A}$ & 1,850 & $20 \mathrm{th}_{2}$ & 26th " & + & $" \quad$, \\
\hline Spinal cord & $\begin{array}{l}255 \bar{A} \\
261 \mathrm{~A}\end{array}$ & $\begin{array}{l}1,400 \\
3,020\end{array}$ & $\begin{array}{l}\text { 20th }, " \\
\text { 20th ", }\end{array}$ & $\begin{array}{l}3 \text { toth ", } \\
28 \text { th ", }\end{array}$ & + & $"$ \\
\hline Parotid & 265. & 1,950 & - & $\begin{array}{l}\text { Accidentally } \\
11 \text { th day }\end{array}$ & \pm & Negative. \\
\hline grana & 2664 & 3,390 & Survived & & & \\
\hline $\begin{array}{l}\text { Adrenal } \\
\text { gland }\end{array}$ & $\begin{array}{l}249 \mathrm{~A} \\
267 \mathrm{~A}\end{array}$ & $\begin{array}{l}2,070 \\
2,790\end{array}$ & - & $\begin{array}{l}\text { l.5th " } \\
17 \text { th " }\end{array}$ & \pm & $\ddot{.}$ \\
\hline Ovary & $\begin{array}{l}259_{A} \\
271_{A}\end{array}$ & $\begin{array}{l}2,520 \\
1,691)\end{array}$ & Survived & $\begin{array}{l}\text { Accidentally } \\
\text { loth day }\end{array}$ & & \\
\hline $\begin{array}{l}\text { Boue inar- } \\
\text { row }\end{array}$ & $\begin{array}{l}262 \mathrm{~A} \\
264 \mathrm{~A}\end{array}$ & $\begin{array}{l}1,750 \\
1,850\end{array}$ & Survived & 8th day & - & Negative. \\
\hline Liver & $\begin{array}{l}250_{A} \\
26 S_{A}\end{array}$ & $\begin{array}{l}2,350 \\
2,320\end{array}$ & Surrived & 6 th, & & \\
\hline Kidney & $\begin{array}{l}254_{A} \\
270 \mathrm{~A}\end{array}$ & $\begin{array}{r}720 \\
2,150\end{array}$ & .", & & & \\
\hline $\begin{array}{l}\text { Heart blood } \\
\text { defibrinated }\end{array}$ & $\begin{array}{l}269 \mathrm{~A} \\
272 \mathrm{~A}\end{array}$ & $\begin{array}{l}1,750 \\
1,740\end{array}$ & $"$ & $\begin{array}{l}\text { Accidentally } \\
\text { 3rd day }\end{array}$ & - & \\
\hline Lung & $\begin{array}{l}251 \mathrm{~A} \\
263 \mathrm{~A}\end{array}$ & $\begin{array}{l}3,290 \\
1,970\end{array}$ & $\begin{array}{c}\text { Surrised } \\
"\end{array}$ & & & \\
\hline $\begin{array}{l}\text { Mesenteric } \\
\text { gland }\end{array}$ & $\begin{array}{l}273 \mathrm{~A} \\
27+A\end{array}$ & $\begin{array}{r}750 \\
1,540\end{array}$ & $"$ & & & \\
\hline
\end{tabular}

In this monkey the virus was found in the brain and spinal cord only, and could not be demonstrated in the ovary, spleen, bone marrow, liver, kidney, the blood, the lung, the mesenteric glands, adrenal glands, or parotid gland.

\section{ELIMINATION OF THE VIRUS FROM THE ANIMAL ORGANISM}

As is the case with the viruses of herpes, rabies, \&e., the pathogenie agent of enzootic encephalo-myelitis is eliminated by the saliva and nasal secretions. The results of the German school (Zwick, Seifried, and Witte, 1926; Ernst and Hahn, 1926) are in agreement with regard to this point. The urine of animals ill from the disease has always proved a virulent. 


\section{HISTOPATHOLOGI OF BORNA DISEASE}

\section{HoRsE.}

Siedamgrotzky and sichlegel (1896) described the disease as a 'serous leptomeningitis'. Both Johne (1896) and Ostertag (1900 et seq.) failed to find lesions in the brain or its coverings, and considered the disease to be an intoxication of the central nervous system by bacterial toxins. Dexler (1900) refers to Borna disease as a disseminated encephalo-myelitis with leucocytic infiltration around the ressels and in the nerve substance. Oppenheim (1907) considered it to be an acnte localized meningo-encephalitis of a non-purulent nature, the meninges being more especially affected. Joest and Degen (1909), who made a more detailed study of the histo-pathology of Borna disease of the loorse, regarded it as an acute meningo-encephatomyelitis, non-purulent in charicter, with perivascular infiltrations by lymphocytes in the cord and brain. Cellular 'inclusions' were also found in the ganglion cells of the Ammon's horn, in the lipjocampus, and sometimes also in other regions of the brain. These "inclusions' they described are within the unclens, round in shape, and arranged sometimes in pairs. They stain red with Mamn's or Lentz's stain. and have often an unstained halo around then. Their dimensions vary from the limit of visibility to the size of a nucleolus. Heydt (191.) was able to confirm the findings of Joest and Degen in every detail. Moussu and Marchand (1924) (sce also thesis of Monssu, 1926) did not find the intranucluar corpunseles described by Joest and Degen.

The cases investigated by Monssu and Marchand were of an acute haemorrhagic type and polymorphonuclear lucocytes were found in the lesions in largr numbers. 'They described an agglomeration of infilt rating mononuclear cells surrounding the nerve-cells in the brain, produeing in certain eases deformation of these cells by eompression of the eull membrane. These authors did not reeord actual neurono. phagia.

\%wick, Seifried, and Witte (1924), I3eck and Frohbïse (1926), and Emst and Hahu (1927) contirmed the work of Joest and Degen (1209) Zwick and his collaborators emphasize the fact that the ferman worlits have never found degenerative lesions of the neuron nor neuronoplagia in any region of the nervous system where they were searehied for.

\section{CATTLE.}

'The similarity of the disease in cattle and horses, as indicalerl hy a study of the lesions in the eentral nervous system with the presence of virus in these lesions, has heen encontioned by Ernst and Hahn (1527). They demonstrated the corpuseles of toest-Degren in the

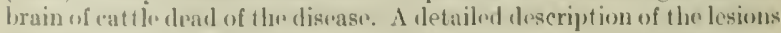
has also breng given in the thesis of Musssn (1920t). Ho states that

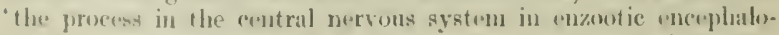
myelitis of eattle consists of a difuse polio-enephlalitis with a prodominanee of lesions in the cerebral cortex, of which the derper layers 
are more particularly affected. There are similar lesions in the basal ganglia of the cerebral hemisphere, in the peduncle, in the medulla oblongata, and even in the spinal cord; but these lesions are always less marked than those in the cerebral cortex. This encephalitis is accompanied sometimes by perivascular lesions and diffuse capillary haemorrhages. It is easy to understand that these lesions may lead to rapid death when affecting the medullid oblongata'.

\section{SHEeP.}

Priemer (1925), Beck (1925), Moussu (1926), Miessner (1926), and Ernst and Hahn (1927) marle a study of the lesions in the central nervous system in sheep dead of the disease. They came to the conclusion that the tissue changes were analogous to those produced by the virus of the eoume type. Beck was the first to demonstrate the intranuclear corpuscles of Joest-Degen in the nerve-cells of the brain of sheep dying from the spontaneous disease.

No observer has described any departure from the normal in the histology of other organs either in sheep, liorses, or cattle.

\section{Experimental Borna Disease in Horses and Sheep.}

The lesions described in the nervous system of horses and sheep infected experimentally are identical with those found in the spontaneous disease.

\section{T. Rabbits Infected Experimentally.}

The first description of lesions in the central nervous system in rabbits infected with the virus of encephalo-myelitis was given by Moussu and Marchand (1924). These authors were apparently working with a virus which differed from those isolated by workers in Germany; and. while this difference may possibly be accounted for by an increased virulence, their description of the lesions has remained unique and unconfirmed up to the present. It is as follows:

'In rabbits which die soon after the inoculation, the alterations are those of an acute meningo-encephalitis with a predominance of lesions in the pia mater. The meninges are infiltrated with immature cells of which a large number contain eosinophile granules. These same cells can be found around intracerebral vessels (cortical or subcortical). There are alterations of the choroid plexus, and epitbelium of the ventricles; there is infiltration of the subependymal zone and the pyramidal zones are much altered. The lesions of the cerebellum are identical with those of the brain, while the alterations in the vessels of this region are also as intense as in the meninges.

No bacteria were found, nor intranuclear inclusions. In animals which died at a later stage the lesions were less intense. The lesions predominate in the anterior region of the brain and are those of a subacute cncephalo-myelitis. The inflammatory lesions of the meninges are only observed in the septum and in the spaces between the convolutions. The same may be said of perivascular infiltrations. 
Embryonic cells ("cellules embryomaires") are present, containing eosinophile granules. There is an in Hammation of the ependyma with subependymal lesions.

In the olfactory lobe one finds small inflammatory areas. The cellular lesions are well marked, but less intense than in the preceding form. In the cerebellum one finds several areas of periarteritis situated in the white matter. No bacteria or inclusions can be found.'

Zwick. Seifried, and Witte (1926), like Beck and Frohböse. Ernst and Hahn (1927), and lliessner (1927), who have been interested. in passing, in the histopatholngy of the eentral nerrous system of rabbits infected experimentally, devote only a few lines to the question. In general, the summary of their findings may be given as follows: Iacroscopically, apart from the brain and cord, which appeared to be hyperaemic, all the organs preserved their nomal aspect.? A microscopic stuly of the lesions in the brain revealed a slight meningitis with mononuclear cells; more or less infiltration of the cerebral cortex and the Ammon's horn with lymphocytes: perivascular infiltrations, especially in the small and middle-size vessels; and the presence of intranuclear corpuscles in the large ganglion cells of the Ammon's horn. Twick and his collaborators, as well as other investigators who have studied the disease in Geruany, have never observed degenerative processes in the nerve-cells nor recorted neuronophagia. Kwick found perivascular infiltrations in the spinal cord in cases which had paresis or paralysis.

The summary given above records brietly the observations made by other workers whose attention has beril directed partienlarly to the lorin, while the participation of the spinal cort in the pathological process has been referred to only exceptionally. There is no publislned work on lesions of the nerve-roots, spinal ganglia, and peripheral nerves.

\section{Arthors OhsenvatoNs.}

A. Rabbit.

(1) Macroscopicul and Microscopicul Findings in Diterse Orgams.

()ur olservations have been made on animals infectme rither with the strain of virus originating from horses (/wick) or that originating from shere (Diessner). On post-nortem eximmination in the majerity of casts. a eongestion of the mening 's which may sometimes be intrine is fouml. In other casis the aspect of the nerrous system may be normal.

Sometinus tho stomach presents the lenticular haemorrhages

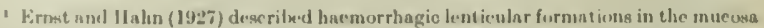
of the slommels of rnbbits dead of Bornu discass. We have found thene lenticular for.

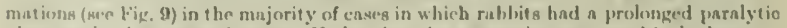
phase anil a long ngomal slage. Under the mieroseope they nplunred fo be haenor.

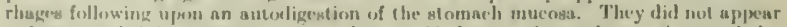

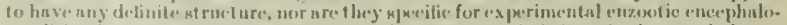
myelitin, sine we huve fuund ilem nlso in herpetic enephalit is anel of her morbid con. ditions. 
referred to above, but we have found that these are not a specific reaction to the virus (Fig. 9). In the larger number of cases examined in detail (more than thirty rabbits) the kidneys showed a marked congestion. This hyperaemia was not limited to the cortical zone, but affected the medullary zone to the same extent. Sections from such kidneys showed that there were small multiple haemorrhages in the region of the glomerulus, as well as in the collecting and convoluted tubules. These extravasations formed sometimes actual haemorrhagic areas. The epithelium lining the renal tubules was normal, there were no infiltratire processes peri- or intratubnlar. The condition may be described as renal congestion; not a true nephritis.

On microscopic examination the parotid showed occasionally small areas of infiltration composed of lymphocytic elements surrounding certain of the striated canaliculi; at the same time the cytoplasm of certain of the cells of the acini had become oxyphilic when stained by IIann, while the nucleus appeared oedematous and took up an abnormal eccentric position in the cells. Although many sections of the parotid of rabbits were examined, these lesions were found only occasionally. Without presuming that they were produced by the action of the virus, it should be mentioned that they coincided with the presence of virus in this organ. In rabies and distemper. oxyphilic corpuscles, intra- or extra-cellular, staining red by Jann's nethod, have been described as concomitant with the presence of virus in the parotid. No actual corpuseles have been found by us in the parotid of animals infected with the virus of enzootic encephalomyelitis.

In the medullary zone of the adrenal small accumulations of lymphocytic elements were occasionally seen. The lung, the liver, the spleen. the testicle, and the ovary appear macro- and microscopically normal.

Characteristic lesions of an intense nature are found only in the nerrous system. We may class these in two categories, (1) infiltratice and $(2)$ degenerative. Both types of lesions may be met with in the brain, mesencephalon, cerehellum, spinal cord, and spinal ganglia. In the nerve-roots and peripheral nerves (sciatic and brachial nerves examined) only infiltrative lesions have heen found.

\section{(2) Lesions in the Central Nerious System.}

(a) The Brain. The pia mater is infiltrated with mononuclear feucocytes, varying in individual eases. In some areas only a trace of this infiltrative process way be seen, while in others three or four layers of infiltrative cells occur. They are especially marked in the region of the meningeal ressels as weil as in the spaces between the convolutions, and may form actual meningeal plaques. The infiltrating elements are lymphocytes, plasma cells, and large mononuclears. Tessels of the pia mater are often surrounded by 'cuffs' constituted by mononuclear leucocytes (Fig. 10). The most intense lesions of the meninges are generally found at the base of the brain. In sections 
cut at right angles to the surface of the brain vessels passing from the meninges into the cortical substance surrounded by lymphocytic 'cuffing' have often the aspect of septa (Fig. 11). In the cortex difiuse infiltration of lymphocytes accompanied by proliferation and mobilization of the neuroglial cells occurs. Especially in the hippocampus (the so-called 'elective zone' in herpetic encephalitis of the rabbit), the neuron degenerates. the nucleus swells. the chromatin becomes rarefied. collects towards the periphery of the nucleus, and in its place appear small oxyphilic globules which nay be at the limit of risibility or may reach the size of a nucleolus. Some of the neuroglial cells of this region appear to undergo the same legenerative process. It is similar to, although less intense than that described by Levaliti, Harvier, and Yicolau (1922) in experimental herpetic encephalitis in the rabbit, leading to the formation of encephalitic ncurocorpuscles, and is not of a specitic nature. The oxyphilic degeneration of the nucleus may lead to the formation of larger corpuscles surrounded by a halo, morphologically identical with those described as specific in Borna disease by Joest and Degen (1909). The nucleus may react in the same way to other canses. Even the halo is not wanting in the figures given by Levaditi. Harvier, and Nicolau. We regard this phenomenon as possibly the result of the action of a karyotropic virus, the degenerated karyoplasm fusing round the pathogenic agent. These nuclear lesions may be found in all regions of the brain, although the German writers bave described their presence onty in the Cornu Ammonis, in which, inleed, they are more constaintly found. They may be single or in pairs surrounded or not by a characteristic halo. When sections are stained with IIann's stain or toluidin blue-eosin, the intranuclear corpuscles are stained rose or resl, while the nucleolus is more of a violet tint. They occur also in the pyramidal cells of the cerebral cortex and even in the meuroglial cells (large granulo-adipose cells of the hippocampus).

In the Ammon's horn newly formed capillaries are sometimes seen. The vessels of this region appear dilated, gorged with bloort, and their adventitia infiltrated with several layers of mononuclear leucocytes. Plasma cells are abundant in the process of perivascular infiltration. We have never found such a large number in rabies of the dog or rabibit, in poliomyelitis of monkers, in human enceplualitis, in cluronic herpetic encephalitis of rabbits, or in the raseular lesions produced by the presence of the so-called 'Encephalitozom cuniculi'. Sumall lyuphocytes may also be found in large numbers in these perivascular iufiltrations, but large mononuclears cells are also presient to a less extrnt. The presence of polymorphomelear lencocytes is exceptional.

Sumetiues in the thickness of the "eufting" are elegenerated lyuphocytis or plisuria cells. The nuclens of these degenerated cells las becone intens.ly oxyphilic. It is remlucel in size and courlensed in 'hlecks' without any definite structure. Wheu Mam's stain is useel, the protoplasin, in the ease of the elegenerated plismal cebls, stains rose; the unchanged elements stain blue. Ilere nul there in the 
mass of the infiltrating cells rare fragments of degenerated chromatin ean be found, probably arising from degenerated mononuclear lencocytes or pyknosed polymorphonuclear cells. The intensity of the infiltration varies. Somptimes the perivascular 'cuffing' is constituted by one, two, or three layers, while in other cases a massive nodule resembling a gumma may be found with a small vessel in the centre. These alterations occur not only in the vessels of the Ammon's hom, but in all the regions of the central nervous system where 'cuffing' may be found.

In the Cornu Ammonis areas of mononuclear infiltration are seen between the ganglion cells, in the row of fusiform cells, or in the chain of small granular cells (Fig. 12). Neuroglial cells of neoformation may also participate in this infiltrative process.

We have never found true neuronophagia at this site, but we have enconntered a curious phenomenon, the exact nature of which we had some trouble in letermining. In a section of brain examined under the oil immersion we found in one of the large ganglion cells of this region stained with toluidin blue-eosin a species of 'cyst' in the interior of the protoplasm (Figs. 13, 14. 15, 16). The rest of the cell preserved its normal aspect. The 'cyst' compressed the nucleus and pushed it towards the periphery of the cell, forming a marked depression in the nuclear membrane. The diameter of this 'cyst' was about $7 \mu$. It was marked off from the eytoplasm of the neuron by a membrane, and contained six basiphilic granules of equal size, placed symmetrically at its periphery.

On subsequent minute examination of the cells of the Ammon's horn we found these 'cysts' again in several preparations. They have been found only in this region and always in the protoplasm of the cell. Their diameter varied from $5 \mu$ to $9 \mu$. During the search we have seen occasionally plasma cells, the nucleus of which had undergone degeneration, which in its appearance recalled this intracellular 'cyst'; the karyoplasin was condensed into several small round intensely chromatophilie granules, apparently attached at equal distances to the nuclear membrane. The presence of a protoplasmic circle around this formation removed from our minds the supposition that we were dealing with a 'microsporidian cyst', and showed distinctly that it was a degenerated infiltrating cell (Pl. I, Fig. 3). The staining reactions indicated that the cystic formations were the degenerated nuclei of the plasma cells which had penetrated into the interior of the large cells of the Ammon's horn. We have found such bodies in approximately 5 per cent. of cases examined. They have never been met with in the brain of normal rabbits, or in the brain of rabbits which have succumbed to infection with the viruses of herpes, rabies, or vaccinia.

We have described these formations in detail. since the elucidation of their nature required extended observations. Many control animals were examined to ensure that we were not dealing with a spontaneous 'microsporidian' disease of the rabbit.

Pathological changes other than the above are found inore con- 
stantly in the Ammon's horn, especially in cases showing intense intiltrative lesions. For instance, a number of the nerve-cells may show degenerative changes characterized hy the following appearances. The nuclens appears oedematous, the chromatin is fragmented, while the protoplasm shows more or less adrancel tigrolysis. The protoplasin also contains vacuoles and the cellular meinbrane is denticulated. In some cells. also. of the Ammon's horm, the nucleus. and sometimes too the protoplasm, hecomes oxyphilic. The fusiform cells which are found in the upper part of the row of large ganglion cells show intense muclear degeneration; the karroplasu is cond'nsed in a "block' and stains red with Mam's stain. When a preparation so stained was decolorized gradually, and examined after each stage of the process until these degenerated nuclei became a pale rose colour. it was found that they had no definite structure. but consisted of a round mass of homogeneous condensed chromatin much smaller in size than the unchanged nuclei. This type of muclear degeneration has also been met with in the mestucephalon (Pl. III, Fig. 4).

We have alrealy referred above to the fact that oxyphilic corpuscles which may or may not be surrounded by halos are found in the mucleus of some of the cells of the Ammon's horn. They can be distinguished from the nucleolus by their different staining reactions (Pl. I. Fig. 2). These intranuclear corpuscles-the specific inclusions' of the German workers-may be single or in twos or threes, rarying in size. Sometimes they may be at the limits of risibility. or they may be as large as $2 \mu$ or $3 \mu$. These corpuscles occur elsowhere. They may be found in the cytoplasm of the cell and are possibly expelled intra ritam. but as it is possible for the nucleolus of a cell to be dislodged by the microtome knife. the same factor might carry the intranuclear corpusele into the cytoplism.

Oir opinion is that the intranuclear 'inchsion' in Burna disease is possibly a ruaction of the karyoplasm against the pathological agent which penetrates the interior of the moleus. Possibly the chromatin masses around the infective virus elements. This is sugcrested hy the staining reactions, since the condensed mass of chromatin which forms the corpusele undergoes degeneration from the centre towards the priphery (the centre appears oxyphilic and the periphery basiphilic in certitin corpuscles).

Aromel the lateral ventricles woll-marlienl intiltrations are fomul. these being in some cases very intense. The choroid plexus is also infiltrated. The cpithelium of the rentriche and of the ependyma is unchanged.

()ecasionally in the parenchyna in the region of the ventriche, or (ven in the cerebral cortex itself in the superticiul areas, karyokinetic tigures muy lue seen. Prolnably this karyohinesis is in mobilizinl cells of the viscular endothelium which hive penetruted into the n.rve substance. In certain preparatious wo luve sern 2, 3. or even 4 karyolinutuc ligures. 'The mitusis sonetimes undergoes oxyphilic dege-lieration. 
There are lesions affecting the area above and below the ependyma and also the surrounding zone: a mobilization of the nenroglial elements takes place, while at the same time lymphocytic elements are found in the immediate proximity of the neuron. Up to a certain point this phenomenon is comparable with the 'satellitism' described by Metchuilioff in senility. Certain of the nerre-cells are surrounded on all sides by 'satellite' cells and cells of infiltration, which occasionally penetrate the interior of the cell. Six, eight, and even ten neurons may be seen 'besieged' in one microscopic field. The cells which come in immediate contact with the nerve-cell push in the cellular membrane and form 'cups' in the periphery of the cytoplasm, giving the nerve-cell a denticulated border. This phenomenon is more commonly met with in sections from rabbits dying within the first 20 days after inoculation. The intensity of 'satellitism', is in inverse proportion to the meningeal and perivascular lesions. When the meningitis and perivascular cuffing are at a minimum 'satellitism' may represent the only departure from the normal discovered in the brain.

From the examination of a large number of preparations we are led to beheve that 'satellitism' is a stage which may either disappear during the erolution of the disease, resulting in a quasi-normal state, or become intensified and be followed by neuronophagia. We have found neuronophagia present in sections of brain showing marked 'satellitism' (1ig. 17). Our conception of the various stages of the struggle against the virus is as follows: When the nervous system is invaded by the rirus the neuroglial elements and mononuclear lymphocytes are attracted to the parasitized neuron. If the neuron succeeds in freeing itself from the virus. the local reaction ceases at this stage, and the resorption of the satellite elements follows; but if the neuron rlies in the struggle against the virus after undergoing intense degeneration, it is invaded by the satellite cells and rare polymorphonuclear lencocytes; the process has now reached the stage of neuronophagia. When the struggle between the neuron and the virus terminates without neuronophagia taking place the animal survives until the meningeal lesions, perivascular infiltrations, and infiltration of the Ammon's horn become incompatible with life. In this case death talies place at a later stage, i.e. in from 25 to 50 days.

These conclusions as to the evolution of the morbid process in the brain, formed from observations on the character and position of the lesions in a large number of rabbits dying early or late after inoculation, have received further support from the study of the histogenesis of the alterations in the central nervous sytem of six rabbits killed at regular intervals after inoculation. i.e. on the 5th, 10 th, 15 th, 20th, and 27 th day, and of one which died on the 31st day. In these animals also, the microscopical examination of sections of various parts of the nervons system showed that the first modification in the central nervous sytem is the mobilization and proliferation of the neuroglial cells aromd the neuron-'satellitism', this being more marked in the pons and the medulla oblongata. In the process of 'satellitism' one finds uot only' neuroglial cells but also mononuclear 
cells taking part. Later, infiltration of the Cornu Ammonis, the meninges, and the vascular tissues takes place. In the subjects of our experiments the latter process began to appear towards the 15 th or 20 th day after the inoculation.

The presence of polymorphonuclear cells is quite exceptional no matter at what stage of the infection or from what site one examines sections of the central nervous system; the infiltrative lesions axe constituted from the beginning by mononuelear cells.

There are notable differences between the development of the encephalitis of Borna disease in the rabbit and chronic herpetic encephalitis produced experimentally in the same species. In tho brain infected by hexpes an acute stage is observed in which polymorphonuclear lencoeytes take part, and are fonnd in large numbers in the perivaseular 'cuffing' as well as in the nodnlar lesions at the base of the brain in the region of the hippocampus. If the animal survives this acute stage and recovers what have been temed by Levaditi and Nicolau (1922) 'lésions d'immunité may be fomd. These are small nodular or diffuse areas of parenchymatous infiltration situated in the hippocampus (the 'zone elective') and are proluced by mononuclear cells that have replaced the polymorphomolear lencocytes with which the intlammatory process commenced. In those rabbits which just fail to resist the disease and die in 20 to 30 days, the lesions are more intense. but. as in the case of the "lésions d'immunité", the infiltration consists of mononnclear cells which have taken the place of the polymorphonuclear leucocytes that predominated in the acute stage of the intlammatory proess. In the case of the infection of the brain of the rabit with the virus of Borna disease, polymorphonuclear leucocytes do not play a part in the early inflammatory process; during this early stage, one observes only 'satellitisin' of the neuron, while the infiltrative lesions are proluent by mononuclear cells alone from the beginning of the process until the tinal stage.

(b) The Mid-brain and Vechulla Oblongata. In the meseneephalon and the medulla oblongata similar infiltrative and elegenerative lesions occur. 'C'nfting' of the vessels is frequently observell. Certain of the nerve-cells appear to he in a state of advaneed tigrolysis (Nissl's granules have disappeared). De'generation both of the mueleus and the cytoplasm is frequently found. C'ertain of the cells appear to have their protoplasm split up, tlu. nuelens heing peripheral. swollen, and eompletely degenerated (l. 1, tig. 1). (hecasionally typical neuronophagia is eneonntered. In these regions also we have demonstrated the presence of the intranuelear eorpuscles of Joest.

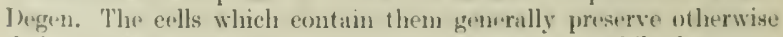
their normal aspeet; the melear menthrume is intact, while the protoplasm is structurally unchanged nud stains normally. 'The converso is also true; we luwe never found the eorpuscles of Joest-1)urgen in evils in actvaneed stages of degeneration or disintegration. Nenri bonlies in rabies ure also only found in urerve-eells which are otherwise normal. In the mesencepplaton, as mentioned ubove, ono meets most 
frequently with 'satellitism' of the neuron, which in certaim cases goes so far as to constitute true neuronophagia (Fig. 18). In the mesencephalon also we may find small islands of mononuclear cells in the parenchyma without any relation to the ressels. In certain cases we found neuroglial cells (grannlo-adipose cells) showing nuclear oxychromasia and occasionally small oxyphilic corpuscles within the nucleus, similar to the so-called 'encephahitis neurocorpnscles' of herpes described by Levaditi. Harvier, and Nicolan (1922).

(c) Cerebellum. In the case described the lesions in the cerebellnm were much more intense than the average, since usually the alterations consisted only of slight meningitis and perivasenlar infiltration accompanied by occasional 'satellitisın' of the cells of Purkinje. In the septum there was a marked infiltration with mononnclear cells. Massive perivascular 'cuffing' was present, especially in the white substance between the convolutions. In the ressels themselres, which were gorged with blood, an excessive number of mononuclear cells were found. There was an intense infiltration in the granular layer, which in some cases was completely destroyed and replaced by areas formed exclusively of mononuclear cells. Here and there in the islands of lymphocytes 'basket' cells with a pale-staining degenerated protoplasm were found, their border appearing irregular. Several of the cells of Purkinje appeared to be hyperchromatic, and their nucleus was in some cases ecentrie and stamed by acid stains. In others the nucleus was not separated from the rest of the protoplasm since the remains of the nuclear membrane appeared to have disappeared. Other Purkinje cells were degenerated and appeared as cell shadows. In other parts the karyoplasm of certain of these cells was condensed around the nucleolus. Satellitism of the basket cells and the cells of Purkinje was noticeable, but true neuronophagia was not seen. The lesions were confined to certain areas; other parts of the cerebellum were perfectly normal.

In a case where the inoculation of the virus was made by the intratesticular route the lesions in the cord were especially well marked, and in the cerebellum the satellitism of the cells of Purkinje was occasionally so advanced as to constitute almost a true neuronophagia.

(d) The spinal Cord. Generally it may be stated that the intensity of the lesions found in the brain or in the spinal cord corresponded with the intensity of the symptoms observed during life. In the rabbits we have examined pathological changes were always present in the cord whether svmptoms of affection of this part of the central nerrous system were present or not, but these were much more intense when the symptoms produced by affection of that region dominated the cerebral symptoms.

As in the case of the brain, the meninges of the cord are not as a rule greatly affected. Only in isolated cases was a serere meningitis found.

The anterior and posterior septa may be more or less infiltrated with mononuclear cells. Perivascular 'cuffing' is seen both in the 
grey and white matter of the cord. In the anterior and posterior horns infiltrations with mononuclear cells may be seen.

The most intense infiltrations are found in the posterior horn. while in the anterior horn degenerative lesions of the neuron are more common. The process of degeneration in the nerve-cells is the same as that in other regions of the coutral nervous system: tigrolysis occurs, nuclear oxychromasia exists, while the whole cell shows a marked hyperchromasia. Vacuolization of the cytoplasm, a degeneratire process, may also be seen (PI. II. Fig. 1), while in rare cases when the lesions as a whole have been exceptionally intense, occasional neuronophagia was recorded (Fig. 19). The phenomenon of 'satellitisn' appears to be nore commonly met with in the cord than in the brim itself. The intrauuclear corpuscles of Joest-Degen found in the cord have generally been in the nerve-eells of the anterior horn (Pl. I. Fig. 5: Pl. III, Fig. 2).

Here and there small islands of lymphocytes may be fomm infiltrating both the white and the grey substance, these islands being uncomnected with ressels. Frequently it has been observed that the zone of lissauer is the site of a well-marked mononuclear infiltration.

The lesions found in the spinal cord are comparable with those found in poliomyelitis. The neuronophagia so characteristic in the cord of monkeys infected with the virus of the latter lisense (to which rabbits are generally consilered not to be suseeptible) is also present in the cord of rablits infected with the virus of Borna disease, lout to a less ilegree.

\section{(3) Lesions in the Peripheral Nerrous system.}

(a) The l'osterior Nerve-roots arising from the cells in the zone of Lissaluer have infiltrative lesions which vary in intensity. This zone, as has been stated above, is generally intiltrated with mononuclear colls. The infiltration takes place between the nerve filamesuts, am eonsists of a chain of lymphocytus. In some eases only traces of this infiltration can be seen, while in other cases massive perivascular intiltration may ocenr (F'ig. 20). "The interstitial intiltration in the anterior nerveroots is very discrete or absent.

This process of radiculitis has not been mentioned by of her workers who have studied the disease in animals infected exporimentally; nor has the process of intiltration of the nerve-roots been ilescribed in the spontaneous disense.

(b) The spinal Cianglia. The most intense lesious in the periplural nervous systen lave bern found coustantly in the spimal ganglia. The process of infiltration in the posterior nerve-rots becomes more interses as they anter the ganglion, and lotween the nervetilires which pass through the sulsataner of the ganglion a well-narkind monumelear intiltration is sern. In the rest of the ganglion the fusions as a rule are very intensa.

The alterations in the gingelion and the various alements faking part in the infiltrative and degenerative processes at this site ano nlways the same, mo natfer from what individual case or from what region 
of the cord (cervical, thoracic, or lumbar) the ganglion is taken (Figs. 21, 22). The changes are as great and the lesions of the same importance when the ganglion originates from a case showing alterations in the cord which are scarcely discernible as from a case where such changes are sery pronounced.

The capsule of the ganglion shows neither infiltration nor degeneration. In the interior of the ganglion mononuclear interstitial infiltration is abundant. The small intragangliomic ressels show perivascular "cuffing". The infiltrating mononuclear elements are found disseminated between the nerve-cells or massed together forming actual nodules comparable with those described by Tan Gehuchten and Tehs (1900) in rabies (Fig. 23). The mononuclear cells may be grouped together in small islands between the nerve fasciculi which traverse the ganglion. The ganglion cells themselves appear to be 'choked' by the infiltrative process in some microscopic fields. In certain parts these cells undergo profound changes: the nucleus becomes oxyphilic, the protoplasm loses its granular nature, assuming a homogeneous appearance, and becomes slightly oxyphilic when stained with toluidin blue and eosin. We have found that the changes in the cells of the ganglion are more unarked than in any other region of the nerrous system; and the intranuclear corpuscles are larger and in greater number bere than in any other site. In some microscopic fields the nucleus of every cell may contain one or two corpuscles of Joest-Degen surrounded by a halo.

The most important and frequent type of lesion in the ganglion, however, is neuronophagia. Lymphocytes, plasma cells, and large mononuclears penetrate the peripheral zone of the neuron. One often finds a clear zone in the protoplasm around these infiltrating cells suggestive of the action of a proteolytic ferment liberated by the invading cells. Later the mass of detritus of the neuron is removed by the macrophages aided by occasional polymorphonuclearleucocytes. The number of infiltrating cells mcreases, the whole body of the nerve-cell bemg invaded, and finally, in place of the neuron, one finds nothing but a nodule formed by mononuclear cells (Figs. 23. 24,25 , and 26 ). The most intense lesions of both an infiltrative and degenerative character are found in the peripheral zone of the ganghion; this point will be discussed again later.

(e) The Peripheral Neries. In the peripheral nerves infiltrative lesions are also found. A detailed study has been made of lesions found in the sciatic and brachial nerves. The technique employed in carrying out this research was as follows:

All the rabbits of which the sciatic and brachial nerves were sectioned for histological examination had been inoculated intracerebrally with the rims of Boma disease. We removed the terminal part of the cord (sacral) with the roots of the sciatic nerve and their various ganglia together with a portion of the peripheral parts of the uerves. This whole was fixed in Duboseq-Brasil-Bouin Huid. Longitudinal sections were made after the manner figured (Fig. No. 27).

We have found lesions in all cases exammed, these being more 
intense towards the origin of the nerve and becoming less intense towards its termination. The alterations consist of interstitial or perivascular infiltrations with mononnclear cells. The nerve-sheath is, as a rule, unaffected. In certain cases the infiltrations appear to 'dissect' the nerve filaments (Fig. $2 S$ ). The whole process constitutes a rlescending neuritis produced by the rirus propagating centrifugally. 1

Recently G. Marinesco and 5 . Draganesco (1927) published their observations on the pathogenic process in herpes zoster. A complete clinical report is given of cases in which the localization of the lesions in the nervous system suggested to the authors that the infection commenced by an ascending neuritis followed by a ganglio-radiculitis and myelitis. Wollwill (1924). Levaditi (1926). Pette (1924). Foerster (1924). and others adranced similar hypotheses as to the centripetal propagation of the infection. In support of their theory as to virus ascending from the peripheral nerves, Marinesco and Mraganesco refer to the lesions in the corresponding ganglia: "In the ganglion the most intense lesions were in the peripheral zone ... this topography of the inflanmation explains the spread of the infection by the pericapsular lymph ressels. to the interior of the ganglion."

However, from a comparison of the description of the lesions produced by the downward extension of the rirus in rabbits infected with the virus of Borna disease, and those in herpes zoster, it will be seen that the histological pictures are identical. We have found lesions in the peripheral nerve not only close to the ganglion as described by Marinesco in zoster, but also in the terminal filaments farthest removed from the ganglion. showing that the virus in our experiments diffused by centrifugal propagation. These facts allow us to assume that the topography of the lesions is not a criterion by which to judge the portal of entry of the virus with a sufficient legree of accuracy. Comparable lesions can be produced in the central and peripheral nervous systen both by infection intracerebrally or by inoculation of the virus into the sciatic. i.e. no matter whether the infection is aseending or descending.

This example of lesions being produced in the periplueral nervous system after introduction of the virus into the centrial nervous system (brain), suggests the possibility of infection being central in origin in the case also of burpes zostur. A similar pathogenic process is unt excluded in recurrent herpes, peripheral forms of epidemic enceplanlitis, and perhaps also in certain cases of sciatica.

\section{(4) Summary and Discussion.}

The inoculation of the virns of anzontic encepholo-myolitis intracerehrally into rablits proeluces clanges in the uervous system. which are those of a meningoeencephalo-myelitis, a ganglios-rucliculitis, and a peripheral interstitial neuritis.

'Th" lesions in the central nervons systems as weell as in the spinal

3 We have Ixed able Io demunalrale the presence of virus in the peripherat nerves ly uneculation uf their enulnions inlo the brain of rabbila (see p. 45). 
ganglia are both infiltrative and degenerative. The meningitis and the perivascular and parenchymatous infiltrations are produced by mononuclear cells.

Pathological 'satellitism' of the neurom is most pronounced in the mesenceplalon, medulla oblongata, and spinal ganglia, but may be found also in other regions of the cord and brain. It may in some cases be so advanced as to constitute true neuronophagia. The latter phenomenon is most common in the paravertebral ganglia.

The intranuclear corpuscles of Joest-Degen, considered by the present writers to be evidence of an attempt at defence by the nervecell, and referred to as specific "inclusions' by other workers, may be found in the various regions of the brain, cord, and spinal ganglia. They are almost constantly present in the large ganglion cells of the Cornu. Ammonis and the nerve-cells in the spinal ganglia. In our opinion the cell. which reacts against the presence of the virus by the formation of intranuclear corpuscles has formed a barrier to the extension of the destructive action of the virus in 'blocking' the infective elements within a condensation of its chromatin. It is feasible to conceive that this process removes the virus and renders it inoffensive: for this reason the cell maintains its integrity. In those cases where the cell becomes degenerated or neuronophagia takes place, one may suppose that the nucleus has been incapable of surrounding the infective particles by condensation of its chromatin and thus limiting the extension of the activity of the virus. This failure to form intrannclear corpuscles may be due to the quality of the virus (virulence), the quantity of the virus, or the deficiency in the normal resisting power of the neuron, the result being that the virus multiplies and ultimately destroys the cell. One must recall that the figure described on p. 56 supports this view as to the method of production of the corpuseles of Joest-Degen.

The infiltrations in the nerves are interstitial in character and are produced by the invading mononuclear cells arranging themselves in chains between the nerve filaments. Perivascular 'cuffing' also occurs.

A peripheral interstitial neuritis occurs in Borna disease after the introduction of the virus into the brain, and the anthors, without excluding the possibility of ascending infections, luave suggested that herpes zoster, ${ }^{1}$ recurrent herpes, the peripheral forms of epidemic encephalitis, and perhaps also certain forms of sciatica may be the secondary manifestations of a disease, the original focus of which is in the central nervous system.

The hypothesis has already been advanced (see p. 38) that in cases of infections with these viruses central infection of the brain takes place; but the central nervous system, being able to resist the action of the virus more efficaciously, shows no manifest disturbances, while the peripheral nerves, poor in methods of defence, do not rid themselves of the infecting elements which proliferate and produce lesions.

1 The work of Head and Campbell (1900) on the pathology of herpes zoster also suggests that zona is a secondary peripheral manifestation of a disease originating in the eentral nervous system. 


\section{B. The Guinea-pig.}

Macroscopic Examination. The brain and spinal coril appeared congested. No other organ showed pathological changes except the stomach, in which occasionally the nom-specitic lenticular haemorrbagic areas. similar to those described in the rabbit, were found.

Microscopic Examination. Lesions were found in the central and peripheral nerrous sytem and in the kidney. The alterations in the stomach wall, when they existed, were comparable with those found in the rabbit, namely, autodigestion of the mucosa with small localized haemorrbage. As in the case of the rabbit. the kidneys showed marked congestion, but no actual nephritis was recorded.

Central Nerrous Siystem. The lesions found in the brain were similar to those in the rabbit, except that their intensity was less. The intranuclear corpuscles of Joest-Digen were usually found in the Cormu Ammonis and elsewhere (PI. I, Fig. 4). Inliltritive and degenerative lesions characteristic of the disease were foumd (Pl. III, Fig. 3).

The lesions in the mesencephaton, cerebellum, and spinal cord were as in the rabbit. The intranuclear corpuscles of Joest-1)egen were frequently present in the interior horn of the spinal cord.

Pcripheral Sertous siystem. Infiltrative processes with mononuclear elements were found in the nerve-roots, but they were not so inarked as in the rabbit. The lesions in the spunal ganglia were similar in nature to those described in the rabbit, but were not so acnte. The lesions in the peripheral nerves were more intense in that portion nearest the ganglia.

\section{The Rat and Mouse.}

The organs, except the mervons system anel the lideney, were macrosecopically and microseopically normal. In the brain anil spinal (ord the lesions foumd were similar to those in the rabbit and the gninea-pig. The intranuclear corpuscles of Jost-Decgen were foumel in the brain of rats and mice. Intiltrative lesions of at discreto nature were also fouml in the sciatic nerve of the rat.

\section{The Monkey (Macacus rhesus).}

()ur description of the lesions found in the monliey is male from a sturly of spetions from different parts of the nervous system of Monkey .1. 1 (Macaeus rhesus). The protocol of the "xperiment in which this animal wats infeeted is given on p. 334. Similar lesions were fomel in . Vonkey X. 3, although the clinieal pieture in the case of the latter monkling was ilifferent from thit of M. I.

The macrosentical and microserpieal examination of the splesen, liver, pancreas, lumg, myocarlimu, testicle, ovary, parotil glanel, and the mextentrice and inguinal lymple glatuls did not reveal any pathes-

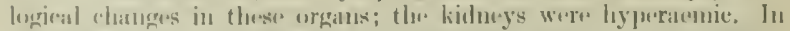
the atromal glant there was alight infill ration with lyouplocytes in the medullary zone, the lymphocytes being disseminated in the 
parenchyma or grouped together in small islands. The brain appeared to be normal by naked-eye examination.

(1) Lesions in the Central Nervous System.

(a) The Brain. Frontal Lobe. Meningitis of a mild character was present in some areas, becoming intensified near those vessels in which slight perivascular infiltrations were observed. The pathological process in the meninges might be described as an 'irritation' rather than a true meningitis, while the perivascular 'cuffing' consisted of three or four layers of cells only in the walls of the vessels in contact with the brain; in the rest of the vessels the process of infiltrition hardly existed. Certain of the small vessels penetrating the cerebral parenchyma from the meninges were surrounded by characteristic 'cuffing'. There was infiltration with mononuclear cells in the septum. The lesions in the meninges, the 'cuffing' (Fig. 30), and the infiltration of the septum, were produced by lymplocytes, plasma cells, and macrophages exclusively. In the parenchyma, and especially in the white matter, extensive 'cnffing' of the vessels could be seen, consisting of teri to twenty layers of infiltrative cells. Some of the pyramidal cells appeared to be degenerated. Intense satellitism of the neuron was present in some instances, and in certain of the cells oxyphilic corpuseles surrounded by a halo of the type described by Joest and Degen were found (PI. III, Fig. 1). The karyoplasm was rarefied in the greater number of the cells containing 'inclusions', suggesting that the degenerated chromatin was condensed in the corpuscles. In the deeper part of the brain, both satellitism and the intranuclear corpuscles of Joest-Degen were less frequent than in the peripheral zone.

Parietal Lobe. The meninges were infiltrated with mononuclear cells (Fig. 29) which formed plaques in certain regions. There was discrete infiltration of the septum. In the brain substance, perivascular infiltrations, consisting of many layers of cells, were found forming small nodules: that these were perivascular was evidenced by the presence of a small vessel in the centre of the nodule (Fig. 31). No neuronophagia was recorded in this region of the brain, although the acute 'satellitism' of the neuron sometimes suggested the phenomenon. Occasional nerve-cells in a state of degeneration had eccentric nuclei and their protoplasm was undergoing tigrolysis. No actual parenchymatous infiliration could be seen, but rare monomuclear cells were dispersed in the parenchyma. A large number of nervecells in this region contained large oxyphilic corpuscles surrounded by halos within the nuclei.

Oecipital Lobe. Meningitis was rarely observed in this region of the brain. Certain of the meningeal vessels had several layers of mononuclear cells on their walls in contact with the brain. In the septum, infiltration was not well marked, although several venules were surrounded by 'cuffing'. Rich perivascular infitrations were found in the parenchyma, more especially near the large pyramidal cells. Pathological 'satellitism' of the neuron by neuroglial elements and 6409 
occasional lymphocytes was not uncommon in the occipital lobe: these satellite cells sometimes produced marked depressions in the protoplasm of the host cell. The intranuclear corpuscles were of very much smaller dimensions and were observed less frequently than in the parietal lobe.

Hippocampus. The lesions in the meninges were similar to those found in the occipital lobe. The perivascular 'cuffing' in the parenchyma was poor in elements. There was a slight infiltration with mononuclear cells between the large and small pyramidal cells. The number of 'inclusions' was greater in this region than in the occipital lobe.

Cornu Ammonis. In this region of the brain the 'cuffing' around the vessels was so extensive as to suggest a nodule or pseudo-gumma: the presence of a small ressel in the centre of the noclule was discerned with difficulty. In addition, there were small groups of mononuclear cells bearing no relation to ressels. In certain cases 'satellitism' was so advanced that it conld almost be described as neuronophagia. The large ganglion cells preserved their normal structure and nearly all contained within their nucleus well-marked corpuscles of the JoestDegen type.

Basal Ganglia. Perivascular 'cuffing' was observed. In some of the degenerated nerve-cells the nucleus could not be lifferentiated from the rest of the protoplasm. Pathological 'satellitism' of the nerrecells was intense. Intranuclear corpuscles were found on occasion, not only in the nucleus but even in the cytoplasm. Small islets of monomuclear cells were also found.

Pons. The process of perivascular infiltration was abuudantly present in this region.

Many of the nerve-cells were in an advanced stage of degeneration, while the nuclei were swollen and unrecognizable as such. The protoplasm of the cells was in a state of tigrolysis and its contour was broken in many places by splitting. The cells containing intranuclear corpuscles were otherwise morphologically normal. No areas of infiltration were seen.

(b) Cerebellum. There was slight infiltration of the meninges and septum with monomelear cells: the pareuclyyma was not intiltrated. The layer of the small granular cells had a normal aspect. Certain of the cells of Purkinje were degenerated. In some of the latter eells oxyphilic corpuscles with a characteristic halo were recorded.

(c) Mclulla Oblongata. Meningeal changes were slight. Veasels wero normal without 'cufing' and the parenchyma was not infiltrated. ()ecasional neurons slowed (vidence of eommencing degeneration, and in eertain of these large oxyphilie corpusches were present.

(1) Spinal ('ord. Cerrical Region. 'T'ho numinges were normal and no 'culling' was present in them or in the grey or white matter. A slight diffuse infiltration was olserved. In the nuterior horns nondegenerated ne+urous had intranuclear corpuseles (Joest-Degen tyje). In certain rogions satellitism was in marked feature. 'T'he gone of tho cells of lissaner was infiltraterl with lyuplocytes. 'The posterior 
nerve-roots showed interstitial infiltration and sometimes even 'cuffing' in the ressels. The corresponding spinal ganglia showed intense interstitial infiltrations: only rare polymorphonuclear leucocytes were found. The protoplasm of certain of the cells in the ganglia had andergone tigrolysis, and in some cases also had become oxyphilic; the nucleus of these affected cells was eccentric. Neuronophagia was frequently seen and nodules of mononuclear cells comparable with those found in rabies were not uncommon. Large intranuclear corpuscles were found in nerve-cells of the ganglia which otherwise preserved their morphological integrity (Fig. 35).

Thoracic Region. No meningitis was present, nor was there any evidence of 'cuffing'. There was slight infiltration of the posterior horns and a concomitant degeneration of certain nerve-cells of the anterior horns. In the latter region also rare intranuclear corpuscles were found (Pl. II, Fig. 2). The posterior nerve-roots showed interstitial infiltration and 'cuffing' around the ressels.

Lumbar Region. No perivascular infiltrations and no meningitis could be seen. There was a slight diffuse parenchymatous infiltration with lymphocytes. Satellitism of the neuron was present, both in the anterior and the posterior horns. There were well-marked lesions in the lateral horns: the protoplasm was markedly oxyphilic and the nuclei of the cells were eccentric. Sometimes the satellite cells penetrated the protoplasm of the degenerated neurons and constituted almost true neuronophagia. Certain small nerve-cells of the anterior horn showed neuronophagia. Intranuclear corpuscles were rare. Interstitial infiltrations and 'cuffings' were seen in the posterior nerveroots (Fig. 34).

In the spinal ganglia the lesions were of a similar nature to those encountered in the upper regions of the cord, but were more intense (Fig. 36). Jeuronophagia was a constant feature. The nuclei of cells containing intranuclear corpuscles of the Joest-Degen type showed a rarefication of the karyoplasm, but no other inorphological changes were present in such cells (Pl. III, Fig. 5).

Sacro-caudal Region. In the large nerve fasciculi rich infiltration with mononuclear cells could be seen, together with marked 'cuffing' round the ressels (Fig. 33).

In the posterior roots of the nerves the interstitial infiltration and 'cuffing' round the vessels was rich.

The spinal ganglia showed similar lesions to those recorded in the lumbar region. The capsules of such ganglia were unaffected, and the lesions were marked in the periphery of the ganglion. In the nerves, after their exit from the ganglion, lesions similar to those seen in the nerve-roots were found. Massive infiltration with mononuclear cells was seen between the fasciculi of the nerves (epineurium), in the connective tissue around the nerve (perineurium), and even in the endoneurium. 'Cuffing' of the vessels was also seen.

(e) Sciatic Nerce. A study of transverse sections from the sciatic nerve after its exit from the greater sciatic foramen showed that there was a diffuse infiltration between the nerve fasciculi; this was 
generally more pronomnced in the interior of the fasciculi. In the thickness of the nerve an intense perivascular infiltration was seen (Figs. 38 and 39). Often the connective tissue of the sheath was unchanged, while intense infiltrative lesions were seen in the thickness of the nerve.

Examination of longitudinal sections made from the sciatic nerve half-way between the greater sciatic foramen and the popliteal region showed that interstitial infiltration with mononuclears existed along with massive perivascular 'cuffing', while the nerve-sheath itself appeared perfectly normal.

(f) Brachial Nerre. The alterations seen in this nerve were analogous to those described in the sciatic nerve; even in the lower third of the fore limb intense lesions were found (Fig. 37).

The infiltrative lesions of the nerve-roots and peripheral parts of the nerves, as well as the alterations in the paravertebral ganglia, show that in the monkey, as in the rabbit infected intracerebrally with the virus, the infective agent travels from the central nervous system to the periphery along the nerves, producing the lesions described above, which constitute a ganglio-radiculatis and deseending peripheral interstitial neuritis.

\section{(2) Summary.}

In the brain there existed a mild meningitis with perivascular infiltrations and diffuse parencliymatous infiltrations, which sometimes formed actual nodules; massive perivascular infiltration was also seen in the parenchyma; there was degeneration of nerve-cells and satellitism. Intranuclear corpuscles of the type described by Joest and Degen were more easily found and more numerous than in the rabbit.

In the cerebellum there was found a slight meningeal reaction with perivascular 'cuffing', satellitism of the cells of Purkinje in certain areas, and rare oxyplitic corpuscles (Joest-Degen type) in the nuclei were recorded.

In the spinal cord no meningitis was recorded and there was in absence of 'cuffing' in the vessels of the coverings of the cord. In the posterior horn, a diffuse infiltration was observed, this being more marked in the lumbar region. In this region of the cord also al similir infiltration was seen in the anterior and lateral horns. In the anterior horns degeneration in the nerve-cells was recorded, and sometimes upuronophagia.

In the peripheral nerrous system an inliltrative rudiculatis existed.

The spinal ganglia were intensely affected, showing lesions both infiltrative and degenerative; neuronophagia was a common feuture.

A peripheral nenritis (sciatic and brachial nerves) was present, consisting of interstitial and perivascular infiltration.

The topography of the lesions as a whole shows that the virus introduced into the brain produces lesions locally, spreads to tho rest of the eentral nervous system, and finally travels down the periplural nerves. The cells in the lesions are nhost exchsively mononuclears. 


\section{IMMUNITY}

All authors agree that in the horse an attack of enzootic encephalomyehitis contracted spontaneously does not render this animal immune to a second attack; with regard to the disease in cattle and sheep, no precise records are available as to this point. The rabbit appears to behave differently. Zwick (1926) and his collaborators observed that in one case a rabbit which had been infected experimentally and had shown symptoms typical of the disease ultimately recovered and resisted a second intracerebral inoculation. The same authors succeeded, altbough not constantly, in producing a solid immunity by repeated inoculation of virus either subcutaneously or intravenously. They showed likewise that the introduction of a large quantity of virus intraperitoneally may render rabbits refractory to subsequent infection. Ernst and Hahn (1926) have shown that the inoculation of virus intracerebrally into rabbits does not lead to the development of the disease, if, during the period of incubation, such animals receive repeated inoculations of virulent material into the reims.

Zwick and his collaborators (1926), in the few experiments which they record in attempts to demonstrate antibodies in the serum of immunized animals by neutralization of virus in ritro, did not obtain very conclusive results.

In passaging the strains of virus with which we bave been working, viz. a strain originating from horses (Zwick) and a strain originating from sheep (Miessner), we have never found any healthy uninoculated rabbit refractory to infection.

\section{Attempts at Conferring Imaunity to Rabbits by Ixoculatioxs of Nox-attendated Virus.}

\section{A. Intravenous Inoculatian.}

(1) Four rabbits were inoculated intravenously with 1.5 c.cms. of a virulent centrifugalized emulsion, which, when inoculated into the brain of a rabbit, produced the disease and death at the end of 39 days. The rabbits inoculated intravenously did not show any symptoms and gained weight. Between 91 and 206 days later they were inoculated intracerebrally with fresh passage virus. Table $\mathrm{X}$. below shows that a single intravenous inoculation of virulent emulsion does not produce immunity in rabbits.

(2) Another rabbit, No. 69, weight 1,980 gms., received three inoculations of virulent material into the veins.

16.5.27. First intravenous inoculation of 3 c.cms. of centrifugalized emulsion.

21.5.27. Animal normal. Weight $1,780 \mathrm{gms}$.

29.5.27. Animal normal. Weight $1,640 \mathrm{gms}$.

30.5.27. Second intravenous inoculation of 5 c.cms. of virulent emulsion.

8.6.27. Animal normal. Weight $1,600 \mathrm{gms}$.

13.6.27. Third intrarenous inoculation of 1.5 c.cms, of virulent emulsion.

14.6.27. Animal normal. Weight $1,680 \mathrm{gms}$.

22.6.27. Animal normal. Weight $1,670 \mathrm{gms}$. 


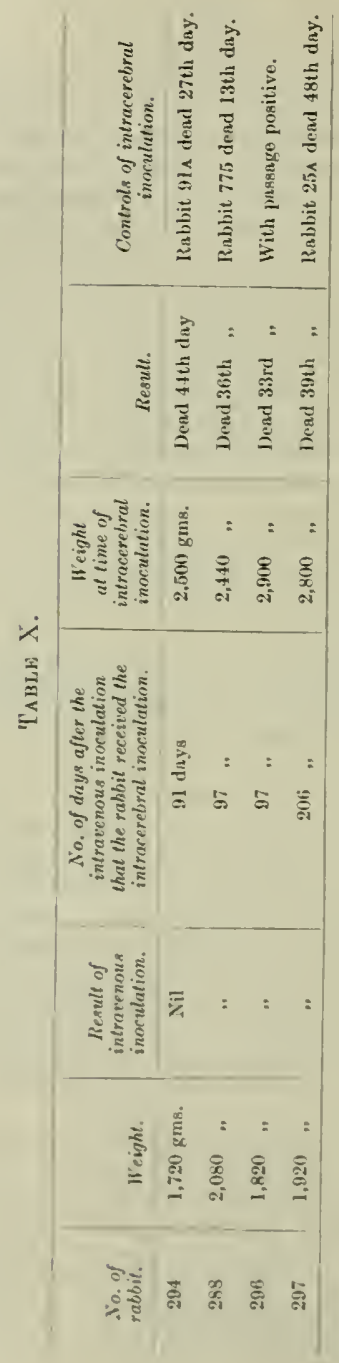


On 23.6.27 the rabbit received a test inoculation of virulent material at the same time as a control. The control died after 34 days with symptoms and lesions characteristic of the disease in the central nervous system. The rabbit prepared by intravenous inoculations behaved as recorded below.

30.6.27. Animal normal. Weight $1,750 \mathrm{gms}$.

7.7.27. Animal normal. Weight $1,950 \mathrm{gms}$.

10.7.27. Animal normal. Weight 1,680 gms.

14.7.27. Commencement of the disease. Weight $1,580 \mathrm{gms}$.

23.7.27. Typical symptoms of the disease. Weight $1,400 \mathrm{gms}$.

26.7.27. Animal died during the day. Weight 1,230 gms.

Microscopic examination of the brain and spinal cord revealed the presence of characteristic lesions.

In this case three intravenous inoculations did not lead to immunity to cerebral infection.

That four intrarenous injections of virulent material may, however, produce a solid immunity is shown by the experiment recorded on p. 75 , Rabbit 67 .

That the intracerebral inoculation of a filtrate (Mandler filter) of virulent emulsion does not lead to the development of immunity may be concluded from the experiments mentioned on p. 13.

The effect of introducing a thick emulsion of virulent brain into the trachea of rabbits was tested, but it did not produce the disease nor immunity in animals so treated. $0.5 \mathrm{c.cm}$. of a virulent emulsion of brain was introduced into the trachea of three animals. As they did not present any morbid symptoms for 174 days they were inoculated intracerebrally with a virulent emulsion. They all died from enzootic encephalo-myelitis after 37,27 , and 40 days respectively. (See p. 33.)

Rabbits which survive corneal or intratesticular moculations of virulent material may become refractory to the disease as tested sub. sequently by intracerebral inoculation.

\section{B. Corneal Inoculation.}

The experiment recorded on p. 31 (Rabbit 81 s) shows that infection by the corneal route can iminumize the rabbit against a subsequent inoculation by the cerebral route.

\section{Intratesticular Inoculation.}

Some measure of immunity may also follow intratesticular inoculation. Two rabbits (273 and 289$)$ were inoculated into the right testicle with $1 \mathrm{c.cm}$. of a virulent cerebral emulsion. One of these rabbits, No. 289, died after 105 days. Typical lesions were found in sections of the various parts of the central nerrous system, and passage of its brain to a fresh rabbit gave a positive result.

The other rabbit, No. 273, survived, and when inoculated by the 
intracerebral route 112 days later it proved to be immune. The control rabbit inoculated by the intracerebral route died on the 45th day.

\section{IJ. Attenpts at Comferrixg Inaunity to Rabbits by Ixocelation of Attexuated Vires.}

\section{A. Virus Inactivated by Ether.}

Roux ${ }^{2}$ sbowed the attenuating action of ether on the rirus of rabies. Later Remlinger (1919) used an ether-treated virus subcutaneously to produce an immunity in rabbits to intracerebral inoculation with fixed rirus. Alrisatos (1922) and Hempt (1925) used ether-treated rirus as a means of raccinating man against rabies.

Marie and Mutermilch (1927) have shown that one can immunize rabbits against rabies by inoculating intrathecally virus treated with ether. We bave tried to immunize rabbits against the virus of encephalo-myelitis, employing a similar technique, with the difference that the virus treated with ether was inoculated into the brain; the proof of the avirulence of the virus treated with ether and the technique employed has been described on p. 22.

The results obtained are given below.

Two rabbits, $220 \mathrm{~A}$ and $217 \mathrm{~A}$, weighing 2,450 and $1,950 \mathrm{gms}$. respectively, received two intracerebral inoculations of $0.5 \mathrm{c.cm}$. of ether-treated virus at an interval of 5 days. Twenty-one days after the last inoculation they were inoculated intracerebrally along with a control rabbit, $14 \mathrm{~A}$, with fresh rirns. Rabbit $217 \mathrm{~A}$ died on the 42nd clay, Rabbit $220 \mathrm{~A}$ on the 17 th day, and control Rabbit $14 \mathrm{~A}$ on the 30 th day after inoculation, and typical microscopic lesions were found in the central nerrous system of all three.

Thus two successive intracerebral inoculations into rabbits of virus treated with ether did not produce immunity to subsequent intracerebral inoculation.

\section{B. Virus killed by Chloroform.}

The proof that rirus treated with chloroform is inactivated has already been given on p. 21. In the experiment about to be described, rabbits were twice inoculated intrace cebrally with virus treated with chlornform, the interval between the inoculations being 5 days. The' animals were tested 3 weeks after the second inoculation, and since the experiments were made at the same time as the experiments with cther-trated virus, the eontrol Rabbit 14A served for lotls.

'Tlu" rabbits prepared with virus treated with chloroform sucembed

\footnotetext{
1 The exprimenls in attempls lo immunize wilh virus Ireated with ether, chloro. form, or formalin recorded are preliminary and for orimlation; it is possible that modifieations in technique might change the remults eriginally whined. There are at present under experiment other series of animala, and the results oluained in these

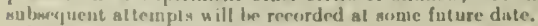

- Roux's unpuldialual obervations.
} 
to a subsequent intracerebral infection after 37 and 42 days respectively. Cultures made from these brains were negative, but lesions characteristic of infection with Borna disease were found on microscopic examination of sections of brain, cord, and spinal ganglia.

\section{Virus treated with Formol.}

On p. 22 it was shown that virus treated witl $0 \cdot 2$ per cent. formalin for 18 hours at room temperature failed to infect rabbits by the intracerebral route.

The vaccine was prepared the day before use by subjecting fresh virulent brain material to the action of formalin in this concentration. A batch of ten rabbits was prepared by subeutaneous inoculation of this vaccine: the results of the experiment are recorded in Table XI. The results obtained in this experiment were not very satisfactory. Of the ten rabbits prepared by inoculation of formolized virus two died accidentally, five died following upon infection with the test dose given intracerebrally, aud three proved to be immune to the test dose given intracerebrally.

\section{Virus Inactivated by Ultra-violet Light.}

An experiment on this subject is recorded on p. 20 in which a rabbit which survived after having received an inoculation of virus exposed for 5 minutes to the action of rays emitted by the mercury are proved to be still susceptible to infection by the intracerebral inoculation of virulent material.

\section{Search for Virucidal ANtibodies in the Serum of ImMunized ANimals.}

The serum of the immune rabbit. $223 \mathrm{~A}$ (see p. 75 ), was taken and mixed with equal parts of a centrifugalized virulent cerebral emulsion; at the same time two further mixtures of the same cerebral emulsion were made, one with equal parts of normal rabbit serum and the other with physiological saline. The three mixtures were kept for 2 hours at $37^{\circ} \mathrm{C}$. and were subsequently inoculated intracerebrally into rabbits.

The results were: (1) the rabbit inoculated with the mixture of virus and immune serum died on the 14th day after inoculation; its brain passaged to a fresh rabit killed in 35 days; the lesions found in sections of the brain of both of these rabbits were those of experimental Borna disease.

(2) The control rabbits inoculated with the mixture of normal rabbit serum and virus died 39 and 34 days respectively after inoculation of Borna Disease, the lesions found on microscopical examination of sections of the nervous system being typical.

(3) The rabbits inoculated with the mixture of virus and physiological saline also succumbed to the inoculation. 


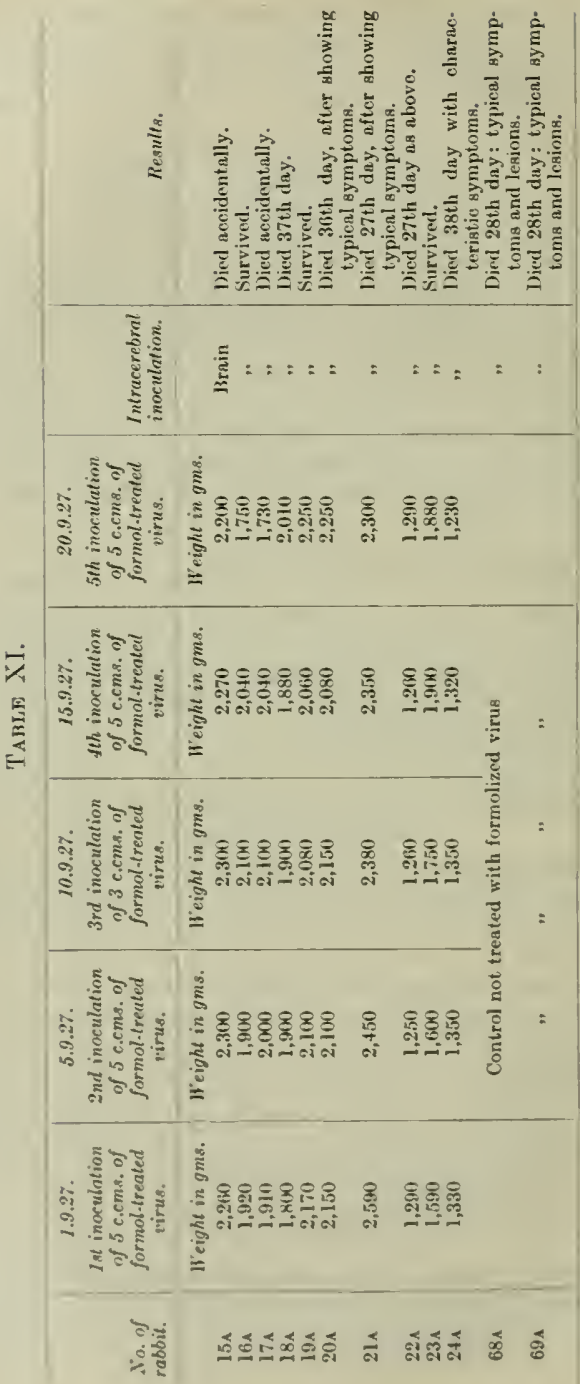




\section{Experiments on Cross Immunity between the Strain of Equine and that of Ovine Origin.}

Our experiments have been carried out with two strains of enzootic encephalo-myehitis, the one originating from the horse (Zwick's strain), and the other from the sheep (Miessner's strain).

Experiment 1. Rabbit 223A. Weight 2,280 gms. A diluted emulsion of virulent brain (Zwick strain) which had been pulped and preserved in glycerine at room temperature for several weeks was inoculated into the brain on 22.10.26. The animal lost weight slightly, developed paresis of the hind quarters about the 20th day after the infection, but subsequently recovered, and on $15.12 .26,54$ days after the inoculation, it appeared perfectly normal and had a weight of $2,400 \mathrm{gms}$. On this date it was inoculated intracerebrally with fresh passage virus (Zwick strain) and survived, while the control rabbit (Rabbit 68A, weighing $1,150 \mathrm{gms}$.) inoculated by the same route fell ill on the $20 \mathrm{th}$ day following upon infection, and died on the 25th day. Characteristic lesions were found throughout the central nervous system on microscopic examination.

Rabbit 223A was therefore immune against infection with the strain of equine origin. On the 12.5 .27 (i.e. 202 days after the first inoculation, and 148 days after the second inoculation with the equine strain, it was inoculated intracerebrally with the strain of ovine origin. At the same time a control rabbit was similarly inoculated. Rabbit $223 \mathrm{~A}$ continued in health, and gained in weight. The control showed symptoms of Borna disease 20 days after the inoculation, and died 27 days after the injection. The usual characteristic lesions were found in sections of the central nervous system of this control rabbit, and a portion of the brain infected another rabbit.

Experiment 2. The fact that repeated inoculations of fresh virus into the veins of rabbits may immunize them against subsequent intracerebral inoculation has already been referred to (see p. 71). We prepared rabbits by vaccinating in this way with a virus of ovine origin. ${ }^{1}$ A fresh virulent emulsion of brain was centrifugalized for 5 minutes. The supernatant fluid was carefully pipetted off and inoculated in the marginal vein of the ear of rabbits, care being taken that the injection was earried out very slowly.

\section{Rabbit 67. Weight 1,580 gms.}

12.5.27. First injection of 2 c.cms. of a virulent centrifugalized emulsion into the vein.

16.5.27. Weight 1,600 gms. Second injection of 3 c.cms. of a virulent centrifugalized emulsion into the vein.

21.5.27. Weight 1,680 gms. Animal normal.

30.5.27. Weight 1,700 gms. Weight normal.

5.6.27. Weight 1,800 gms. Animal normal.

7.6.27. Third injection of $5 \mathrm{c.cms}$. of a virulent centrifugalized emulsion into the vein.

1 Several animals were prepared in the same way, but we give below the protocol of the rabbit which served for an experiment of cross immunity between the equine and ovine strain. 
8.6.2\%. Weight 1,690 gms. Animal normal.

13.6.27. Weight $1,820 \mathrm{gms}$. Fourth injection of $3 \mathrm{c.cms}$. of a virulent centrifugalized emulsion into the rein.

22.6.27. Weight 1,870 gms. Animal normal.

On 23.6.67 the animal, together with a control rabbit, was inoculated intracerebrally with an emulsion of fresh virus of equine origin.

Rabbit 67. Weight 1,870 gms.

30.6.27. Animal normal. Weight $1,980 \mathrm{gms}$.

\begin{tabular}{|c|c|c|c|}
\hline 7.7 .27 & ", & ", & 2,050 \\
\hline 14.7 .27 & ," & ," & 2,200 \\
\hline 20.7 .27 & ," & , & 2,150 \\
\hline 25.7 .27 . & " & " & 2,100 \\
\hline 28.7 .27$. & .. & ,. & 2,000 \\
\hline 15.8.27. & ", & , & 2,100 \\
\hline 29.8.27. & , & . & 2,150 \\
\hline
\end{tabular}

Control.

Rabbit 17\$B. Weight 1,7\%0 gms.

30.6.27. Normal. Weight $1,820 \mathrm{gms}$.

7.7.2\%. " " 1,850,

14.7.27. " " " $1,800 "$,

18.7.27. Commencement of the disease. Weight $1,650 \mathrm{gms}$.

20.7.27. Typical symptoms of the disease. Weight $1,540 \mathrm{gms}$.

25.7.27. Severely ill. Weight 1,300 gms.

26.7.27. Found dead 33rd day after inoculation.

Microscopical examination of sections of the central nerrous system-eharacteristic lesions.

This experiment shows that the virus of orine origin inmunizes against that of equine origin.

Experiment 3. A rabbit (81s) which had resisted inoculation with virulent virus of orine origin, by scarification of the cornea, was inoculated intracerebrally 110 days later with fresh rablit passige virus of equine origin. At the same time a control rabbit $(25 \mathrm{~A})$ was inoculated intracerebrally with the same fresh passage rirus. Rabbit 81 s remained well, while the control, $25 \mathrm{~A}$, showed typical symptoms of Borna disease 32 days after inoeulation, and died on the 45 th day. In this case also the virus of ovine origin immunized Rabbit $81 \mathrm{~s}$ against the pathogenic action of the virus of equine origin introdueed into the lirain.

Conclusion. From the above experiments the following conclusions can be drawn:

(1) Rabbits which have become resistant to the virus of enzootie encephalo-myelitis of equine origin prove also to be refractory to infection $b y$ intracerubral inoculation of the virus of orine origin; the converse is also true.

(2) Rabbits which have become imnunized agaiust mzootic "neephalo-myrlitis lirep this acquired immmity for ut least 148 days. If the immunity is reinforeed by repeated inveulations it may linst ut least 2 (ii3 diys. 
V. Experiments on Cross Immunity between the Virus of Exzootic Excephalo-myelitis axd other Viruses of the Filter-passing Group.

\section{A. Herpes. ${ }^{1}$}

On the basis of the following experiment we arrived at the conclusion published as a preliminary note in the British Journal of Experimental Pathology (1927) that rabbits immunized against the virus of herpes are still susceptible to infection with the virus of Borna disease.

Four large rabbits, $111_{\mathrm{A}}, 183 \mathrm{~A}, 185_{\mathrm{A}}$, and $18 \mathrm{~A}_{\mathrm{A}}$ were immunized against herpes. On 7.6.27 their immunity was tested by the intracerebral inoculation of fresh herpetic virus; they resisted such infection, while the control rabbit, No. $148_{A}$, infected by the same route, died on the 6 th day. Sixteen days later the four surviving rabbits were inoculated intracerebrally with the virus of encephalomyelitis, together with a control rabbit, No. 1S2A. All the rabbits showed symptoms typical of experimental Borna disease and died; the results are recorded below.

\begin{tabular}{|c|c|c|c|c|c|c|c|}
\hline No. of rabbit. & \multicolumn{5}{|c|}{ Date of death. } & $\begin{array}{c}\text { Culture of } \\
\text { brain. }\end{array}$ & Lesions. \\
\hline 1114 & \multicolumn{5}{|c|}{ Died on the 40 th day after inoculation } & Negative & Typical. \\
\hline $183 \mathrm{~A}$ &,$\quad$, & 32 nd & " & ", & ," & ". & , \\
\hline $185 \bar{A}$ & $"$ & 31 st & $"$ & $"$ & $"$ & , & " \\
\hline $187 \mathrm{~A}$ & $"$ & 32 nd & ", & ", & , & ", & .. \\
\hline $\begin{array}{l}\text { Control Rabbit } \\
182 \mathrm{~A}\end{array}$ & ", & 40th & $"$ & $"$ & " & $"$ & " \\
\hline
\end{tabular}

Conclusion. No cross immunity exists between herpes and enzootic encephalo-myelit is.

\section{B. Rabies. ${ }^{2}$}

On 9.9.27 two rabbits proved to have been immunized against the virus of Borna disease (Rabbit 223A, see p. 75, and Rabbit 67, see p. 75 ), together with, as a control, Rabbit $41 \mathrm{~A}$, were inoculated intracerebrally with a 'street' virus of rabies. The two rabbits, 223A and 67, which were immune to Borna disease, became paralysed on the 8th day after the inoculation with rabies and died on the 10th day; cultures from the brain were negative. Negri bodies were found in sections of the Ammon's horn of both rabbits. The control rabbit became paralysed after 8 days and died on the 12th day; Negri bodies were found in sections of the Ammon's horn.

Conclusion. No cross immunity exists between rabies and enzootic encephalo-myelitis.

\footnotetext{
1 We thank Dr. Perdrau, of the National Institute for Medical Research, for kindly putting a strain of this virus at our disposal.

3 We thank Dr. Mlanouelian of the Pasteur Institute, Paris, for his kindness in putting this strain at our disposal.
} 


\section{Polio-myelitis. ${ }^{1}$}

In the experiments with this virus two strains have been used, (1) a strain of low virulence kindly furmshed by Professor MacIntosh, (2) a rery virulent strain kindly provided by Professor Petit. This latter strain, which has been utilized by us in another series of experiments, killed monkeys by intracerebral inoculation as indicated below:

\section{TABLE XIII.}

Monkey (Macacus rhesus) No. 5. Died the 9 th day after inoculation.

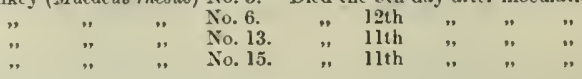

The lesions produced by this strain of polio-myelitis in the central nervous system of monkeys were very intense, neuronophagia was frequently found in the anterior horns of the spinal cord as well as in the paravertebral ganglia.

The virus of polio-myelitis taken from monkeys infected experimentally is generally considered as non-pathogenic for the rabbit.

In a first series of experiments we gave repeated intracerebral inoculations of polio-myelitis to young rabbits; some time afterwards the rabbits so prepared were infected by the same route with the virus of enzootic encephalo-myelitis.

Table XIV gives the results of this experiment.

Thus the four rabbits having received three successive intracerebral inoculations with the virus of polio-myelitis and one rabbit which received no such inoculation, proved to be still susceptible to infection with the virus of Borna disease.

The conclusion that absolutely no cross immunity exists between the virus of polio-myelitis and that of Borna disease, however, is weakened by the following experinient on a monkey.

Monkey M. 2 (Macacus rhesus), which had apparently almost completely recovered from an intracerebral inoculation of the virus of Borma disease, after having shown the inorbil symptoms recorded on p. 36, was inoculated into the brain with i passige virus of poliomyelitis (strain Petit). At the same time two controls of a comparable size and the same species were sinilarly inoculated. The subsequent history of the two controls was as follows:

\section{13 (Macacus rhesus)}

5.10.27. Inoculated intracerebrally with the virus of polio-myelitis.

10.10.27. Normal.

11.10.27. Paralysed, found procumbent.

12.10.27.

1 Our thanks are due to M. Ie I'rof. A. I'etit, of the Pasteur Institule, and I'rof. Mime. Intosh of the IBland Sutton Institute for supplying un with strains of polio-ntychtis viruk.

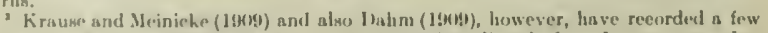
('x p.riments giving prositive results, uxing virus takest directly Irom lsumas euses, but the general opinion held to-day is that the virus of polio-myelitis is not pathogenie for rabints. 


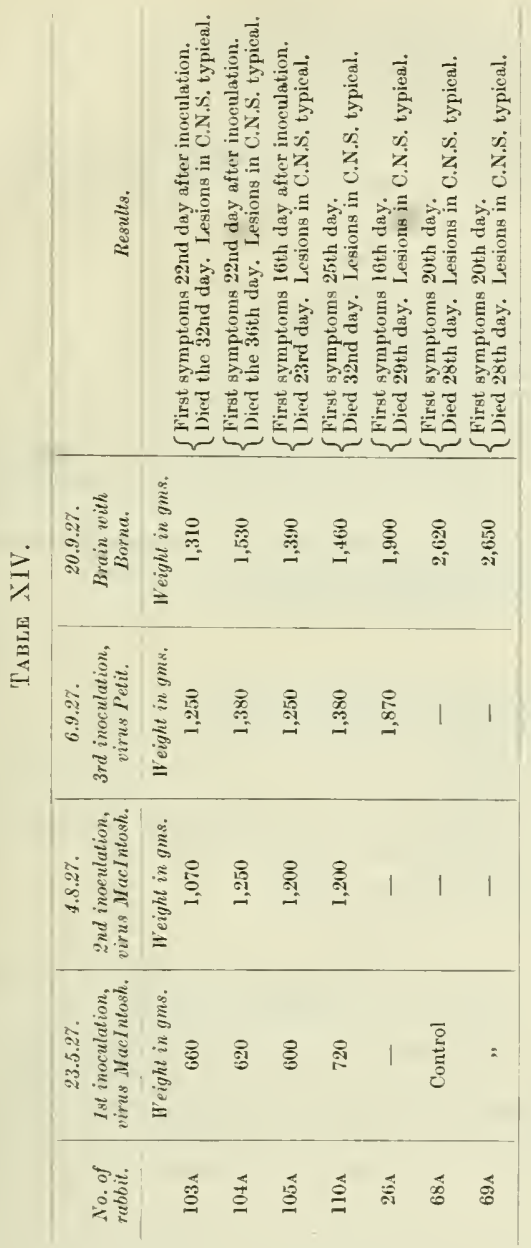


13.10.2\%. Paralysed, found procumbent.

14.10 .27 .

15.10 .27 .

16.10.27. Found dead, 11th days after inoculation.

Cultures of brain. Negative.

Sections. Lesions typicat of polio-myelitis.

\section{15 (Macacus rhesus)}

5.10.27. Inoculated intracerebrally with the virus of polio-myelitis.

10.10.27. Normal.

11.10 .27 .

12.10 .27 .

13.10 .27 .

14.10.27. Paralysis of the left arm.

15.10.27. Found procumbent and paralysed.

16.10.27. Found dead 11 th day.

Cultures of brain. Negative.

Sections. Lesions typical of polio-myelitis.

Monkey M. 2 (Macacus rhesus), which had survived the inoculation with Borna disease, when inoculated with polio-myelitis, bchaved as follows:

5.10.27. Inoculated into the brain with the virus of polio-myelitis 130 days after the inoculation with the virus of Borna disease.

10.10.27. No added symptoms up to this date.

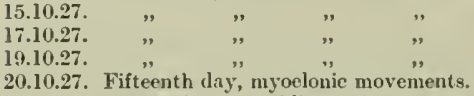

21.10.27. Epileptiform trembling movements.

22.10.2\%. Slight paregis of the lind quarters.

23.10.27. Paresis more marked.

24.10.27. Total paralysis of the hind quarters and partial paralysis of the fore. limbs.

25.10.27. Could make movoments with the head, but the total paralysis of the arms and legs prevented it from getting up.

26.10.27. Same condition.

27.10.27. Same condition, but still feeling.

28.10 .27 .

29.10.27. Animal in a comatose state".

30.10.27. " " "

31.10.27. Died 26 days after the inoculation with the virus of polio-myelitis and 156 day's after the infection with Borna.

Whe have drawn attention in the course: of this monograph to the resemblance between the symptomatology and histological pieture in polio-myelitis in the monkey and experimental enzootic enecphaloinyelitis in the same speeies. The differmens between them are the longur period of ineubation and the slower "rolution and less intensity of the lesions in the nervous systrm in the latter thisense.

Nonkey VI. 2 died ufter a lapso of time much lomger than the average for animats inoculated with polion-myelitis, the strain used generally lilling the species of animal in from 9 to 11 days. We had, therefore, to setermine whether it died from polio-myelitis or from a persisting infection of borna disease. On an anatomo-pat hological 
study of the various parts of the nervous system of this monkey the lesions of experimental enzootic encephalo-myelitis were found, including the corpuscles of Joest-Degen. The general aspect of the alterations in the lumbar region of the spinal cord indicated that these were produced by the virus of Borna disease and not by the virus of poliomyelitis. This conclusion received further support when emulsions from rarious parts of the nervous system were passaged to fresh animals. The results of these inoculations were as follows:

(1) Rabbit $460 \mathrm{~A}$, weighing $2,320 \mathrm{gms}$, and Rabbit $462 \mathrm{~A}$, weighing $1,740 \mathrm{gms}$., were inoculated intracerebrally with an emulsion of the brain of Monkey MI. 2. The former died on the 37 th day and the latter on the 38th day after infection, and lesions characteristic of experimental Borna disease were found in sections of the various parts of the nervous system of both animals. A passage was made with the brain of Rabbit $462 \mathrm{~A}$ to a fresh Rabbit $405_{\mathrm{A}}$, weighing $1,330 \mathrm{gms}$. Rabbit $405 \mathrm{~A}$ succumbed on the 42 nd day of Borna disease.

(2) Rabbit $464 \mathrm{~A}$, weighing 1,960 gms., Rabbit $458 \mathrm{~A}$, weighing 1,760 gms., and Rabbit $459_{\mathrm{A}}$ weighing $2,500 \mathrm{gms}$., were inoculated intracerebrally with an emulsion of the cervical region of the spinal cord of Monkey M. 2. Pabbit $464 \mathrm{~A}$ died on the 34 th day, $458 \mathrm{~A}$ on the 30 th day, and $459_{\mathrm{A}}$ on the 30 th day after inoculation, and lesions typical of Borna disease were found in sections of the nervous system of all three. A passage was made with the brain of Rabbit $458 \mathrm{~A}$ to a fresb rabbit, $414 \mathrm{~A}$, which died on the $33 \mathrm{rd}$ day of experimental enzootic encephalo-myelitis.

(3) Rabbit 454A, weighing $1,960 \mathrm{gms}$., Rabbit 455A, weighing 1,960 gms., and Rabbit $463 \mathrm{~s}$, weighing 2,300 gms., were inoculated intracerebrally with an emulsion of the lumbar corl of Monkey M. 2. The first died on the 40th day, the second on the 35th day, and the third on the 34 th day of experimental Borna disease. Rabbit $415 \mathrm{~A}$, weighing 1,850 gms., when inoculated intracerebrally with an emulsion of the brain of Rabbit $463 \mathrm{~A}$, died of Borna disease on the 30 th day.

The results of these rabbit inoculations proved that the virus of Borna disease still existed in the brain and spinal cord of Monkey M. 2.

Monkey M. 20 (Macacus rhesus) was inoculated with an emulsion of a portion of the brain and the cervical cord of Monkey M. 2. It remained healthy for a period of 60 days, when the commencement of paresis of the hind quarters was first observed. Paresis later became accentuated and reached the fore limbs. The animal died on the $68 \mathrm{th}$ day after inoculation, and the lesions of experimental enzootic encephalo-myelitis were found in sections of the central nervous system. Rabbits $340 \mathrm{~A}$ and $341 \mathrm{~A}$ were inoculated intracerebrally with an emulsion of the brain of Monkey M. 20, and both died of experimental Borna disease.

In résumé, the activity of virus of Borna disease which had become dormant in the central nervous system of Monkey M. 21, 130 days after the inoculation, as indicated by the clinical picture, was revived by the introduction of the virus of polio-myelitis by the intracerebral route. As a result of the second infection the monkey died and we 
demonstrated the presence of the virus of Borna disease in its brain and spinal cord, but the virus of polio-myelitis had been destroyed.

Without wishing to attach too much importance to this single experiment, we are forced to conclude that the monkey which survived for 130 days the infection with Borna disease showed an exceptional resistance of an anomalous character to the virus of polio-myelitis. This resistance might be the result of a certain degree of immunity conferred by the first infection. On the other hand, it might be explained in another way. The experiments by Gildemeister and Herzberg (1925) indicate that guinea-pigs which showed lesions on the pads of the metatarsus as a result of infection with the virus of vaccinia develop a certain local resistance to infection with herpetic virus inoculated by the same route. The authors conclude that there is a certain degree of immunity conferred by one virus against infection with the other. In a similar way, certain rabbits, which after recorering from vaccinal keratitis, when inoculated some time later on the same comea with the virus of herpetic encephalitis, sometimes resist the second infection.

IVe do not consider in these circumstances that an immunity results in the proper sense of the word, but rather a local mobilization of the elements of defence provoked by the first virus inoculated, thus conferring on the tissue a certain degree of resistance of a nonspecific character which does not exist normally.

$\mathrm{TH}^{*} \mathrm{intend}$ to repeat our experiment. In addition, monkeys are being immunized against polio-myelitis which will be inoculated later with the virus of Borna disease.

\section{SU'MAAY.}

A solid immunity can occasionally be obtained against 13orua disease in the rabbit by inoculating suitably attenuated virus into the brain.

Multiple intrarenous injections, infection by comeal scarification, or intratesticular inoculation with fresh virus, can also produce in. munity.

We have not succeeded in producing immunity by inoculating virus killed by chloroform, ether, or ultra-violet light intracerebrally into rabbits.

Multiple inoculations subcutaneously of large quantities of formolized virus leads to immunity in a limited number of animals.

Rabbits immunized against an equine strain of the virus of Borna disease were resistant to intracerebral infection with an ovine strain and vice versa.

To cross inmunity was olitained between Borna disease and herpes or rabies. Cross immunity letween Borna disease and polio-nyelitis was not observed when rabbits were the subject of experiment, but in an experiment carried out on a monkey the result suggested that some resistance to the virus of polio-myentitis may he produced by a previous at tacli of experimental borma disease. 


\section{CHEMOTHERAPY}

Various medicaments, calomel, mercuric chloride, salvarsan, atoxyl, have been tried in the treatment of enzootic encephalomyelitis. The greatest success as regards the treatment by drugs has been claimed for the administration of urotropine (hexamethylenetetramine). Moussu and Marchand (1926) obtained remarkably good results in the treatment of the disease in horses and cattle by inoculation of urotropine intravenously. According to these authors, when 15 to $20 \mathrm{gms}$. is administered on the appearance of the first symptoms, the mortahity in epizootics may be lowered from 80 or 90 per cent. to 25 per cent. In Germany Ostertag (1924) has generalized the use of urotropine on a large scale in the treatment of enzootic encephalo-myelitis. H. Bohn (1927) inoculated 30 gms. per day for 4 to 5 days intravenously into affected horses with good results. Trepel (1926) advocates the use of a total of $100 \mathrm{gms}$. during the course of a few days. Grimm (1927) obtained a smaller number of recoveries than the authors cited above. All authors appear to be agreed as to the beneficial action of the drug in Borna disease of the horse.

We have carried out experiments to see whether urotropine was as efficacious in treating the disease in the rabbit as in the horse. We commenced by determining the maximum intravenous dose supported by a rabbit. This appeared to be about $0 \cdot 5$ gms. per kgin., a dose which can be repeated at least eight times at 4 to 5 days' interval. Subsequently the experiment recorded in Table $\mathrm{XV}$ was carried out.

Summary. The dose of urotropine we gave to the rabbit was equivalent, weight for weight, to $100-200$ gms. for the horse and to a total amount of 600 gms., yet we were not able to demonstrate any prophylactic or curative action. 


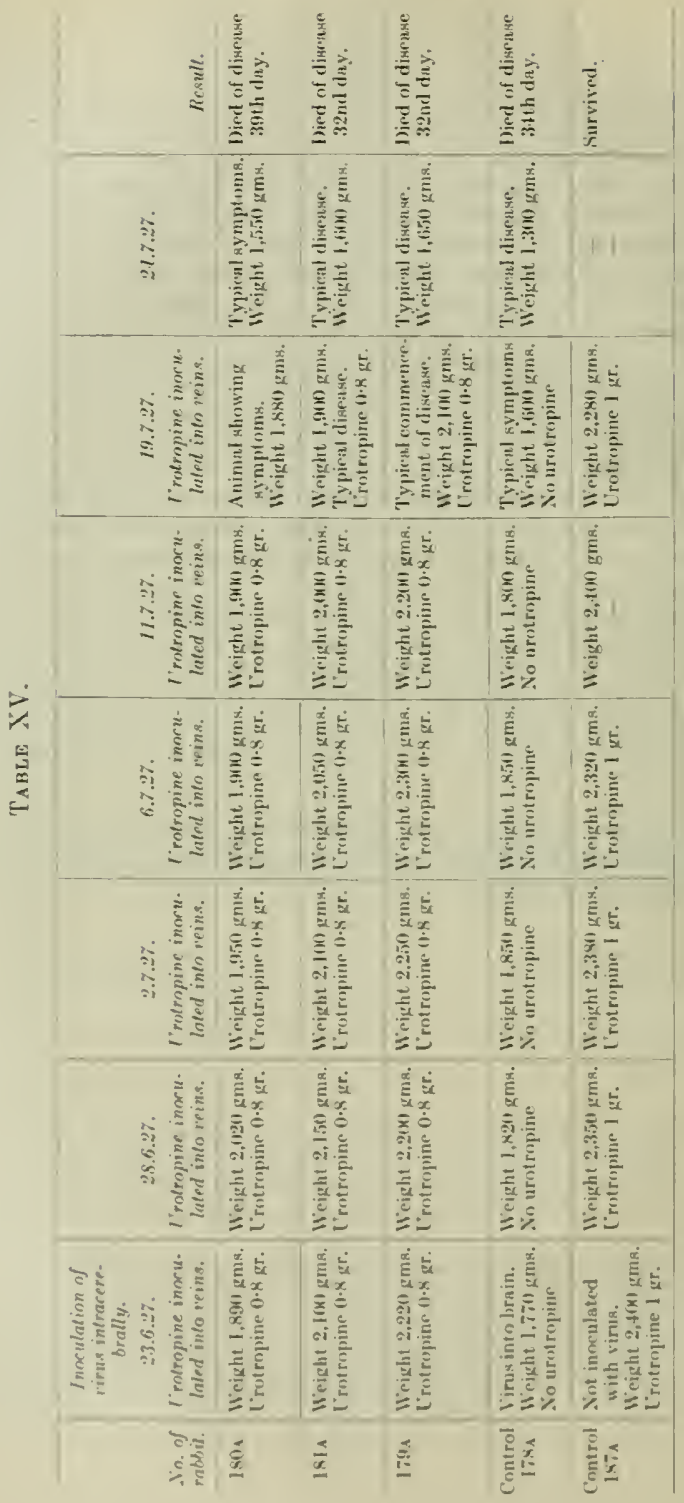




\section{REFERENCES}

Albertin, A. (1926).-Thesis. Lyons.

Alvisatos, G. P. (1922). Deutsche med. Wehnschr., 48, 295.

Batdoin, A., and Schaeffer, H. (1926). Paris Jéd., 16, 249.

BECK, A. (1925). Ztschr.f. Infehtionsk. d. Haustiere, 28, 99.

Веск, A., and Fвон вӧsе (1926). Arrhiv f. wissensch. $u$. pralt. Tierh., 54, 84.

BERIEL, L. (1926).-Lyon méd., 1, 667.

Beriel, L., and Devic, A. (1926). Lyon méd., 1, 671.

Bows, H. (1927). Deutsche tierürztl. Wchnschr., 35, 584.

CaUsel, 11. (1924). Rec. méd. vét., 100, 526.

Christiant (1909). Arch.f. wissensch. u. prakt. Tierh., 35, 253.

DАнм (1909). Wünchen. med. Wchnschr., 56, 2553.

David and Dekester (1926). Bull. et mém. Soc. méd. d'hôp. de Paris, 3, S., 50, 75.

DeXler, H. (1900). Zischr. f. Thiermed., 4, 110.

Diosy, K. (1919). Immunity in Health. Oxford Medical Publications.

Dobberstern, J. (1925). Berl. tierärztl. W chnschr., 41, 177.

Eichbaum, Stöhr, and Wink (1865-6). Hitt. d. tierärzt. Prax. in preuss. Staat. Berlin, 135.

Ellinger, R. (1927). Tieräratl. Rdsch., 33, 201.

ERNST, W. (1925). Wünchen, tierärzll. Wchnschr., 76, 477.

ERsst, W., and Hahy, H. (1926). München. tierärztl. Wehnschr., 77, 46.

- (1927). Wünchen. tierärztl. Wchnschr., 78, 55 .

Flexner, S., and Amos, H. L. (1017). J. Exper, Med., 25, 525.

Foerster cited by Marinesco and Draganesco.

Gildemeister, E, and HerzBerf, K. (1925). Deutsche med. Wchrschr., 51, 97.

GLAMSER (1926). Deutsche tierärzll. Wchnschr., 34, 312.

Grimm (1927). Berl. tierärztl. Wchnschr. (1927), 43, 153.

HeAd and CaMpBele (1900). Brain, 23, 353.

HeMPt, A. (1925). Ann. de l'Inst. Pasteur, 39, 632.

HEYDT (1914). Deutsche tierärztl. Wchnschr, 249.

Hutrra and Marek (1922). Spezielle Pathologie u. Therapie d. Haustiere, 6th Ed. Jena.

JoEsT, E. (1921). Ztschr. f. Infektionshr. d. Haustiere, 21, 97. (1926). Klin. Wchnschr., 5, 209.

JoEst, E., and Degen, K. (1909). Ztschr. f. Infektionshr. d. Haustiere, 6, 348. (1911). Ztschr. f. Infektionskr. d. Haustiere, 9, 1. (1911). Deutsche Ztschr. f. Nerzenh., 42, 293.

JoHn E $(1897,1)$. Deutsche Ztschr. $f$. Thiermed., 22, 369. (1897, 2). Ber. u. d. Veterinäru. im Königr. Sachs.

KанLMETER, G. (1927). Acta med. Scandinal., 65, 709.

KrageruD, A., and Gundersox, T. (1921). Norges offisielle statistik., 7, 15.

Kraus, R., Kantor, L., Fischer, H., and Quirooa, R. (1920). Zischr. f. Immunitätsforsch., $30,121$.

Kratse, P., and IIEINicke, E. (1909). Deutsche med. Wchnschr., 35, No. 12.

Lessage, J., and Frisson, M. (1912). Rel. gén. de mérl. vét., 20, 657.

Levadit, C. (1926). L'herpes et le zona. Masson et Cie, Paris.

Levadiri, C., and Nicolac, S. (1923). Ann. d. l'Inst. Pasteur, 37, 1.

- (1922). Compt. rend. Acad. d. sc., 174, 778.

Levaditi, C., Harvier, P., and Nicolat, S. (1921). Compt. rend. Soc. de biol., 84, 524. (1922). Ann, d. l'Inst. Pasteur, 36, 63 and 105.

LонR (1910). Beitr. z. Bakt. d. Gehirmruckenmarksseurhe d. Pferde. Inaug. Diss. (Leipzig). Dresden.

Mavodelian, Y., and Viala, J, (1926). Compt. rond. Acad.d. sc., 183, 1357. (1927). Compt, rend. Acad. d. \&c., 184,630.

Marchand, L., and Moussu, R. (1924). Compt. rend. Acad. d. sc, 178, 149.

Marce, J. (1909). Ann. de méd. vét., 58, 11.

Marie, A., and Mutermilch, S. (1927). Compt. rend. Acal. d. sc., 184, 911.

Marnesco, G., and Draonxesco, S. (1927). Bull. Acad. de méd., 97, 473.

Minssner, H. (1926). Deutsche tierärztl. W'chnschr., 34, 637.

Motssu, R. (1922). Rec. de méd. vét., 98, 261.

-_(1926). Recherches sur certnin affections du syst. nerveux central des animaux domestiques. Thesis, Vigot Frères, Paris.

Mousstr, R., and Marchand, I. (1924). Rec. de méd. vét., 100, 5 ; 65.

Nicolad, S., and Galloway, I. A. (1927). Brit. J. Exper. Path., 8, 336.

Noscк (1908). Ber. u. d. Velerinärw. im Königr. Sachs., p. 41. 
OPPENaziм. H. (1907). Zlechr. f. Infehtionskr. d. Hausticre, 2, 148.

Ostertag (1900). Berl. tieräratl. Wehnachr., 433.

(1906). Berl. tierärall. W"ehnschr., 62:2.

(1924). Berl. tierärall. Wchnschr., 40, 705 .

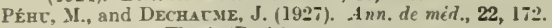

Periot (1921-2). Thesis (Paris).

Petre cited by Marienesco and Draganesco.

Popow (1882), cited by Hutrra and Marek.

Priemer (1925) cited in the thesis of Schmidt. Leipzig (1925).

Prietsch (1896). Ber. u. d Veterinäruc. im Königr. Sachs., p. 126.

Prōger (1896). Ber. u. d. V'eterinäne. int Köōnigr. Sachs., p. 105.

Rattusas, H. (1926). Tierārzll. Rdsch., 32, 841.

Ravisa, A. (1927). Presse méd, 35, 6t6.

ReMLIFier, P. (1919), Compl, rend. Soc. de bial., 82, 52 .

Rосн, М., and BICKEL, G. (1927). Sehureiz. med. Wchnschr., 57, 18.

Roloff (1s68). Mitt. a.d. tieräratl. Prax. in preuss. Staat. Berlin, 135.

SAvigse, A., and LeBLaxc, P. (1897). J. méd. tét. el de zaotech., 1897, 5 \$., 1, 274.

Sсcнunt (1870). Mag. f. d. ges. Tierh., Berlin, 186.

Siedaugrotzky and Schlegel (1896). Arch. $f$. trissenseh. u. prakt. Thierh., 22, 287.

Snoog, A. L. (1923). Med. Clin. North Amer., 7, 1323.

Sifiegl, A. (1922). Ztsehr. f. Infektionskr. d. Haustiere, 23, 147.

TARgowla, J. (1894). Rer. Feurol., 2, 465.

Thomas, A., and Rexpe (1925). Rev. Neurol., 2, 758.

Tromas, H. M. (1S9S). Phila. M. J., 1, 885.

TREPEL (1926). Berl. tieräral. W' chnschr., 42, 881.

Vas Gehtchtes, A., and Nelis, G. (1900). Prese. med., 8, 113.

Viets, H. K. (1927). Arch. Jeurol, and Psychial., 17, 794.

Waldoraxs, J., and PAPE, J. (1921). Berl. tierärzl. W'chnschr., 37, 449.

WaLther (1899). Ber. u. d. Teterinäne, im Königr. Sachs., p. 80.

Wischsikowitch (1889) cited by Hutyra and Marek.

Wohlw mL, F. (192t). Ztschr. f. d. ges. Neurol. u. Psychiat., 89, 171.

Wörz cited by Hutyra and Marek (see above).

Zwick, W. (1925). Berl. tieräratl. I'ehnschr., 41, 453.

- (1926). Seuchenbekampfung, 3,57.

ZWick, W., and SeIFRIED, U. (1924). Berl. tietäratl. Wehnechr., 40, 465.

- (1925). Berl. tierärztl. W chnechr., 41, 129.

ZWICK, W., SEIFRIED, O., and WITTE, J. (1926). Ztschr. $f$ Infektionshy. d. Haustiere, 30,42 . 


\section{DESCRIPTION OF PHOTOGRAPHS AND COLOURED PLATES}

Fic. 1. Photograph of Rabbit No. 275. 29 days after intracerebral infection with the virus of Borna disease, and 3 days before death. The characteristic position of the head and ears is depicted.

FIG. 2. Photograph of Macacus rhesus No. 1. 64 days after inoculation. Paralysis of the hind quarters; paresis of the right arm, the hand not being able to grip any object presented to it.

Fig. 3. Photograph of Hacacus rhesus No. 1. 69 days after inoculation. Characteristic "hunched up' attitude.

Fig. 4. Photograph of Macncus rhesus No. 2. 51 days after the infection by the intracerebral route. Facial paralysis on the left side.

Fig. 5. Photograph of Macacus rhesus No. 2. 67 days after inoculation. 3rd erisis of the disease. Facial paralysis on the right side.

Fig. 6. Photograph of Guinea-pig 95K. 60 days after intracerebral inoculation, and 5 days before death. Paralysis of the hind quarters.

FIG. 7. Photograph of Guinea-pig 1A. 50 days after intracerebral inoculation, and 2 days before death. General paralysis.

Fic. 8. Photograph of Rat No. 14. 63 days after inoculation intracerebrally, and 4 days hefore the death of the animal. At this stage the rat placed on the flank made several useless efforts with the fore-legs to recover its normal position.

Fig. 9. Photograph of the stomach wall of Rabbit 212 which died 44 days after the intracerebral inoculation, showing the haemorrhagic lenticular areas. $\mathrm{L}=$ greater curvature of the stomach; $\mathrm{P}=$ lenticular haemorrhagic areas.

FIG. 10. Microphotograph, $\times 160$. Rabbit 209 dead 71 days after intratesticular inoculation. Neningitis witb mononuclear cells with 'cuffing' around the vessels. $\mathrm{V}=$ lumen of blood-vessel; $\mathrm{C}=$ cerebral cortex; $\mathrm{II}$ - mononuclear leucocyte of inflammatory process.

FIG. 11. Nicrophotograph, $\times 300$. Rabbit $51 \mathrm{~A}$ dead 28 days after intracerebral infection. Perivascular 'cuff' in the cerebral cortex ent longitudinally. $r=$ lumen of blood-ressel; $\mathrm{E}$-endothelium of blood-vessel; $\mathrm{II}=$ mononuclear leucorytes taking part in the infiltrative process.

Fig. 12. Microphotograph, $\times 165$. Rabbit $11 \mathrm{D}$ dead 27 days after intracerebral inoculation. Section showing the aspect of the Cornu 4 mmonis. $\mathrm{F}=$ area of infiltrating lyraphocytes between the nerve-cells; $\mathrm{L}=$ infiltrating lymphocytes; $\mathrm{C}=$ cells containing the corpuscles of Joest-Degen within their nuclei.

FIG. 13. Microphotograph, $\times 800$. Rabbit 25 dead 35 days after cerehral infection. ' ' $y s t$ ' in a nerve-cell of the Ammon's horn. $\mathrm{C}=$ 'cyst'; $\mathrm{N}=$ nucleus; $\mathrm{n}=$ mucleolus.

FIG. 14. Nicrophotograph, $\times 1,00 \%$. Rabbit $80 \mathrm{~A}$ dead 28 days after inoculation intracerebrally. 'Cyst 'in the protoplasm of a nerve-cell of the Ammon's horn. C= 'cyst'; $\mathrm{N}=$ nucleolus.

Fig. 15. Nicrophotograph, $\times 900$. Rabbit 110 dead 27 days after cerehral infection. 'Cyst' in the protoplasm of a nerre-cell of the Cormu Ammonis.

F16. 16. Microphotograph, $\times 1,000$. Rabbit 51 A dead 28 days after inoculation into the brain. 'Cyst' in the protoplasm of a nerve-cell in the Cornu Ammonis.

Fig. 17. Microphotograph, $\times 1,000$. Rabbit No. 22 dead 24 days after cerebral infection. Nerve-cell in medulla oblongata showing neuronophagia. $\mathrm{C}=$ degenerated cytoplasm; $\mathrm{p}=$ polymorphonuclear penetrating neuron; $\mathrm{m}=$ mononuclear cells.

FIG. 18. Microphotograph, $\times 230$ (enlarged two diameters). Rabbit 295 dead 19 days after intracerebral inoculation. Section in the region of the pons showing (d) degenerated nerve-cells, (s) 'satellitism' with commencing neuronophagia, $(\mathrm{n})$ neuronophagia, (l) Jymphocytes in the parenchyna. 
FIG. 19. Microphotograph, $\times 1,000$. Rabbit 278 inoculated intracerebrally and sacrificed 20 days later. Commencing neuronophagia in the anterior horn of the spinal cord in the lumbar region. $\mathrm{X}$-nucleus of nerve-cell: $\mathrm{P}=$ cytoplasm; $\mathrm{N}$ - mononuclear cells.

FIG. 20. Microphotograph, $\times$ bit. Rabbit $4+$ dead 33 days after intracerebral inoculation. Section of the lumbar region of the spinal cord. $S=$ cord; $\mathbf{I}=$ perivaseular 'cuff' in a nerve-trunk; 1 =interstitial nononuclear infiltration; $\mathrm{A}=$ accumulation of mononuclear leucocytes.

Fjg. 21. Microphotograph, $\times$ 66. Rabbit No. 30 dead 36 days after the inoculation given intracerebrally. Spinal ganglion in the lumbar region. $\mathrm{X}$-ganglion nerve-cell in a state of neuronophagia; I formation of a nodule of nononuclear leucocytes which bas formed at the site where a nerve-cell is undergoing neuronophagia; $i$ perivascular infiltration.

Fig. 22. Nicrophotograph, $\times 66$. Rabbit 50. dead 53 days after cerebral inocula. tion. Section of the cord in the lumbar region including a spinal ganglion. I vacuolization in certain ganglion cells; $\mathbf{I}$ interstitial infiltration; $\mathbf{N}$-neurumophagia; $\mathrm{P}$ - perivaseular infiltration.

F1o. 23. Mierophotograph, $\times 1,000$. Rabbit Itit dead 29 days after intracerebral inoculation. Spinal ganglion in the lumbar region. Neuronophagia with the formation of nodules consisting of mononuclear cells. $\mathbb{R}$-remains of a destroyed neuron: $\mathrm{V}=$ vacuole in a nerve-cell; $\mathrm{P}$ - polymorphonuclear: $\mathrm{L}$ - lymphocytes.

Fig. 24. Mierophotograph, $\times 950$. Rabbit $\mathrm{X}$ (), 30 dead 36 days after intracerebra] inoculation. Spinal ganglion in the lumbar region. Jegeneration ol a ganghion cell and commencing neuronophagia. $\mathrm{C}$-degenerated cell which has becotme oxyphilic and is on the way to destruction: $\mathrm{P}$ - polymorphonuclear cells: $\mathrm{L}$ - Iymphocytes; $\mathrm{M}$ mono. nuclears participating in the process of neuronophagia.

Fig. 25. Microphotograph, $\times 1,000$. Rabbit 1 tit dead 29 days after intracerebral inoculation. Spinal ganglion in the thoracic region. $X$-neuronuphagia; (: particle of ehromatin probably originating from a pyknosed polymorphonuclear; II macrophage: $\mathrm{C}=$ cell —ommeneing neuronophagia: L, lymphocytes.

Fio. 26. Microphotograph, $\times$ 800), Rabhit Xo. 30) dead 36 days alter cerebral in. oculation. Spinal ganglion in the lumbar region. M monounclear eells infiltrating; D commencing neuronophagia; $V$ vessel surrounded ly perivascular 'cutf'.

Fio. 27 . Microphotograph, $x 5$. Rabbit 140 A dead 49 days after intracerebral infee. tion with glycerinated virus of passage. Sietion of the terminal part of the spinal coril with roots of the sciatic nerve and corresponding ganglion. M - spinal cord: I? nerveroot; $G=$ spinal ganglion: $S=$ seiatic nerve. In sections cut in this way the lesions in the regions mentioned alove can be seren as a whole.

F16. 28 . Yicrophotugraph, $\times 351$ ). Rabhit 340 A. Longitudiual section of the geiatie nerve near the popliteal region. A perivaseular 'euff' is seen. I' lumten of vesuel. $\mathrm{M}$-infiltrating monunuelear cells; L Iynplucytes in the thickuess of the nerve.

F16. 29. Microphotograph, $\times 150$. Macacus rhesus No. I. Section of the parietal lolse; C-cerebral cortex; al mononuclear meningitis; $V^{\prime}$ - blood-veswel eut hongitulinally with walls infiltrated with mononuclear cells.

Fro. 30. Mierophotopraph, $\times$ 120, Macacus rhesus No. 3. Perivas'ular cufling in the frontal lube of the cerebral curtex. $V$ lumen of vessel; $P$-perivaseular intiltration.

Fio, 31. Microphotograph, $\times 150$. Macacus rhesus $\mathrm{No}$. I. Section ol the parietal lolse of the cerebral cortex. Pнeudo gumma (notule) produced by numonuclear cells, with a small vessel in the (entre (very intense process of perivenseuhar infiltratien). I' blood-vessel; E nodule furmed by monanurlewr colls.

Fis. 32. Microphotngraju, $\times 3$ 3), Maruru rhesus No. 1. Sicotion through taval ganglia. Sumll area of monomucleur exth. $\mathrm{N}$ neuron: I, lympliocytes.

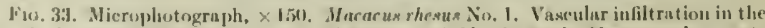

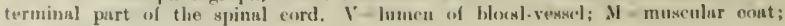
I' infiltrating mononucleor celle.

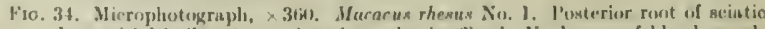

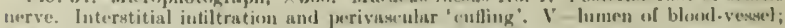

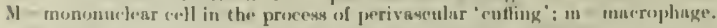

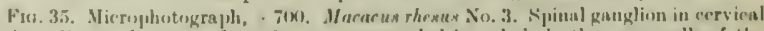
region. ('orpus.les (type, Juest-I)egen) surroumled by a halo in the nerve.cells of the

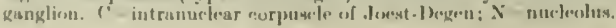


Fig. 36. Microphotograph, ( $\times 36$, enlarged 21 diameters $)$. Maracus rhesus No. 1 . Section of spinal ganglion in lumbar region of spinal cord showing the profound changes which predominate the peripheral parts of the nervous system. (i)=intranuelear corpuscle (Joest-Degen) with surrounding halo; $n=$ norlule of mononuelear cells replacing destroyed neuron; $d$-degenerated ganglion cells; $n p=$ neuronophagia; ic=pericellular infiltration; it =interstitial infiltration; $c=$ capsule of ganglion.

Frc. 37. Nicrophotograph, $\times 55$. Macacus rhesus No, 3. Section through the brachial nerve. Perivascular 'culfing' and interstitial infiltration. $G=$ nerve sheat $\mathrm{l}_{2}$; $V$-perivascular 'cuffs'; $I$ = interstitial infiltration.

Fic. 38. Microphotograph, $\times ₫ 60$. Macacus rhesus $N o$. 1. Transverse section of the sciatic nerve several centimetres from its exit from the greater sciatic foramen-perivascular 'cuff". $V$ =lumen of blood-vessel; $E=$ vascular endothelium; $L=$ lymphocytes.

Fig. 39. Nicrophotograph, $\times 55$, (photograph enlarged $2 \frac{1}{2}$ diameters). Macacus rhesus No. 1. Transwerse section of sciatic nerve after its exit from the greater sciatic foramen. $\mathrm{V}=$ large vessel with perivascular infiltration; $v=$ small vessels showing same phenomenon; 1 = lympbocytes (interstitial infiltration).

\section{COLOURED PLATES}

\section{PLATE I}

FIG. 1. Staining, toluidin blue-eosin. Obj. $5 \mathrm{~mm} .$, oc. $2, \times 260$.

Rabbit 295 dead 19 days after intracerebral infection. Cellular degeneration in the medulla oblongata. $\mathrm{N}=$ neuron in normal state; $\mathrm{C}=$ degenerated nerve-celltigrolysis-oxyphilia-nucleus eccentric: $\mathbf{E}=$ degenerated neuron; $\mathbf{F}=$ fragment of nerve-cell; $\mathrm{L}=$ lymphocytes.

Fic. 2. Staining, Mann, 112 oil immersion, oc, 4.

Rabbit 25 dead 35 days after cerebral inoculation. Oxyphilic corpuscle surrounded by a halo in a nerre-cell in the Ammon's horn. $\mathrm{C}=$ corpuscle (type Joest-Degen) surrounded by a halo.

Fic. 3. Staining, Jann. 1,12 oil immersion, ne. 4 .

Rabbit $80 \mathrm{~A}$ dead 28 days after the inoculation into the brain. $\mathrm{N}=$ nucleus of neuron repulsed by the 'cyst'; $\mathbf{n}=$ nucleolus; $\mathrm{C}=$ ' C $\mathrm{Cyst}$ ', this 'cyst' is the degenerated nucleus of a mononuclear cell which has succeded in penetrating the nerve-cell.

FIG. 4. Staining, toluidin blue-eosin. 1.12 oil immersion, oc. 4.

Guinea-pig $85 \mathrm{E}$ dead 82 days after cerebral infection. Section of medulla oblongata. $\mathrm{N}=$ nucleolus; $\mathrm{C}$-corpuscle of Joest-Degen; $\mathrm{H}=$ halo around the corpuscle.

FIG. 5. Staining, Jann, 112 oil immersion, oc, 4.

Rabbit 209 dead 71 days after the inoculation of the virus into the testicle. Neuron of the anterior horn of the spinal cord in the lumbar region. $\mathrm{C}=$ Intranuclear corpuscle (Joest-Degen); $\Gamma$ nucleolus.

\section{PLATE II}

FrG. 1. Staining, toluidin blue-eosin. 1/12 oil immersion, oc. 1.

Rabbit 243 dead 22 days after inoculation into the brain. Section of the cord anterior horn showing degeneration of the nerve-cells. $\mathrm{V}=$ small blood-ressel; $\mathrm{P}=$ protoplasm of degenerated nerve-cells; 1 ) protoplasm debris; $\mathrm{O}=$ vacuole in the eytoplasm of a degenerated neuron: $C^{\prime}=$ eytoplasm: $\mathrm{L}=$ lymphocytes.

Fig. 2. Staining, Mann. 112 oil immersion, oc. 4.

Macacus rhesus No. 1. Neurons of the anterior horn of the thoracic region of the cord containing corpuseles (Joest-Degen type). $\mathrm{N}=$ nucleus of the nerve-cell; $\mathrm{n}-$ nucleolus; $\mathrm{C}=$ corpuscle (Joest-Degen) surrounded by a halo. At the periphery of the corpuscle a blue staining area is seen.

\section{PLATE III}

Frg, 1. Staining, Jann. 112 oil immersion, oc. 2.

Macacus rhesus No. 1. Pyramidal cells of the frontal lobe containing oxyphilie corpuscles surrounded by a halo. $\mathbf{N}$ =nueleolus; $\mathrm{C}=$ corpuscle (Joest-Degen).

FIg. 2. Staining, Mann. 112 oil immersion, oc. 4.

Rabbit 298 dead 39 days after intracerebral inoculation. Cervical region of the cord: anterior horn. Formation of intranuclear corpuscles in the interior of the nucleus of the neuron. $\mathrm{N}=$ nucleolus; $\mathrm{C}=$ oxyphilic corpuseles; a study of the process of the 
formation of the corpuscles of Joest-Degen has shown that several small oxyphilic corpuscles fuse together to form one large corpuscle surrounded by a halo.

FIG. 3. Staining, orange G. eosin, pol rchrome hlue (Unna). 1.12 oil immersion, oc, 4. Guinea-pig $99 \mathrm{~K}$ dead 19 days after intracerebral inoculation. A lymphocyte has penetrated into the cytoplasm of a nerre-cell of the Cornu Ammonis. $\mathrm{N}=$ nucleolus; $\mathrm{L}=$ Iymphocrtes.

FıG. 4. Staining, Mann. $\frac{1}{2} 12$ oil immersion, oc. 4 .

Rabbit $50 \mathrm{~A}$ dead 28 days after intracerebral infection. Mid-brain. oxyphilic degenera. tion of the nuclear chromatin forming a homogeneous 'block'. ' $C$ '=degenerated nucleus; $\mathrm{N}=$ nucleolus; $\mathrm{S}=$ satellite cell.

Frg. 5. Staining, Mann. 1 12 oil immersion, oc. 1.

Macacus rhesus No. 1. Spinal ganglion of the lumbar region. Corpuscles of type Joest-Degen in the nucleus of the ganglion cells. $\mathrm{C}$ =intranuclear corpuscle surrounded by a halo: $\mathbf{N}=$ nucleolus,

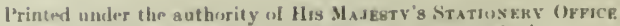
by Irohn Juhnson, at the University l'ress, Uxford. 
ILLUSTRATIONS 



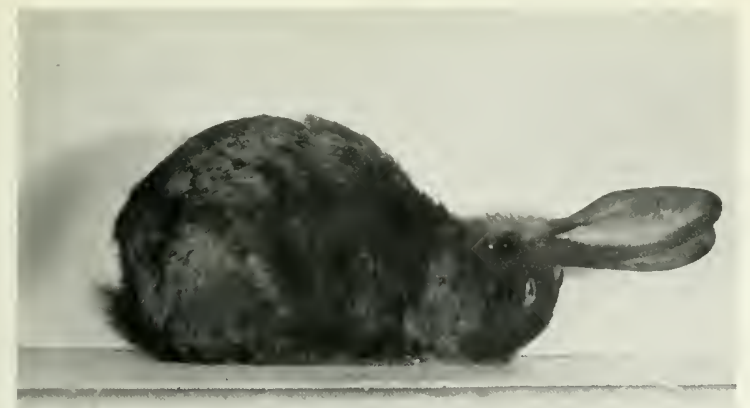

FIG. 1

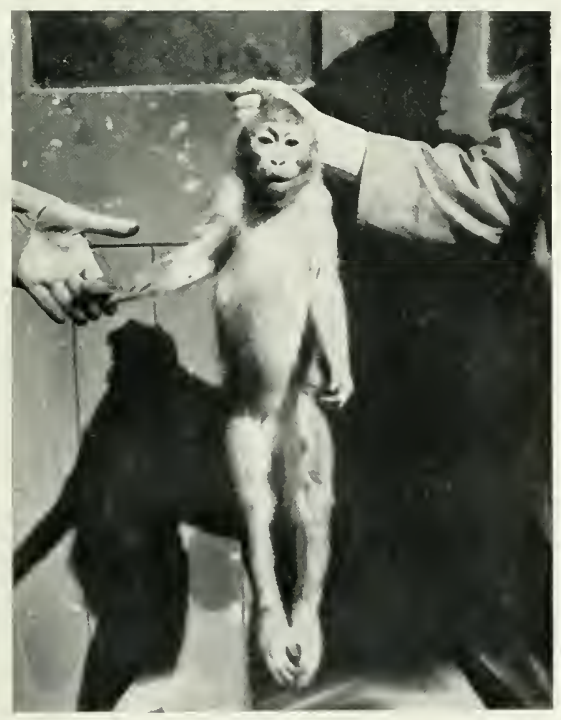

Fig. 2 


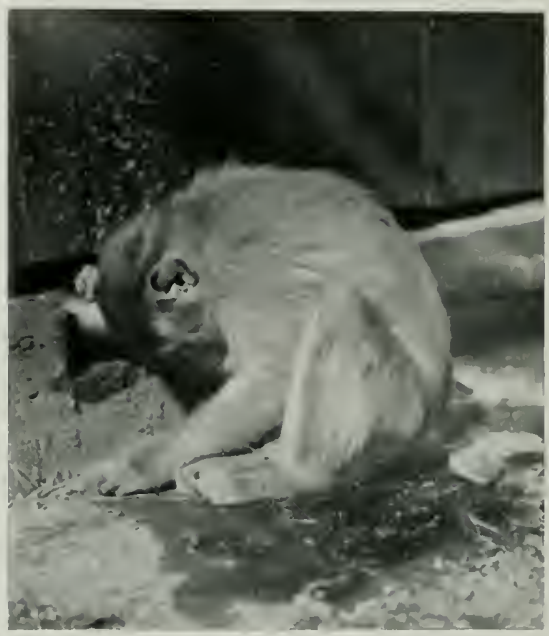

Fic, 3 


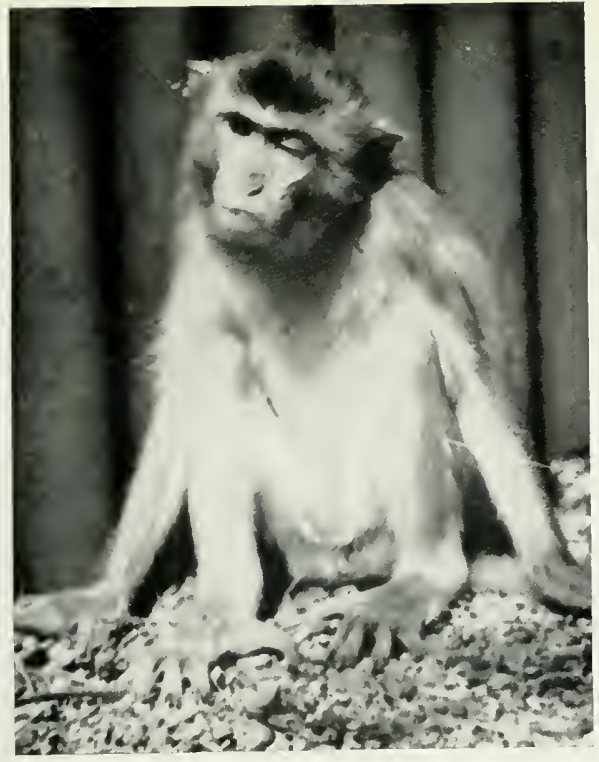

FIt: 4

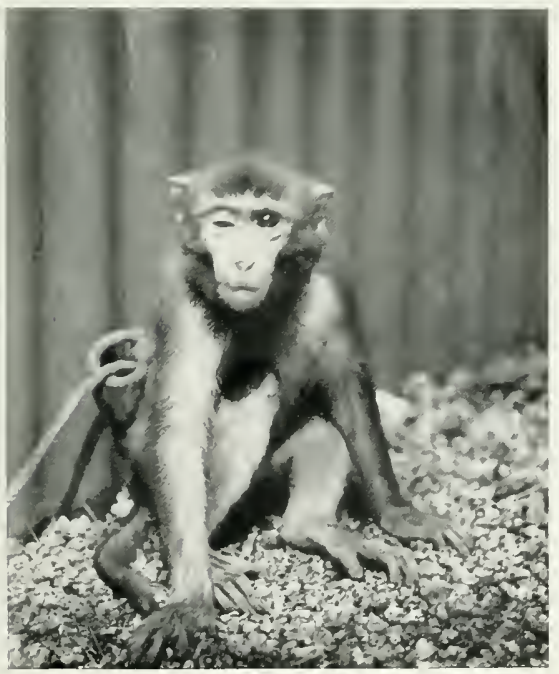

Fis. 


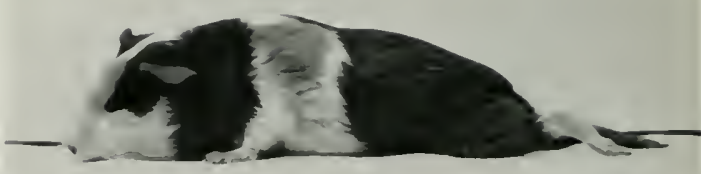

FIf. 6

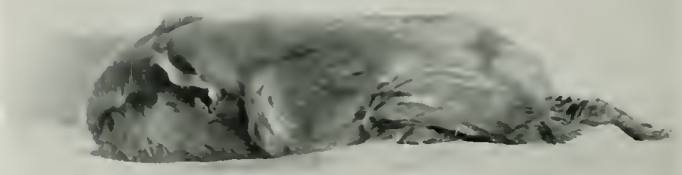

Fis, -

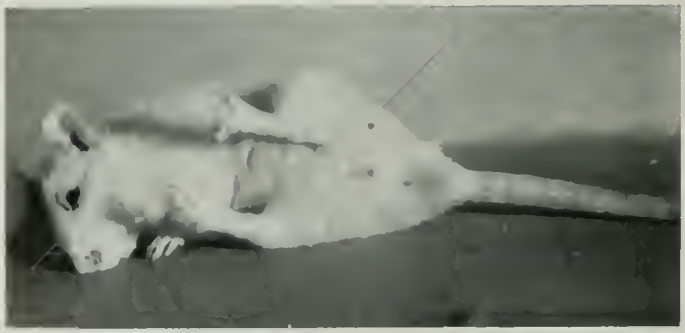

Fin, 


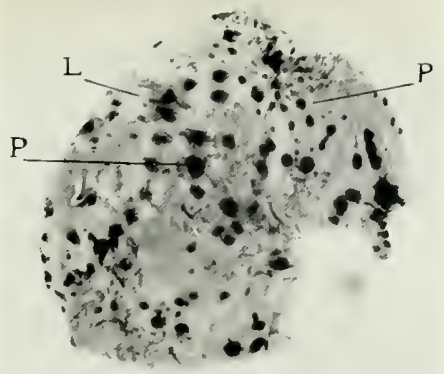

Fic. :

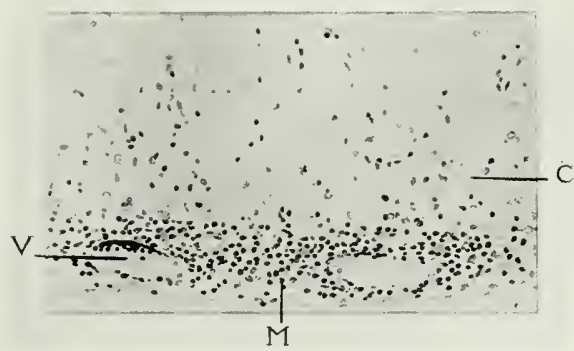

FIต. 10

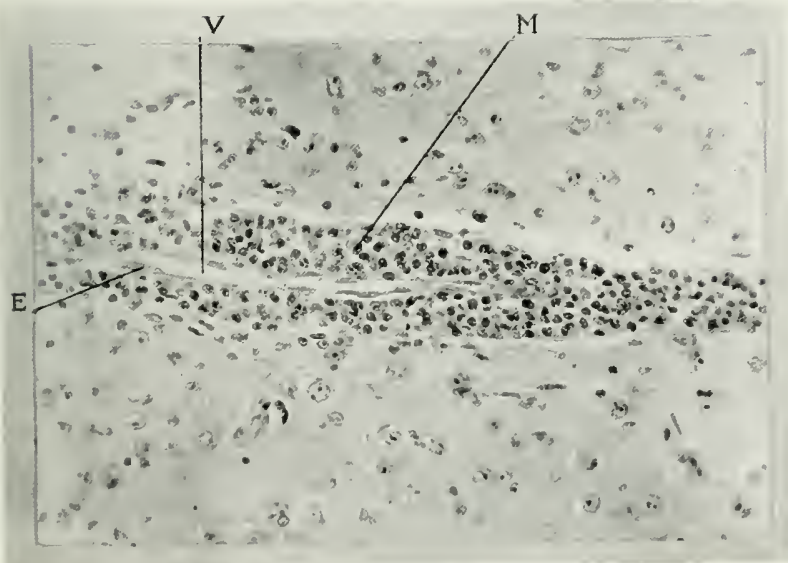




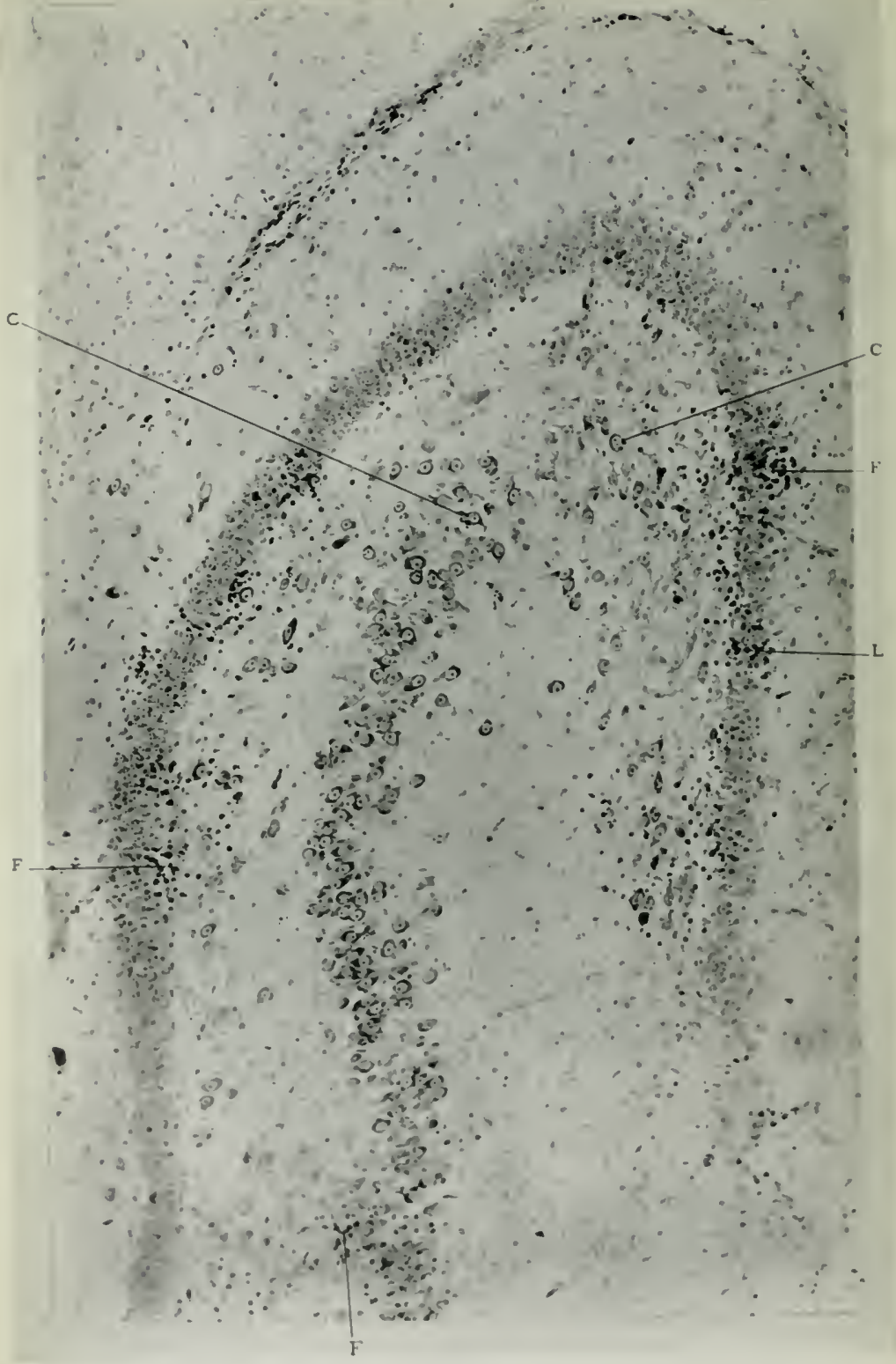




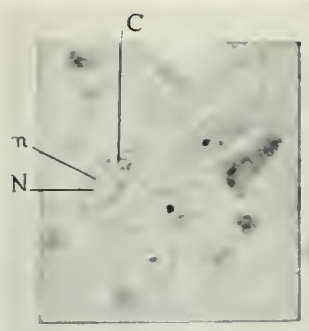

IIti, 1:3

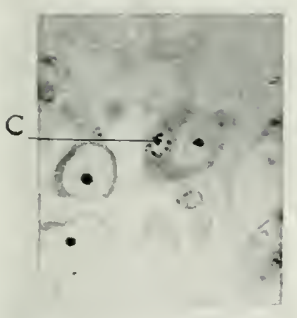

Fig. 15

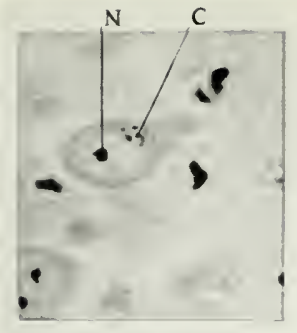

Fic. 14

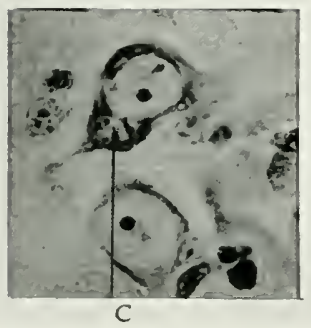

Fie. 16

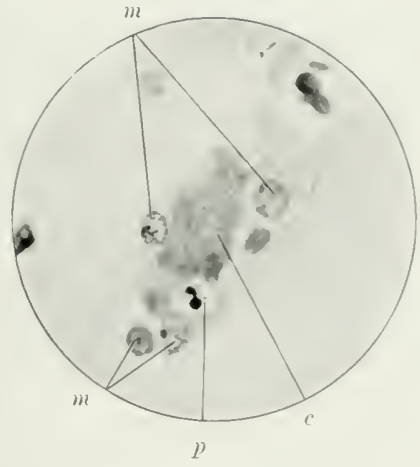

Fig. 1\% 


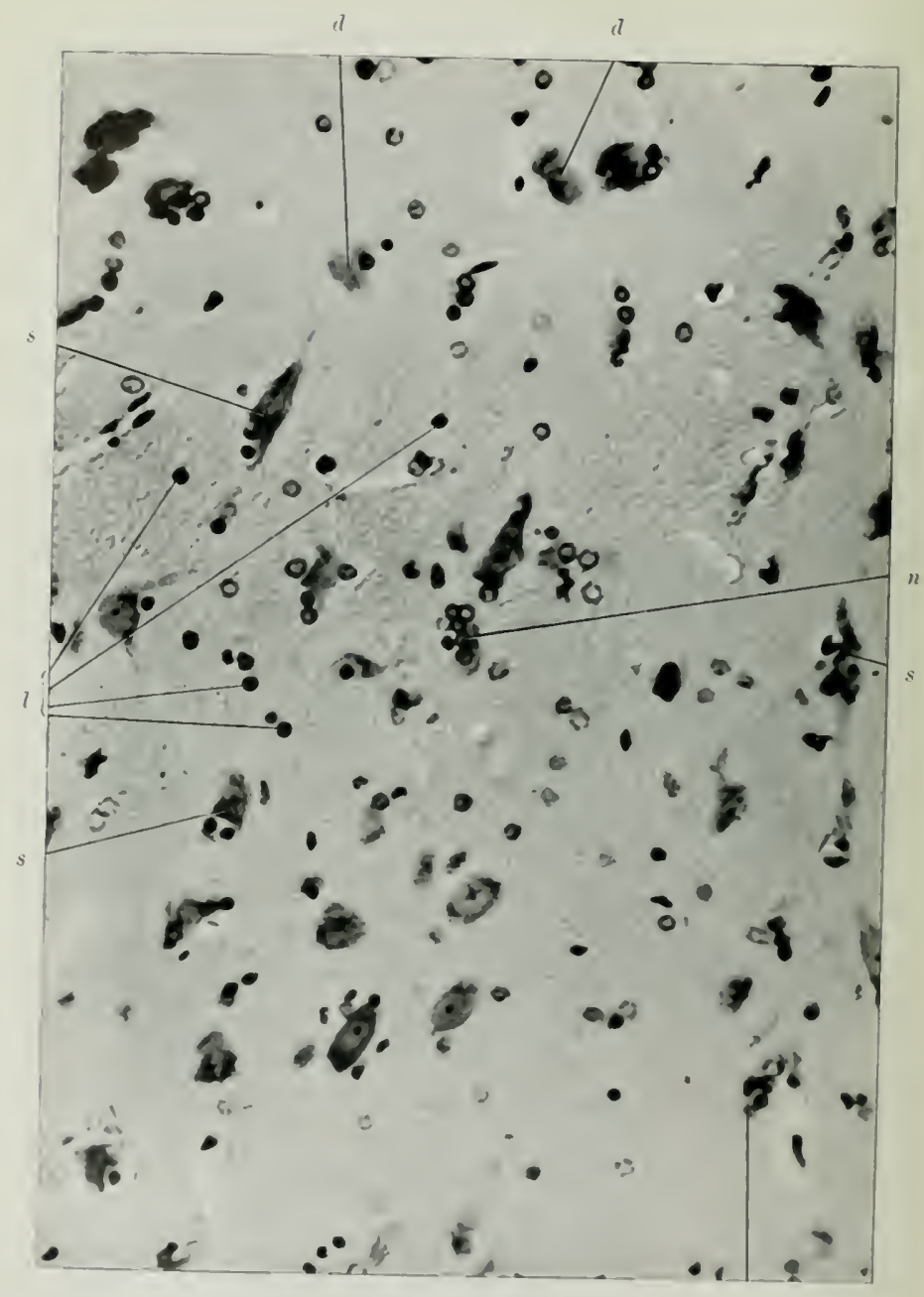

Fite. Is 


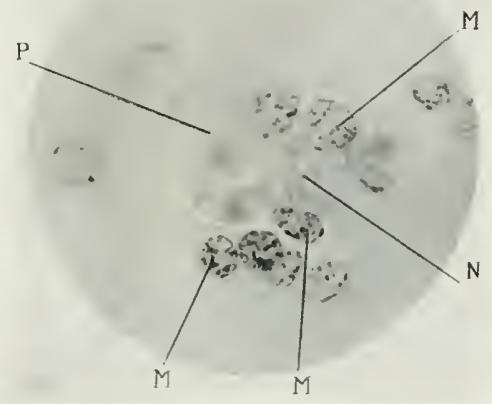

FIG. 1!)

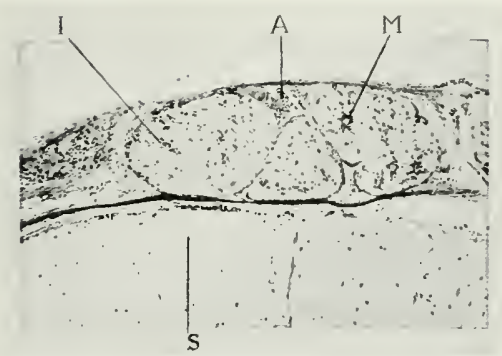

FI:: 201) 


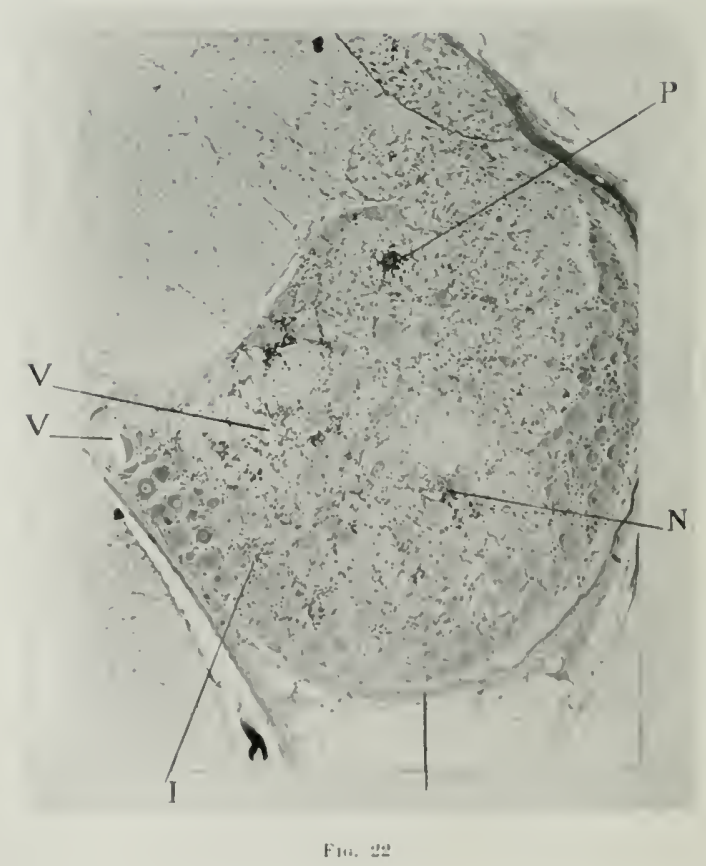




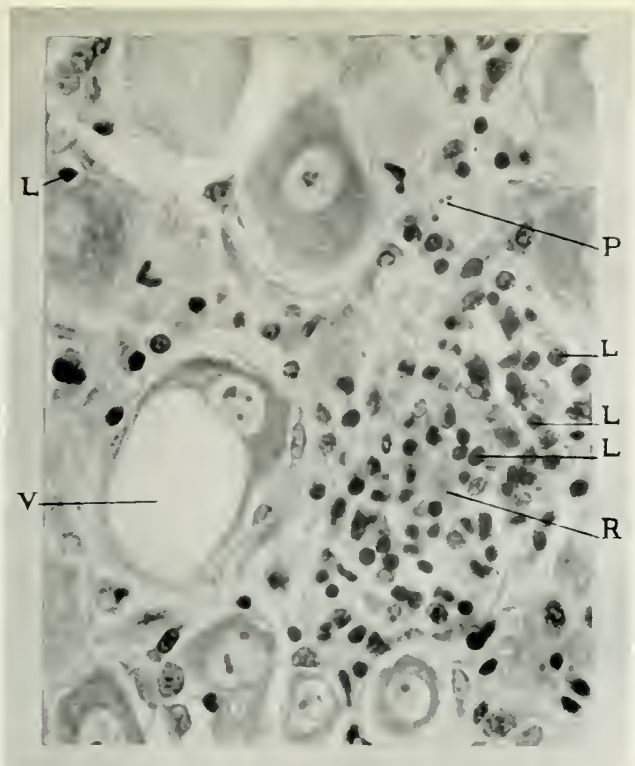

Fic. 2

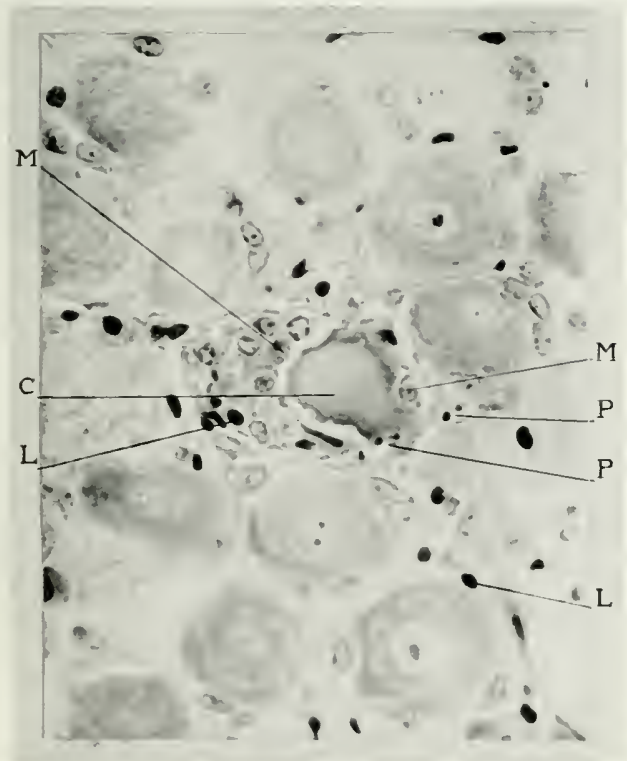

Fig. 24 


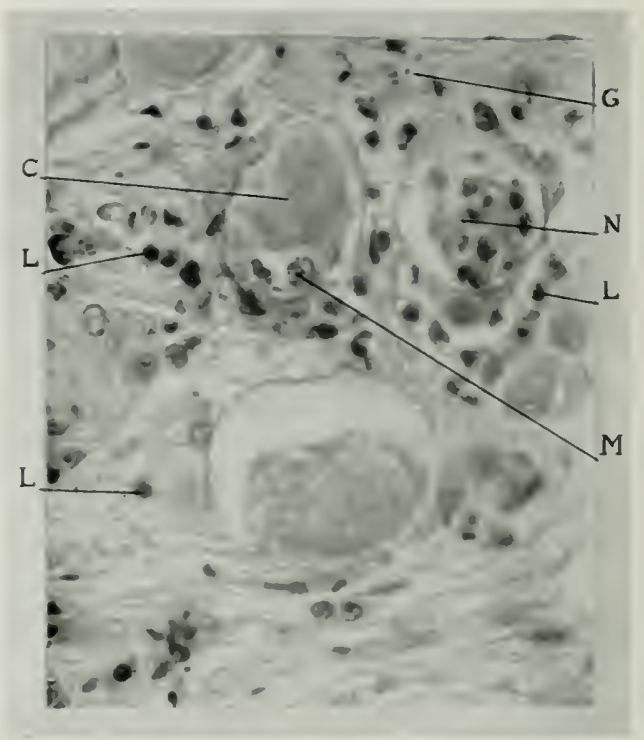

Fto. 25 


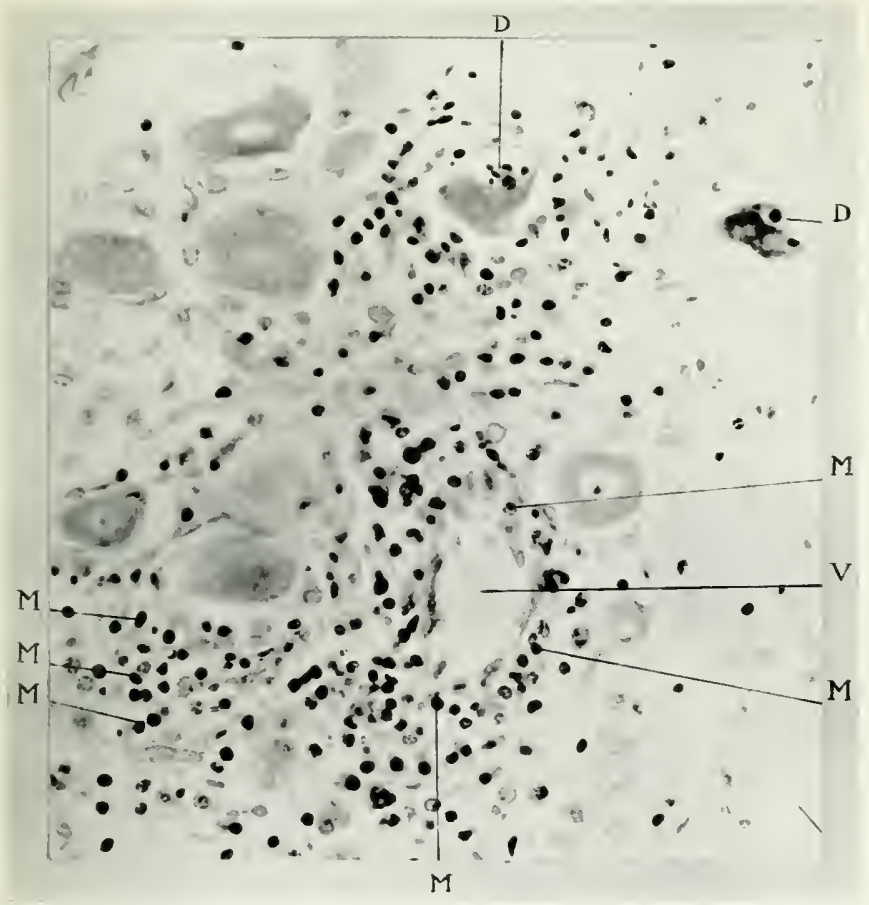

FIti, $y_{i}$ 


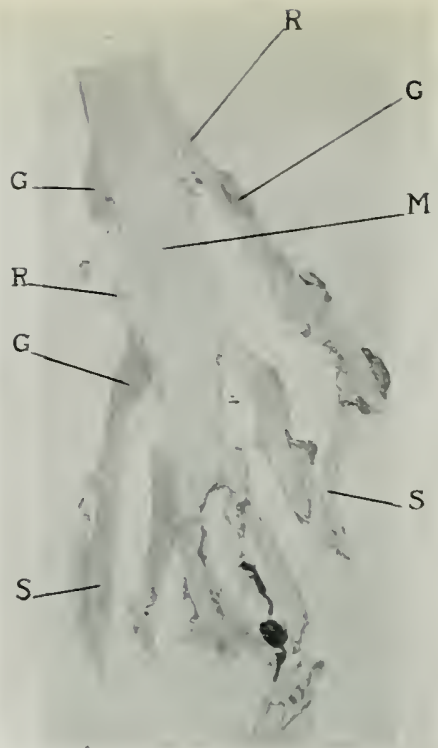

Fig, $=7$

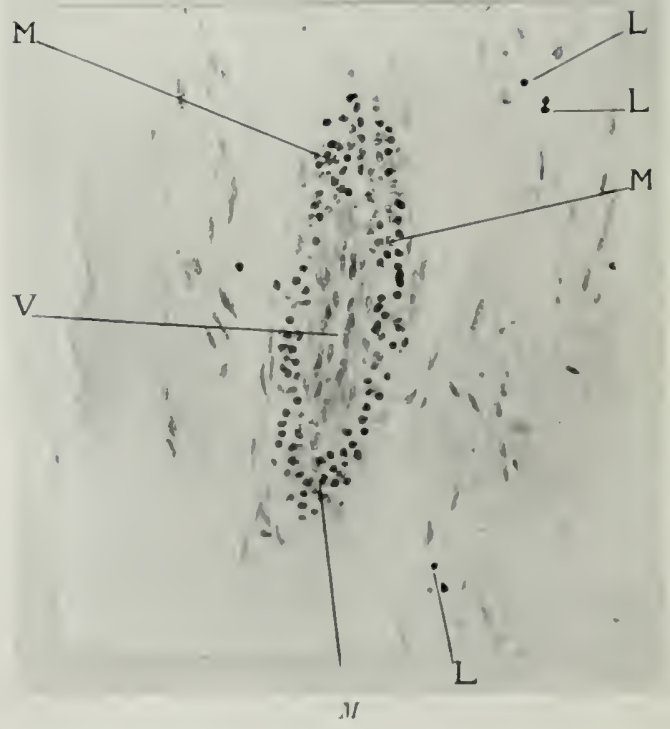

Fua. Is 


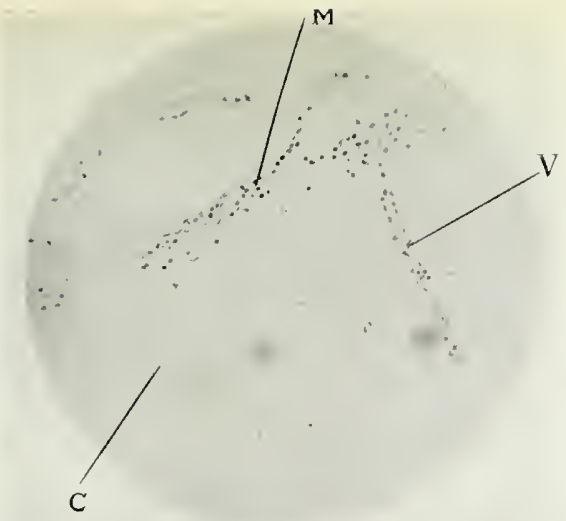

FIG. 29

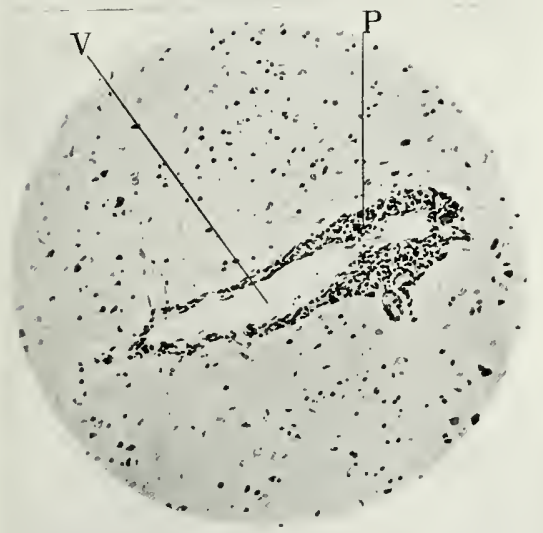

FIf. 30

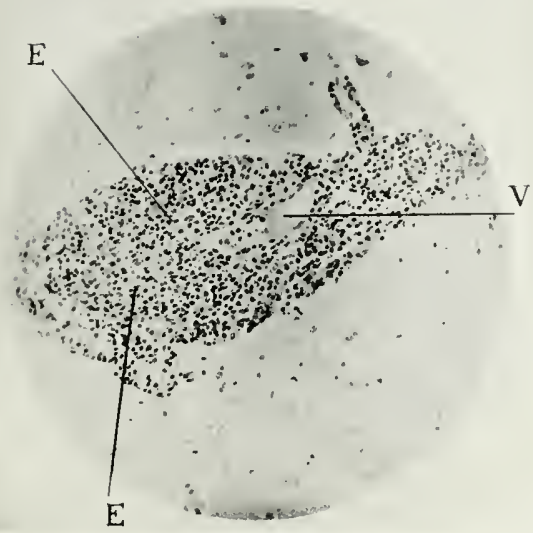




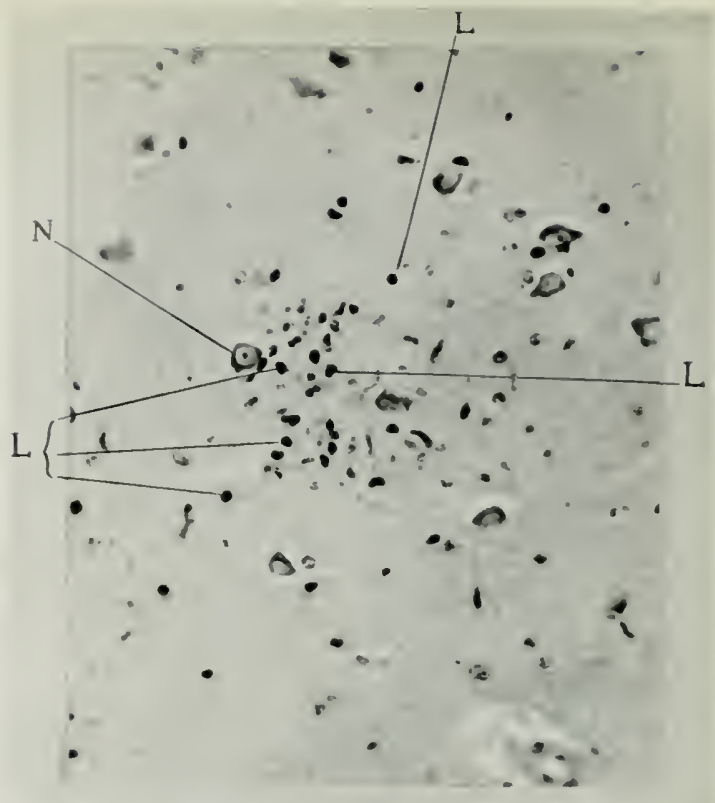

F1:. 32

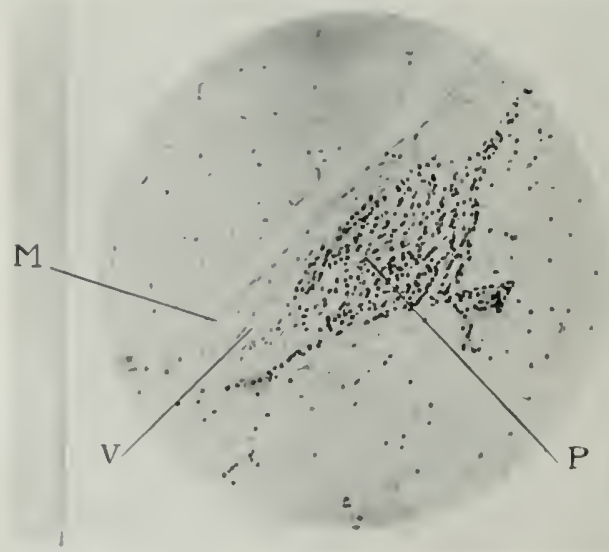

Fii. :3 


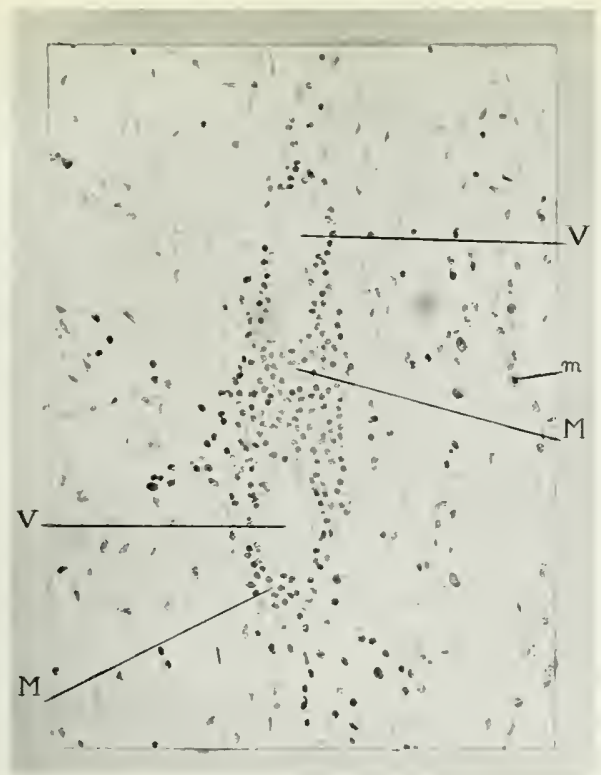

Fig. 84

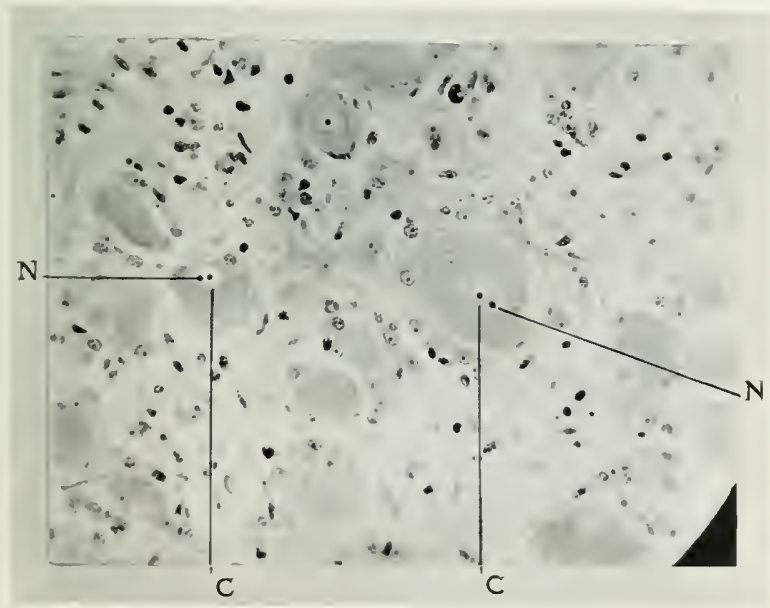

FIG. 35 


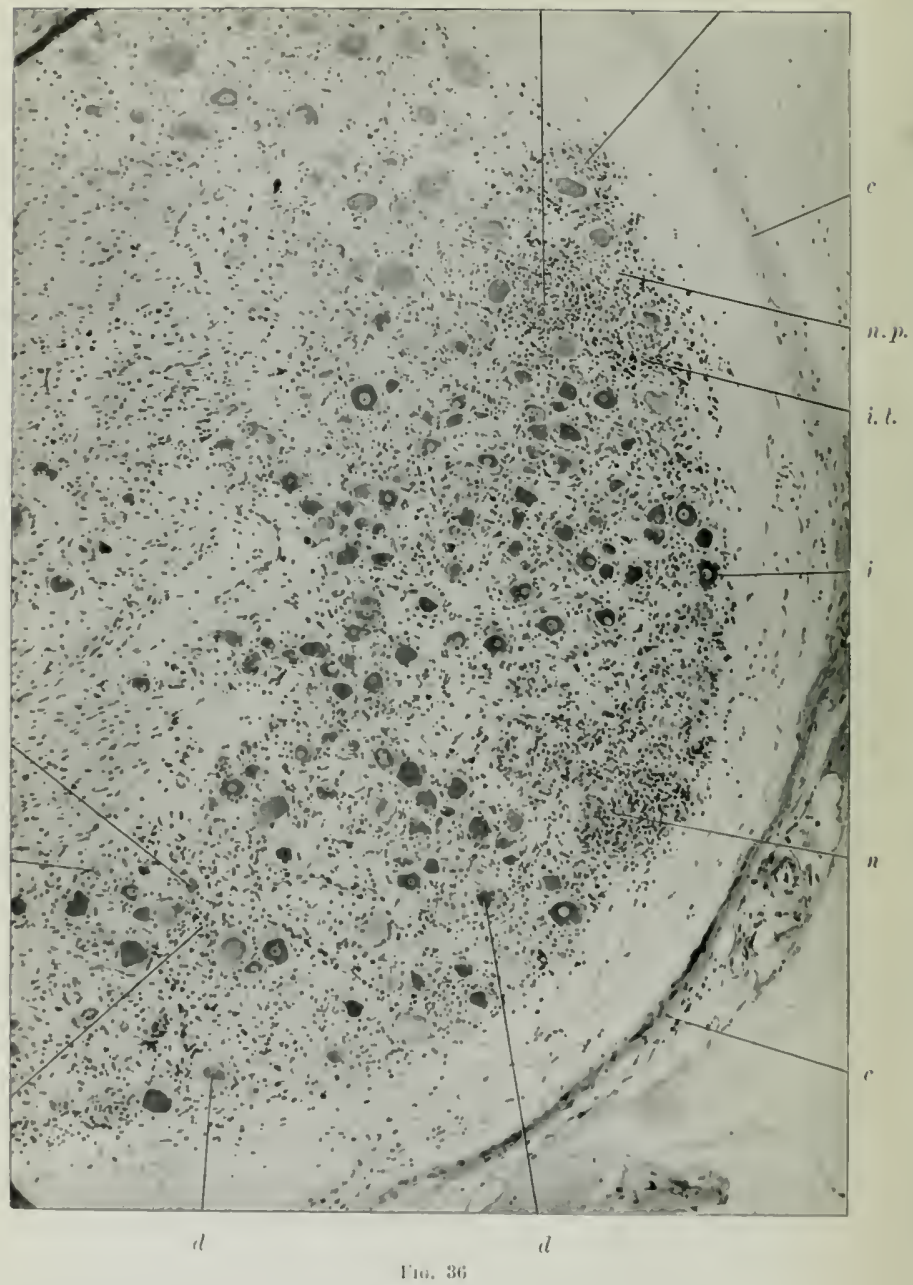




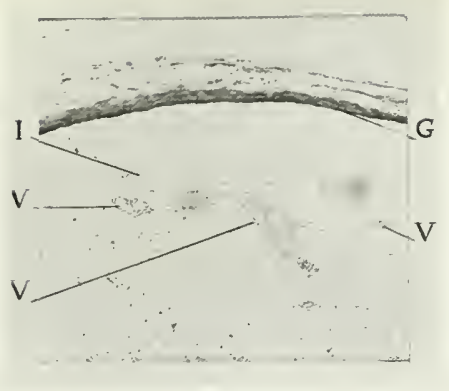

Fig. 3:

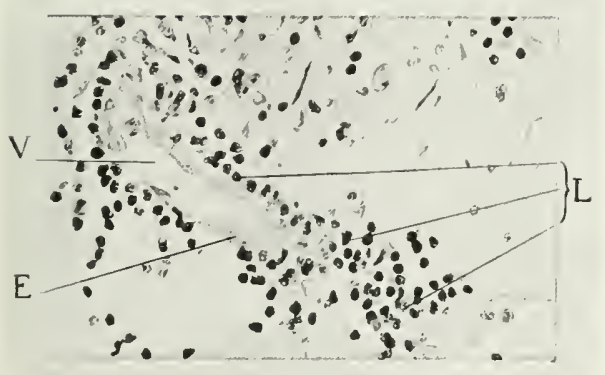

Fic. 38 


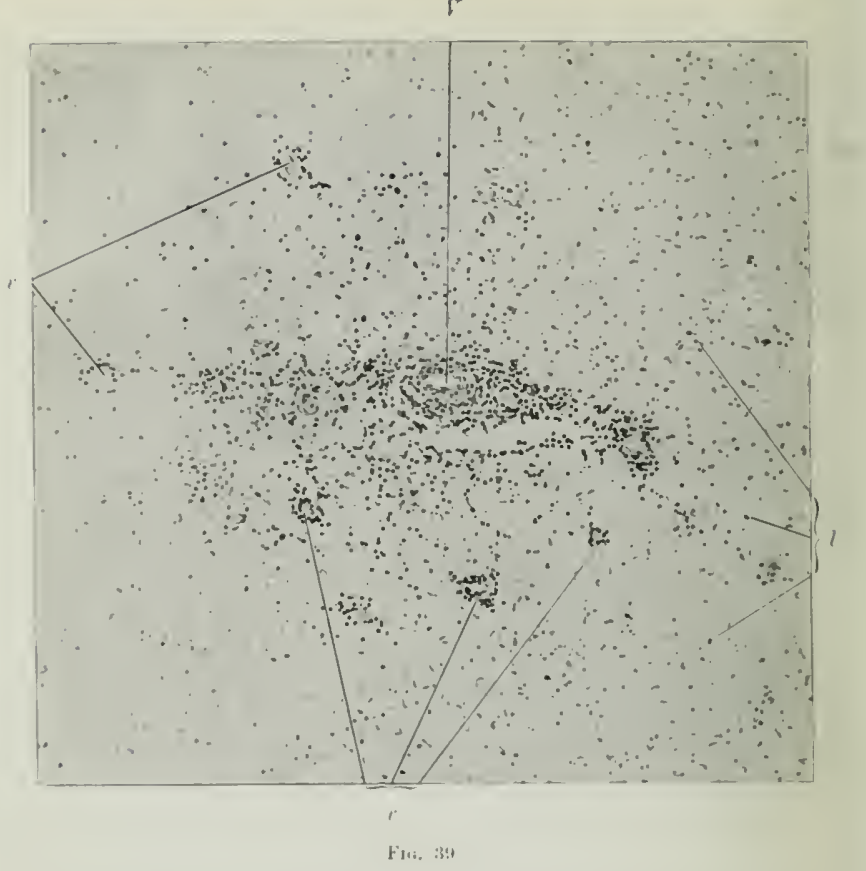


I

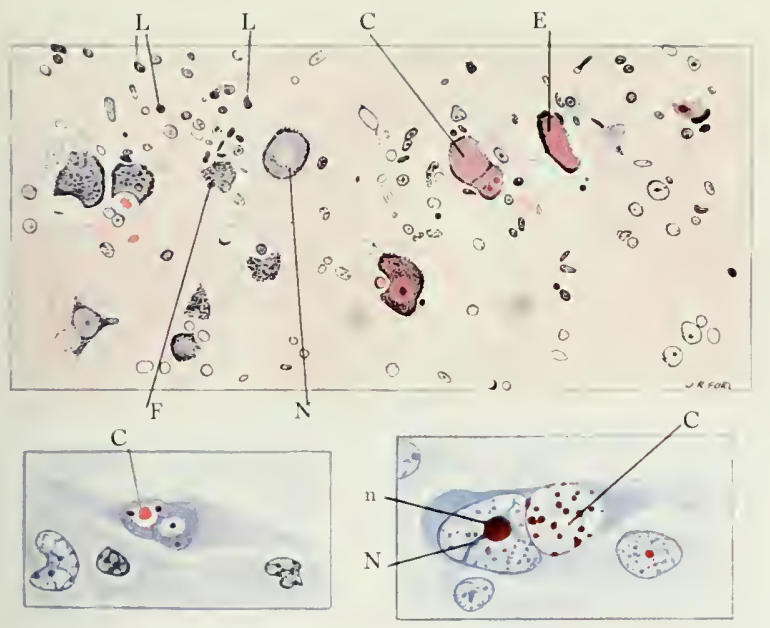

4
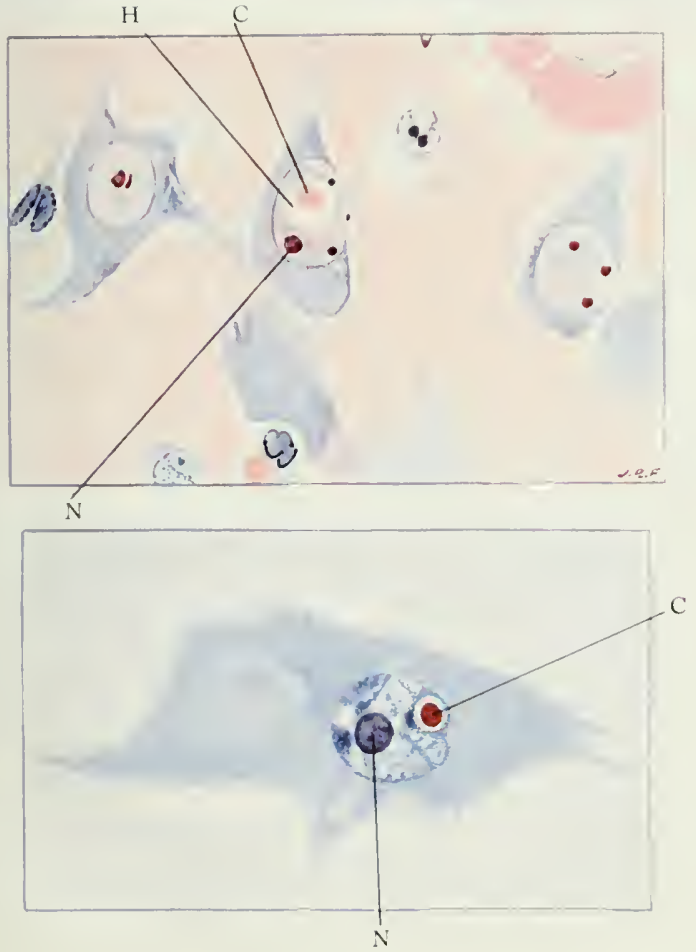

00

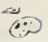
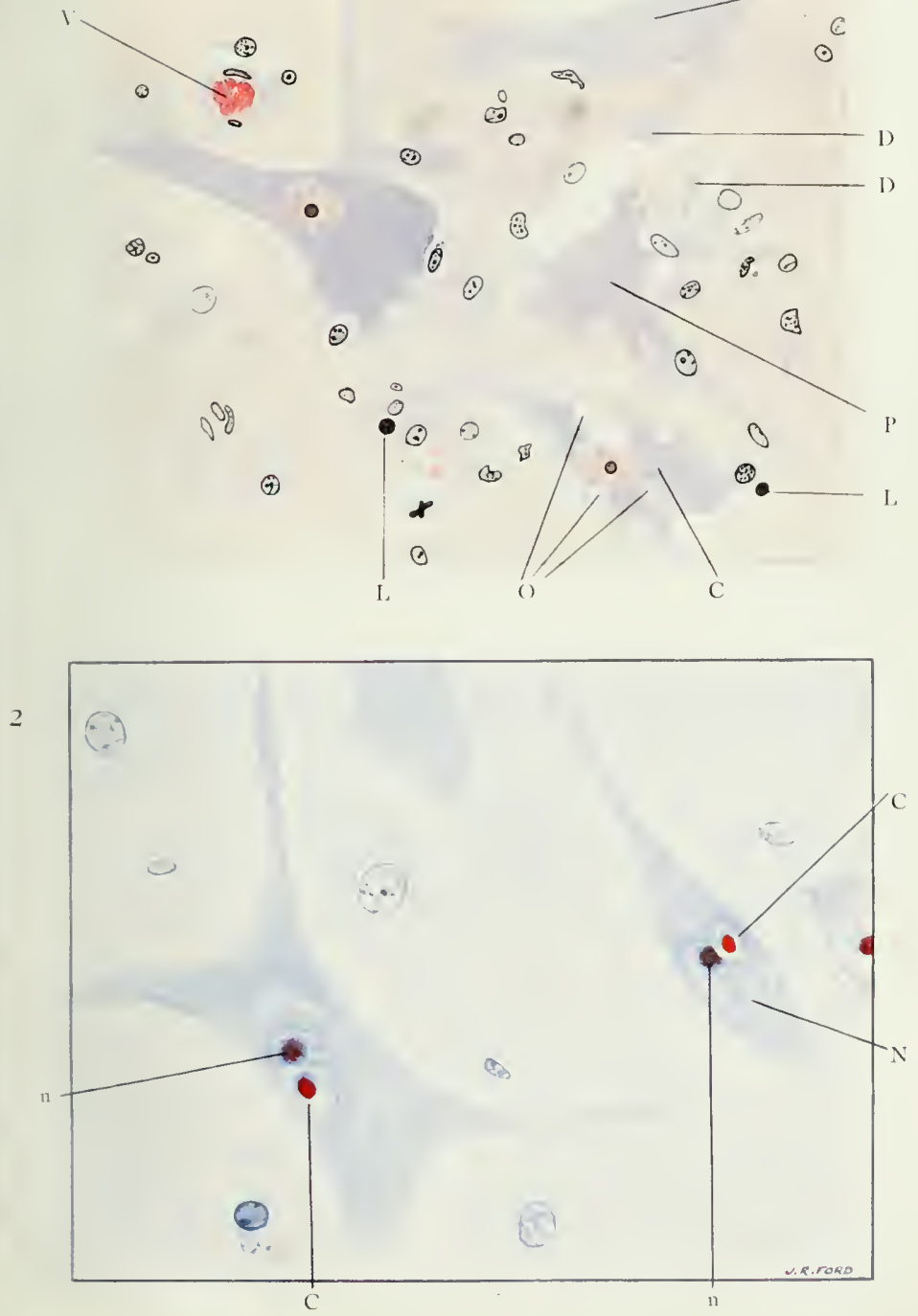



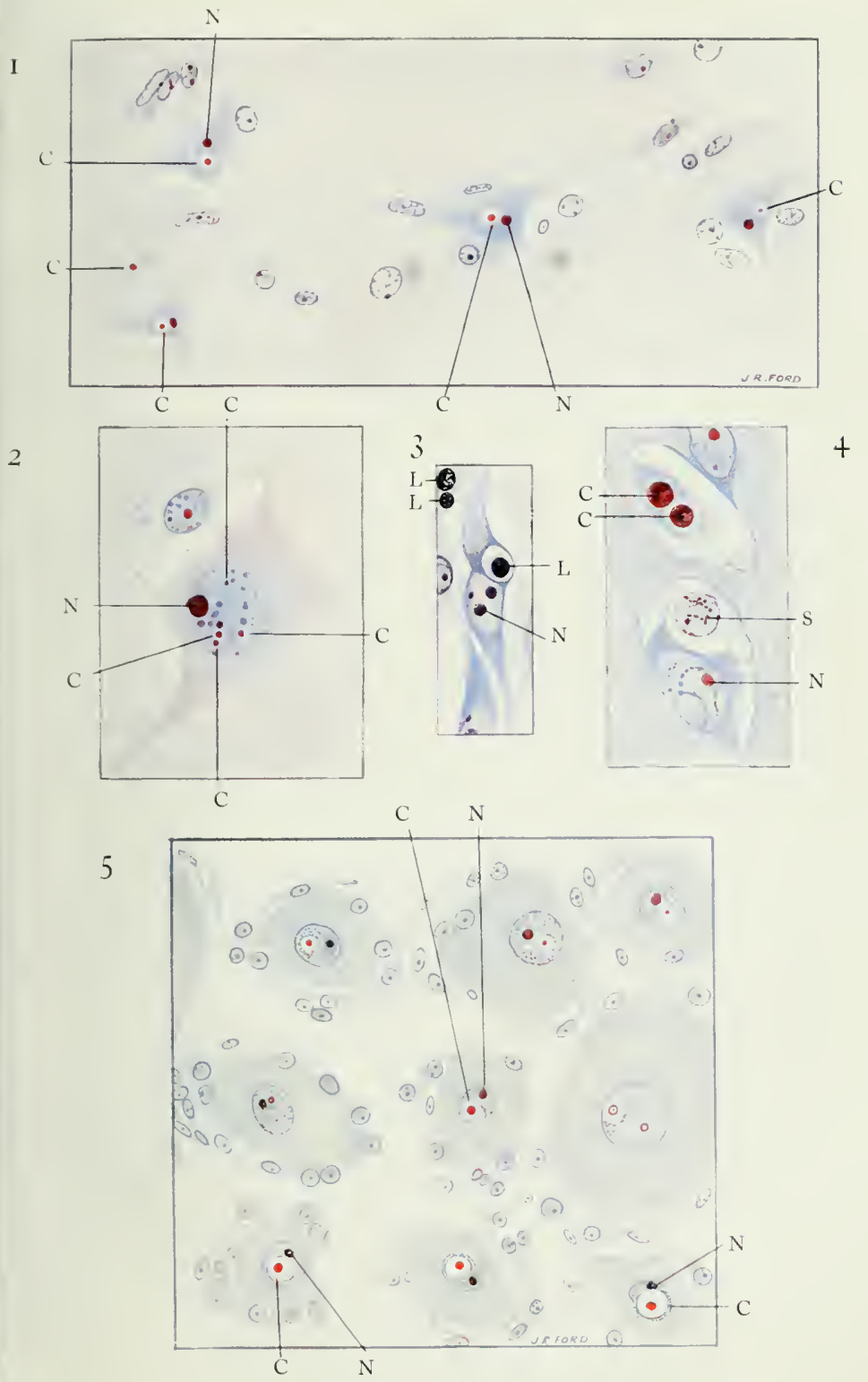





\title{
MEDICA L RESEAR CH COUNGIL
}

(Formerly . Hedical Research Committee, National Health Insuranee.)

\section{LIST OF PUBLICATIONS}

\author{
Septemler, 192s.
}

The following publieations relating to the work of the Medical Research Council ean be purchased dircetly from H.M. Stationery Office, at the following addresses : Adastral IIouse, Kingsway, London, W.C. 2; York Street, Manehester; 1 St. Andrew's Crescent, Cardiff; 120 George Street, Edinburgh; 15 Donegal Square West, Bclfast; or through any bookseller.*

In addition, numerous menoirs upon work aided by the Medical Research Couneil have appeared in Seientific Journals : particulars of these may be seen in the Annual Reports.

\section{ANNUAL REPORTS}

Medical Research Committee, Nos. 1-5, 1914-15 to 1918-19.

Vedical Research Council, 1919-20 to 19:6-\%.

(Price of each report from 1920-1 to 1925-6, 3s. 6d., post free $3 s$. $8 d . ; 1926-7$ [Cnd. $3013], 33 .$, post free $\left.3 s_{.}, 2 l_{\text {. }}\right)$

\section{Alcohol :}

\section{SPECIAL REPORTS, \&c.}

No. 31. Alcohol-1ts Alssorption into and Disappearance from the Bluod under different conditions. By E. Nlellanby. [1919.]

Out of print.

No. 34. The Influcnee of Alcohol on Manual Work and Neuro-museular Co-ordination. By 11. M. Vernon. [1919.] Price 2s., post free $2 s, \mathbf{1} d$.

No. 56. The Lffects of Alcohol and some other Drugs during Normal and Fatigned Conditions. By W. MeDougall and May Smitl. [1920.] Price 1s., post free Is. 1d.

(Book). Aleohol: its Aetion on the Iluman Organism. Second Edition. [1924.] Price $1 s$. paper covers, $1 s .6 d$. cloth bound.

Anaerobic Bacteria : see Wound INFEctioss.

Animals, Diseases of :

Ni. 121. Borna Disease and Enzontie Eneephalo-Myclitis of sliee and (attle. By $\therefore$. Nicolau and 1. A. Galloway. [1928.]

Bacteriology (Miscellanious):

No. 35. The Reaetion of Culture Media, by S. R. Douglas, J. W. H. Eyre, I'. P. Laidlaw, and C. G. L. Wolf. Seeond Edition, revised by P'. P. Laidlaw, [1927.] P'rice Gd., post free $\tau d$.

No. 49. Ou the Destruction of Bacteria in Mlilk by Electricity. By J. M. Beattic and F. C. Lcwis. [1920.] Price 9d., post free 10 .

No. 51. The Laboratory Diagnosis of . Ieute Intestinal Infeetions, including the P'rineiples and Practice of the Agglutination Tests. By the Committee upon Pathological Metliods. [1920.] Price $4 s .6 d$, post free $4 s .8 d$.

No. 64. Catalogue of the National Collection of Type Cultures. Second Edition. [19:5.] Price $2 s$, post free $2 s, 1 d$.

Blood Physiology :

No. 72. The Acid-base Equilibriam of the Blood. By the tIatmoglobin Committee.

[1923.] I'rice 2s., post free 2s. $1 d$.

Sec also SHock, Surgical. 


\section{Cancer :}

No. 99. An Inwestigation into the Statisties of Caner in Different Trades and Profe:sions. By llatthew Young and W. T. Russell. [1926.] P'rice 1s. Gd., post free 1s. $\mathbf{i}$. Sice also Raviesr.

\section{Cerebro-spinal Fever :}

No. 2. Report of the Special Advisory Committee upon Bacteriological Studics of Cerebro-spinal Fever during the Epidenic of 1915. [1916.] Out of print.

No. 3. Baeteriologieal Studies in the Pathology and Preventive Control of Cerebro-spinal jever among the Forees during 1915 and 1916. IBy II. II. Gordon, Martin Flack, I'. W. Bassett-Snith, and T. G. II. Iline and W. J. Tulloch. [1917.] Out of primt. No. 17. (1.) A Report upon the Seasonal Outbreak of Cercbro-spinal lever in tle Navy at Portsmouth, J916-17. By Paul Fildes and S. L. l3aker. (11.) The Treatment if Cerebro-spinal Meningitis by Antimeningococcus Scrum at the Royal Naval IJospital, IInslar, 1915-16-17. By G. P. Adshead. [1918.] I'rice 2s. tid., post free 2s. $s \frac{1}{2} d$.

No. 50. Cerebro-spinal Fever. Studies in the Bacteriology, I'reventive control, and Specific Treatnsut of Cerebro-spinal Fever among the Ililitary Forees, 1915-19. 13y II. 11. Gordon and others. [1920.] P'rice 4s., post free 4s. $3 d$.

Chemotherapy : see stri:ptucueceit. Isprectioss.

Child Life (ANtexatal and lostratal Ixvestigations):

No. 10. The Mortalities of Jirlh, Jufancy, and Childlood. Ily A. K. Chalmers, W. $\mathbf{A}$.

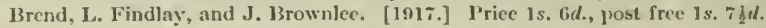

o. .4. Tlac Relation between Hone Conditions and 1 he Inlelligence of School ('hildren. 13y L. Isserlis. [1923.] l'rice $1 s$., post free 1s. $3 d$.

No. 81. The Effect of Maternal Social Conditions and Nutrition ujw) J3irlh-weight and Birth-]ength. By. .1. Bruce Murray. [1924.] Price 1s., post free 1s. 1d.

No. 82. Maternal Syphlilis as a cause of Weath of the linetus and of the New-born Child. I3y J. X. Cruickshank, [1924.] P'riee 1s. Gd.. post free 1s. $7 \mathrm{~s} d$.

No. s6. The Estimation of Foctal Age, the Weight and Lenglh of Normal Fuetuses, and the Weights of Foctal Organs. liy J. N. Cruickshank, M. J. Niiler, and F. J.

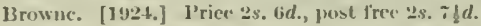

No. 101, Poverty, Nutritim, and (Growth: Studies of (lhild Life in (ities and llural 1)istricts of scotland. [1926.] By 1). Noül Paaton, Leconard Findlay, and ollers. l'rice 10s.

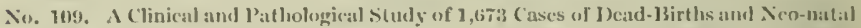
1):aths. Compiled ly E. I. Ilolland and J. E. Lane-Claypon. [192ti.] I'rice 3s. bud, prost free 3s. 7 lid.

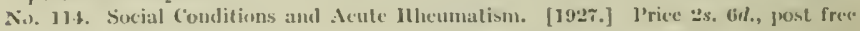
2s. $8 d$.

No. 117. The Toxacnsias of l'regnaney: A Clinical and lienchemical study. By .1. N Crnieksltank, J. llewitt, and K. 1. (o)

No. 1ls. The Cause of linctal Death in III Cases. Hy A. C. l'aluser. [1:23.] l'rice

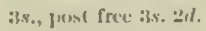

Sec also Niтtitiox; Ifickits.

\section{Dental Disease :}

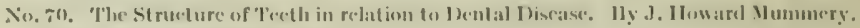

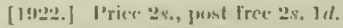

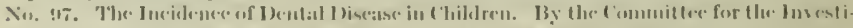

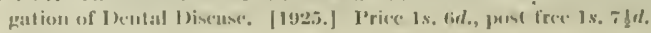

\section{Diphtheria :}

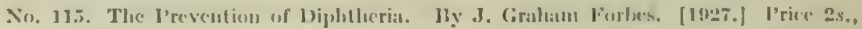
jenst frew 2 s. $1 \frac{1}{b} \%$.

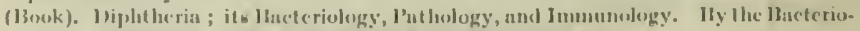

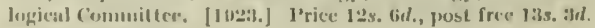

Sie atso limut.sustaris (No. T5).

ii 


\section{Special Reports-continued.}

\section{Dysentery :}

Reports upon Invesligations in the Luited Kingdom of Uysentery Cases received from the Eastern Mediterranean :-

No. 4. I. Amoebie Dysentery and the Protozoological Investigation of Cases and Carriers. 13y ('lifford Dobell. [191\%.]

Out of print.

Nu. 5. 11. Report upon sis Cases of Bacillary Enteritis. By L. Rajehman and G. T. Western. [191\%.]

Out of print.

No. 6. III. Feport upon recovered (ases of Intestinal Disease in the Royal Naval IIospital. Ilaslar, 1915-16. I3y Paul Fildes and otlıers. IV. Report upon eombined C'linical and Bacteriological Studies of Dysentery Cases from the Meditcranean. By

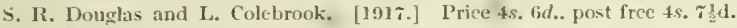

o. 7. 1. leport upen 2,360 Enteritis 'Convaleseents' receivel at Liverpool from various Expeditionary Forees. By E. Glynn and others. [1918.] P'rice 6s., post frec 6.s. 2d.

No. 15. A Study of 1,300 Convalescent Cases of Dysentery from Home Hospitals : with special reference to the Incidence and Treatment of Amoebic Dysentery Carriers. By Clifford Dobell, H. S. Gettings, Margaret W. Jepps, and J. B. Stephens. [1918.] Price 1s, 3r., post free $1 \mathrm{~s} .4 d$.

No. 29. A Contribution to the Study of Chnonicity in Dysentery Carriers. By W. Fleteler and Doris L. Mackinnon. [1919.] Price 9d.. post free 10d.

No. 80. In Investigation of the Flexner-Y Group of Dyscntery Bacilli. By S. Il. Gettings. [1919.] Price 1s, post free 1s. 1d.

No. 40. Stuclies of Bacillary Iysentery eceurring in the British Forces in Macedonia. By L. S. Dudgeon and others. [1919.] Price 3s., [rost free 3s. $1 \frac{1}{3} d$.

No. 42. A Study of the Serologieal Rarees of the Flexner Group of Dysentery Bacilli. 13y Sir F. W. Andrewes and .1. C. Inman. [1919.] I'rice 2s., post free $2 s .1 \frac{1}{2} d$.

See also Food Porsonrsg.

\section{Encephalitis :}

No. 108. The Sheffield Outhreak of Encephalitis in 1924. [1926.] Price 1s.9d., post free 1 s. $10 \frac{1}{2} d$.

\section{Enteric Infections :}

No. 9. A Report upon the U'se of Atropine as a Diagnostic Agent in Typhoid Infections. By H. F. Marris. [191\%.] Price 1s., post frce 1s. $1 d$.

No. 48. A Report on the prohable Proportion of Enteric Infections among Lndiagnosed Febrile Cases invalided from the Western Front since Octoher 1916. By W. W. C. Topley, S. G. Platts, and C. G. Imrie. [1920.] Price :3.. post free 3s. $1 \frac{1}{2} d$.

See also Bacteriology ; Foon Poisonixg.

\section{Epidemiology :}

No. 75. The Schick Test, Diphtheria and Searlet Fever. By.S. F. Dudley. [1923.] Price 1s., post free 1s. $1 \frac{1}{2} d$.

No. 111. The Spread of Droplet Infection in Semi-isolated Communities. By S. F. Dudley. [1926.] Price $1 s .6 d .$, post frce $1 s .7 \frac{1}{2} d$.

So. 120. An Inquiry into the Relationship between IJousing Conditions and the In cidence and Fatality of Measles. By J. L. Halliday. [1928.] ['rice Is.. post free 1s. I $t$.

See also Sulll-pOx; TuBercllosis ; ete.

\section{Flying, Medical Problems of :}

Reports of the Air Medical Investigation Committee :-

No. 28. The Sense of Balance and Stability in the Air. By Henry Ilead. [1919.] Price $9 d .$, post free $10 d$. (Included in No. 53.)

No. 37. The Effects of Diminished Tension of Oxygen, with especial reference to the Activity of the Adrenal Glands. By C. H. Fiellaway. The Far in relation to certain Disabilities in Flỵing. By S. Scott. [1919.] Price 1s. post frec Is. Id. 


\section{Special Reports-continued.}

No. 53. The Medical Prohlems of Flying (inchuding reports on oxygen want, selection of candidates for flying. seose of balance, and flying st rain). [1!20.] l'rice fix.. posi free 6s. + t .

Sin. 8t. The Ipplieation of the Air Fore J'lysieal Fificieney Tests fo Men and Women. 13y 1. 1). Cripus. [1921.] l'riee 1s. Gd., post free 1s. i $\frac{1}{2} d$.

Food Poisoning :

No. 24. A Report on the Investigntion of an Epidenie eaused by Hacilus aerirye. Byy H. Marrian Perry and II. L. Tidy. [1919.] Price 9d., post free 10d.

No. 91. An Investigation of the Salmonella Group, with Special lieference to Food Poisoning. 13y W. G. Savage and 1'. Bruce White. [122.5.] I'rice 3s. fid., post frec 3s. $8 d$.

No. 92. Food Poisoning : a Study of 100 Reeent Outbrenks. 13y W. G. Savage and P. Bruee White. [1925.] Price 2s. 6d., post free 2s, sd.

So. 103. Further Studies of the Salmonella Group. 13y l'. I3nec White. [1920.] I'rive 5s., post free $5 s .2 \frac{1}{d}$.

Haemoglobin : see BLood.

\section{Heart Disease :}

No. 8. IReport upon Soldiers returned as Cases of "Disordered Aetion of the IJeart" (D.A.II.), or Valvular Disense of the lfeart. 13y Sir Thomas Lewis, [1!)17.] Prive 1 s., post free $1 s .1 d$.

\section{Industrial Fatigue :}

(The Annual Reports of the Industrial Fatigue Resenrel l3oard, and special reports on partieular subjects, are publishel for the Council in separate series. 'The suhjects dealt witl inelude aceident enusation, rest pauses, spells of work, movenent study. voeational seleetion, and problems of particular indust ries. A fist ean he supplicil on application to the Secretury of the J3ourd, 1.5 York 13uildings, Adelphi, W.C. 2.)

\section{Influenza :}

No. 36. Studies of Influenza in Ifospilats of the British Armies in Franee, 191S. [1919.] I'riec 3s. 6d., post free 3 s. $8 d$.

No. 63. Studies in the Aetiology of Fipicmic Influenza. ISy J. Mr.Intmh. [1!12:2.]

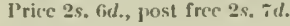

\section{Jaundice :}

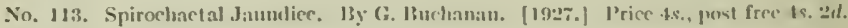

Malaria : sce Quisixe.

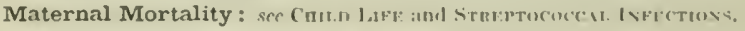

Measles: sce Firmu:moton ( $\mathrm{Nin} 1: 20$.)

Miners' Dietaries : sce Nurritrox.

Miners' Diseases, etc. :

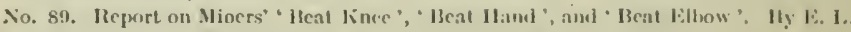
('ollis and 'l. 1. Hewellyn. [1021.] I'riee is. lid., post free Is. Fil.

Miners' Nystagmus : sce Visios.

Sec also .1.11: Nulce: (No, 113).

\section{Nephritis :}

No. 43. Albuminuria nul Wur Xiphritis among lbritish Troops in France. Ity II. Hhelean. [1919.] l'rice 23. fill., just frec $2 . s .8 d$.

\section{Nervo Injuries :}

Ileports of the Committce upon lujuries to the Nervous System :-

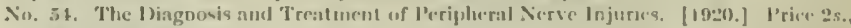
jout frue 2s, 1 d 4 .

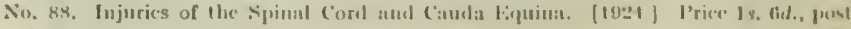
frec Is. $71 d$. 


\section{Special Reports-continued.}

\section{Nutrition :}

No. 13. An Enquiry into the Composition of lietaries, with special reference to the lictaries of Munition Workers. By Viseount Dunluce aud Major Greenwood. [1938.] I'rice $9 \pi$. . post free $10 \pi$.

No. :3s. Report on the Present State of Knowledge of A eeessory Food Faetors (Vitamins) I3y a Commit tee appointed jointly by the Lister Inst itute and Medical Research Counci!. Sccond Edition. [1924.] P'rice 4s. firl., post frec 4s. $8 \frac{1}{2} d$.

No. 87. Report on the Nutrition of Mliners and their Fimilies. By the Committee upon Quantitative Prolblems in Iluman Nutrilinn. [192.t.] Price 1s. 3d., post free is. $4 d$.

No. 10.5. Diets for Boys during the School Age. By II. C. Corry Mann. [1926.] I'rice 2.s. $6 d$., post free $2 s .7 \frac{1}{2} d$.

sce also Cindd Life; Rickers.

\section{Pituitary Extract : see Standarns.}

\section{Pneumonia :}

No. 79. Bacteriologieal and Clinieal Observations on Pheumonia and Empyemata, with special reference to the P'neumococeus and to Serum 'Treatment. By. E. E. Glynn and Lettice Digby. [1923.] Price 5s., post free 5s. $3 d$.

Pneumothorax, Artificial : see Tunrerculosis.

Print, Legibility of : see Visjon.

\section{Protozoan Infections :}

No. 59. A Report on the Oecurrenee of Intestinal l'rotozon in the inhabitants of Britain. By Clifford 1)ohell. [1921.] Price 2s., post free 2s. $1 \frac{1}{2} d$.

\section{Quinine :}

No. 96. Clinical Comparisons of Quinine and Quinidine. By the Committee upon Cinchona Ierivatives and Malaria. [1025.] Price $1 s_{*}$, post free $1 s, 1 d$.

\section{Radium :}

No. 62. Medical Uses of Radium: Studies of the Effeets of Gamma Rays from a large Quantity of IRadium. 13y various authors. [1922.] Price 5s., post free $5 s .3 d$.

No. 90. Medical Uses of Radium : Summary of lkeports from Researeh Centres for $192: 3$ [1924.] Price 1s., post free 1 s, $1 d$.

No. 102. Medieal Uses of Radium : Summary of Reports from Research Centres for 1921. [1926.] Price $1 s, 6 d .$, post frec $1 s .7 d$.

No. 112. Medical Uses of Radium: Summary of Reports rom liesearch Centres for 1925. [1920.] Price is, $3 d .$, post free is, $4 d$.

No. I16. Medical Uses of Radiun: Summary of Rejorts from Research Centres for 1926. [1927.] Priee Is. 3i., post free 1s. 4d.

Rheumatism : see CrILD LIFE (No. 114).

\section{Rickets :}

No. 20. A Study of Social and Eeonomic Factors in the Causation of Rickets, with an Introductory listorieal Survey. By L. Findlay and Margaret Ferguson. [1918.]

Out of print.

No. 61. Experimental Rickets. Ry E. Mcllanby. [1921.] Priee lis., post free 4s. $2 d$.

No. 68. Rickets: the Relative Importance of Environment and Diet as Factors in Causation. By H. Corry Mann. [1922.] l'rice 2s. 6d., post free 2s. $71 d$.

No. 71. The Aetiology and Pathology of Rickets from an experimental point of view. 13y V. Korenchevsky. [1922.] l'rice $4 s$. jost free $4 s_{0} 3 d$.

No. 77. Studies of Rickets in V'ienna, 1919-22. [1923.] Priee 7s. fid., post free 7 s. $10 \frac{1}{2} d$. No, 93. Hxperimental Rickets: The Effect of cereals and their Interaction with other factors of Diet and Environment in produeing lRickets. 13y 1\%. Mellanlsy. [ [925.] 'rice $3 . s .$, post free $3 s .8 d$. 


\section{Special Reports--continued.}

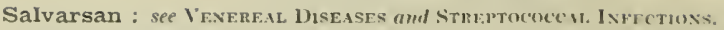

\section{Shock, Surgical :}

Reports of the Committre on Surgieal Sllock and Allieal Conditions:-

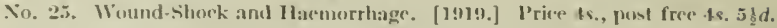

Vi). 26. Trammatic 'Toxaemia as a Faetor in shock. [1919.] ['rice Is., [oust free 1s. Jd.

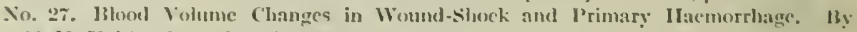
‥ II. Keith. [1919.] P'rice 9d., post frec ] $) d$.

\section{Small-pox :}

No. 98. Studies of the Viruses of Vaceinia and Variola. I3y M. 11, Cordon. [19:5.]

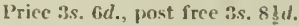

No. 206. Small-pox and Climate in India : Forecasting of Epictemie's. I3y Sir Ldeonard Rogers. [19:6.] I'rice 2s., post free 2.s. $1 \frac{1}{2} \mathrm{~d}$.

\section{Standards, Biological :}

犬o. 69. Pituitary Extracts. By. J. II. Burn and 11. 11. 1)ale. [1922.] I'riec 1s, (td., post free $1 s .7 d$.

See also Veserfat Diseises (

\section{Statistics (MIscellaneous).}

No. 16. A Report on the Causes of Wastage of Labour in Munition Factories. By Major Grecnwood. [1918.] ['riec 1s. 6d., post free 2s. $7 d$.

No, 60. The Use of Death-rates as a Heasure of 11 ygienie Conditions, Jyy John Brownlec. [1922.] Price 3s., post frec 3.s. ] $\frac{1}{3} \ell$.

No. 95. Internal Migration and its Effects upon the Death-1Rates : wilh Special Ref•rence to the County of Essex. 13y A. 13. 1lill. [1925.] I'rice 3s. Gd, post free 3s. 8d.

\section{Streptococcal Infections :}

No. 11 !. I Study of Some Organie Arsenieal Compoumds with a view to their t'se in

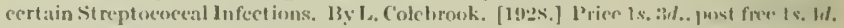

\section{T.N.T. Poisoning :}

No. 11. The Causation and l'revention of I'ri-nitro-tolucne (T.X.T.) I'visoning. Ify. Benjamin Moore. [1917.] l'riee 1s., post free 1s. 1 thd.

No. 58. T.N.T. loisoning and the Fate of T.N.T. in the Aninal Ibody. Ify W. J. (0)1 Jonovan and others. [19:1.] P'rice 3s., post free 3s, 1 d d.

\section{Tuberculosis :}

No. 1. First IReport of the Sipeciat Investigation Commitfee upon the Incidence of J'hthisis in relation to Oceupations.-The Boot and Shoe Trade. [1915.] l'rice 3t., post frec $3 \frac{2}{2} d$.

No. 18. An Investigation into the Epidemiology of I'hthisis P'uluomalis in Great IIritnin

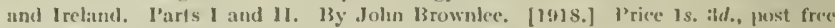
I.s. $4 \frac{1}{2}$ d.

No. 22. An Inquiry into the Prevalence and Actiology of 'Tubereulesis anong Indust rinl Workers, witls special referenec to Fenule Munition Workers. By Major Creenwoud ant

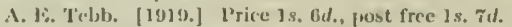

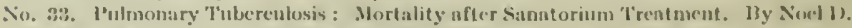

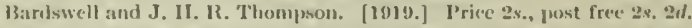

No. 10. An Investigation into the Ejpidemiology of I'ht hisis in (irent 13ritnin and Ireland.

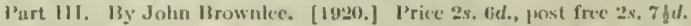

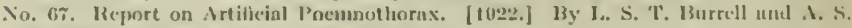
Mate. Nalty. I'rice 2s, 6id., post free 2s, 8d.

No. 76. Tulerculosis in Iusured l'ersons neechted for Treatment by the city of I3rudford Ilealth fommiffec. IIy II. Vallew. [1923.] I'riece Bd., pust frec rd. 


\section{Special Reports-continued.}

No. 83. Tuberculosis of the Larynx. By Sir St. Clair Thomson. [1924.] Price 2s. Gi., post free 2 s. $8 d$.

No. 85. An Inquiry into the After-Histories of Patients treated at the Brompton Hospital Sanatorium at Frimley, during the years 1905-14. IBy Sir P. II.-S. IIartley, R. C. Wingfield, and J. II. R. Thompson. [1924.] Price 1s. 6d., post free $1 s .7 d$.

No. 94. Tubereulin Tests in Cattle, with speeial referenee to the Intradermal Test. By the Tuberculin Committee. [192.5.] 1'rice 3s., post free 3s. $3 d$.

\section{Venereal Diseases :}

No. 14. The Wassermann 'lest. By the Comnittee upon Pathological Methods. Nick Edition. [1921.] P'riee 1s.. post free $1 \mathrm{~s} .1 \mathrm{~d}$.

No. 19. The Laboratory Diagnosis of Gonococeal Infections. Methods for the Detection of Spironema pallidum. By the Bacteriologieal Committee. New Edition. [1923.] Price $1 s .6 d$., post free $1 s .7 \frac{1}{2} d$.

No. 21. The Diagnostie Value of the Wassermann Test. By the Committec upon Pathological Ilethods. [1918.] Price 1s., post free 1s. 1 d.

No. 23. An Analysis of the liesults of Wassernann Reactions in 1,485 Cases of Syphilis or Suspeeted Syphilis. By Panl Fildes and R. J. G. Parnell. [1919.] Price 2s., post free $2 s .1 d$.

No. 41. (1.) An Investigation into the Cltinate Results of the Treatment of Syphilis with Arsenical Compounds. By P'auI Fildes and IR. J. G. Parnell. (Il.) A Clinical Study of the Toxic Reaetions which follow the Intravenous Administration of '914'. I3y' 12. J. G. Parnell and Paul Fildes. [1919.] P'rice 2s., post free 2s. 1d.

No. 44. Ieports of the Spceial Committee upon the Manufacture. Biologieal Testing, and Clinieal Administration of Salvarsan and of its Substitutes. I. [1919.] Price 1s., jost free $1 s, 1 d$.

No. 45. Unsuspeeted Involvement of the Central Nervous System in Syphidis. By Paul Fildes, R. J. G. Parnell, and H. B. Naitland. [1920.] Priee 1s., post free 1s. 1 .

No. 47. The Aceuraey of Wassermann Tests, applied before and after deatl, estimated by Neropsies. I. The Wassermann Test applied before death. By H. M. Turnbull. [1920.] Price 2s. 6.d., post free $2 s . \approx \frac{1}{2} d$.

No. 55. (1.) Results of the Fxamination of Tissues from Eight Cases ol Death following Injeetions of Salvarsan. By H. M. Turnbull. (II.) The Influenee of Salvarsan Treatment on the Developnient and Persistence of Immunity, as indieated by Measurements of Agglutinins. By E. W. Ainley Walker. [1920.] Price 3s., post liree is. $1 \frac{1}{2} d$.

No. 66. Toxie Effects following the Employment of Arsenobenzol Preparations. By the Salvarsan Committec. [1922.] P'riee 2s., post free 2s. $1 \frac{1}{2} d$.

خo. 78. The Serun Diagnosis of Syphilis: The Wassermann and Sigma lieactions compared. [1923.] Price 5s. 6d., post free 5s. $9 d$.

No. 107. The Effect of Treatunent on the Wassermann lieactions of Syphidie Patients. By E. E. Glynn, R. E. Roberts, and P. M. Bigland. [1926.] P'riee 3s. 6id., post free 3s. $8 d$.

Ventilation, etc. :

No. 32. The Seience of Ventilation and Open-air Treatment. Part 1. By Leonard Hill. [1919.] Price 10s., post free 10s. $5 \frac{1}{2} d$.

No. 52. The Science of Ventilatiou and Open-air Treatnent. Part 11. IBy Leonard II IIl. [1920.] Price 6s., post fice 6s. $4 \frac{1}{2} d$.

No. 73. The Kata-thermoneter in Studies of Body Heat and Ellicieney. J3y Leonard IIill and others. [19:23.] P'rice 5s., post free 5s. $21 \frac{1}{2} d$.

No. 100. Methods of Investigating Ventilation and its liffects. By II. M. Vernon and others. [1926.] Price 2s., post frec 2s. $1 \frac{1}{2} d$.

\section{Vision :}

No. 65. First Report of the Miners' Nystagmus Committce. [1922.] Price 1s. 6d., post free $1 s .7 \frac{1}{2} d$. 


\section{Special Reports-continucd.}

No. s0. Second Report of the Miners' Nystagmus Committee. [1923.] I'rice 9d., post frce $10 d$.

Niv. 104. Illumination and Hisual Capacities. By R. J. Lythgoe. [19:26.] l'rice 2s, 6d. jost free $2 s . \tau \frac{1}{2} d$.

No. 110. The Legibility of Print. By R. L. Pyke. [1926.] Price 4s., post free $4 s .2 d$.

Vitamins : sec Nutritiox.

Wassermann Test : sce Vinereal Diseases.

\section{Wound Infections :}

No. 12. The Classilication and Study of the Anacrobie Bacteria of Wat Wounds. B3! J. MeIntosh. [1917.]

Out of print.

No. 39. Report on the Anacrolic Infections of Wounds and the liacteriological and Serologieal Problems arising therefrom. By. the Committec upon Anacrobic Iatcteria and Infections. [1919.] l'rice 6s., post free $6 s .3 \frac{1}{2} d$.

No. 5\%. Studies in Wound Infectious, By. S. 1R. Douglas, . I. Fleming, and 1. Colebruok. [1920.] Price $4 s .6 d$, post free $4 s .8 \frac{1}{2} d$.

The following books were published under the direction of the Aledieal Researeh (om. nittec and are obtainable from the publishers named:

llikk and its IIygienie Relations. By Janet L. Lane-Claypon. 1'rice 9s. net. [Longmans. Green \& Co.]

The Anocbae living in Man. By Clifford Dobell. P'rice 7 s. Gel, nct. [13ale, Sons \& I)anielsson, Ltd.]

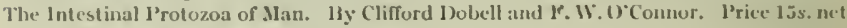
[Bale, Sons \& Daniclsson, I.tU.]

\section{WLISE.IS AGENCIES OF 1I.M. STATIONLIT OFIICL}

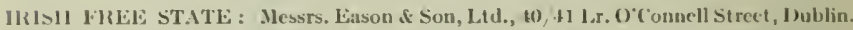

1:AX.1D.1: The Imperial New's Company, Ltd., 235 fort Strect, Winnipeg: 77 st. In.

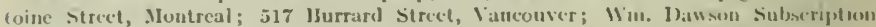

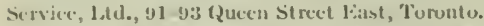

ICSTRALIA : Messrs. Allert of Sun, Ltd., 1so Murray Strect, l'erth, Mestcru Iustrulu. Messrs. Gurclun if Gotch, Ltd., 13lyth Strect, Adclaide; Queen strect, 13rislane; J,ittl' follins Street, Mclhourne; Barrack and Clarence Strects, Sydney; Cinitiere sitreet. leatuncestom, Tasmania.

XIW \%F, IL.I.T1): Messrs. Gordon d Goteh, L.td., Waring-Taylor Strect, Wellington ; tiore Sircet, Auckland; Idichlield street, Chrisfchurch; 1)uwling Strect, 1)uncelin.

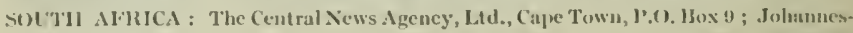

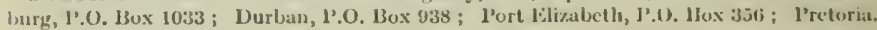

1.NI)I.I : Messrs. Thacker, spink \& Co., Calcuthand simla. Messrs. Thateker \& Co., L.(d., 13ombay. Messrs. Migginbothans, L(d., Madras and Hangalore.

I'A.A. : The British Library of Infurmation, 5 linist tsth Street, New Yurk.

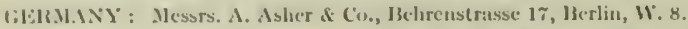

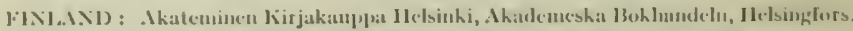

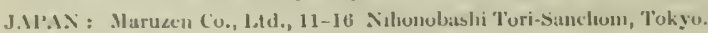




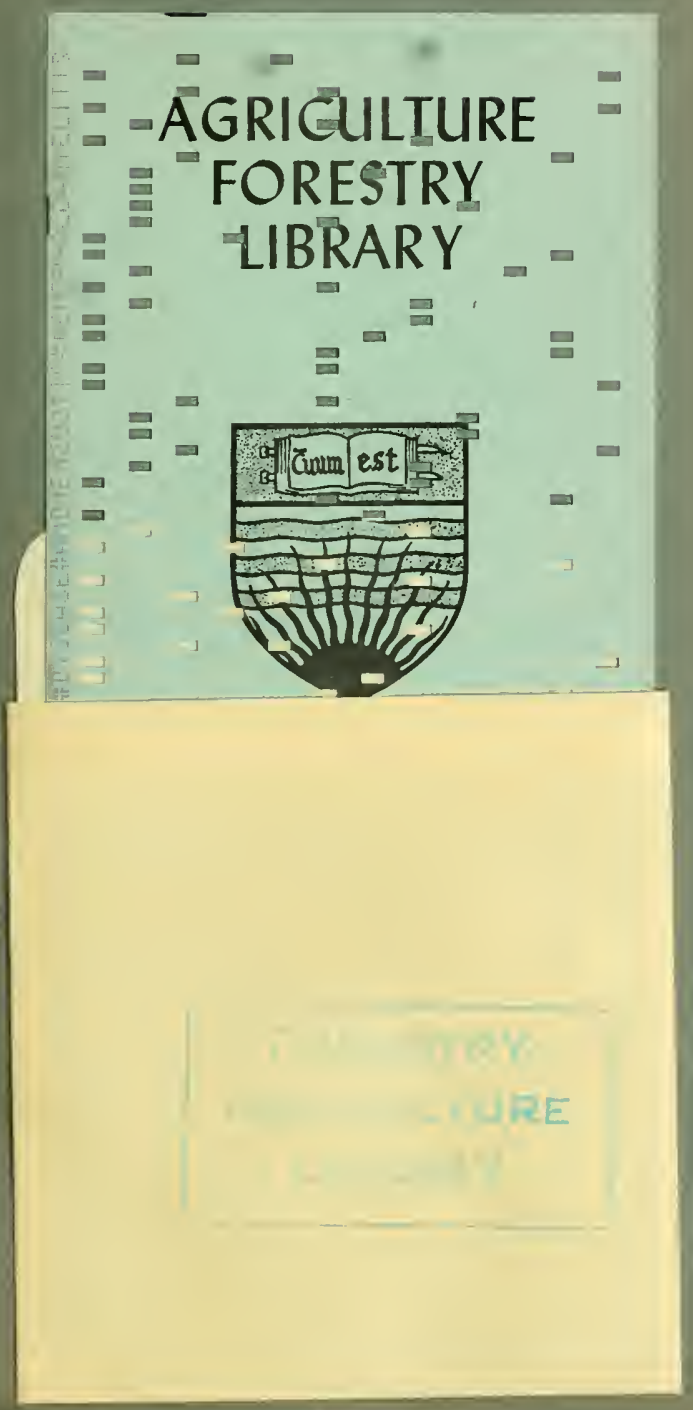


LONDON :

\section{PLBLISHED BY HIS MAJESTY'S STATIONKRY UFFICE}

To be porohased directly from H.M. STATIONERY OFEICK at the following addreses :

ADABTRAL HODE, KINGgWAY, LONDON, W.C. 8:

120 Geores Strekt, Edinberea :

YORK STREET, MANCHEOTRR :

18T. ANDREW'B CREBCENT, CARDIYF:

15 Donzgall Sotare Wegt, Belfast.

or throt gh ang Booksollex.

1928

Price 5s. net. 